UNIVERSIDADE DE SÃO PAULO

FACULDADE DE ECONOMIA, ADMINISTRAÇÃO E CONTABILIDADE DEPARTAMENTO DE CONTABILIDADE E ATUÁRIA

PROGRAMA DE PÓS-GRADUAÇÃO EM CONTROLADORIA E CONTABILIDADE

Alyson Aires de Souza

A abordagem do valor na formação do preço de venda: Um estudo no ambiente business-to-business brasileiro 
Prof. Dr. Vahan Agopyan

Reitor da Universidade de São Paulo

Prof. Dr. Adalberto Américo Fischmann

Diretor da Faculdade de Economia, Administração e Contabilidade

Prof. Dr. Ariovaldo dos Santos

Chefe do Departamento de Contabilidade e Atuária

Prof. Dr. Lucas Ayres Barreira de Campos Barros

Coordenador do Programa de Pós-Graduação em Controladoria e Contabilidade 
ALYSON AIRES DE SOUZA

\section{A abordagem do valor na formação do preço de venda: Um estudo no ambiente business-to-business brasileiro}

Dissertação apresentada ao Departamento de Contabilidade e Atuária da Faculdade de Economia, Administração e Contabilidade da Universidade de São Paulo como requisito para a obtenção de título de Mestre em Ciências.

Área de Concentração: Controladoria e Contabilidade

Orientador: Prof. Dr. Reinaldo Guerreiro

Versão corrigida

(Versão original disponível na Faculdade de Economia, Administração e Contabilidade) 
Autorizo a reprodução e divulgação total ou parcial deste trabalho, por qualquer meio convencional ou eletrônico, para fins de estudo e pesquisa, desde que citada a fonte.

FICHA CATALOGRÁFICA

Elaborada por Rafael Mielli Rodrigues - CRB-8/7286

Seção de Processamento Técnico do SBD/FEA/USP

Souza, Alyson Aires de

A abordagem do valor na formação do preço de venda: um estudo no ambiente business to business brasileiro / Alyson Aires de Souza. -- São Paulo, 2018.

$118 \mathrm{p}$.

Dissertação (Mestrado) - Universidade de São Paulo, 2018.

Orientador: Reinaldo Guerreiro.

1. Valor (Administração) 2. Preços 3. Organização (Administração)

I. Universidade de São Paulo. Faculdade de Economia, Administração e Contabilidade. II. Título.

CDD - 658.0013 
À minha mãe. 



\section{AGRADECIMENTOS}

Ao professor Reinaldo Guerreiro pela orientação, confiança e generosidade sem as quais a realização deste trabalho não seria possível.

Ao professor Rodrigo Paiva pela leitura atenta e crítica do projeto de pesquisa, pelo incentivo e pela generosidade particular de quem exerce a docência como vocação.

Aos professores Wellington Rocha e Ana Ikeda pela leitura crítica do projeto de pesquisa e pelas valorosas contribuições referenciais durante a qualificação.

Ao professor Fábio Frezatti pela atenção e pelos ensinamentos oferecidos durante a disciplina de Seminários de Pesquisa em Contabilidade Gerencial e por me aceitar como "assecla" na disciplina de Solução de Problemas em Contabilidade.

Ao professor Luiz Afonso pelos ensinamentos oferecidos na disciplina de Microeconomia para Contadores.

A todos os demais professores do PPGCC da FEA/USP e a todos os profissionais da FEA/USP. Ao Rob Arita, por compreender minhas ausências no escritório durante as aulas do programa. À Amanda Tavares pelo empenho na realização do contato com os profissionais da ABINEE. A todos os profissionais que responderam ao questionário e tornaram a pesquisa possível.

Aos meus pais e familiares pelo apoio e à Luciana por sua compreensão, carinho, presença e incansável apoio ao longo do período de elaboração deste trabalho. 



\section{RESUMO}

Souza, A. A. (2018). A abordagem do valor na formação do preço de venda: Um estudo no ambiente business-to-business brasileiro (Dissertação de Mestrado). Faculdade de Economia, Administração e Contabilidade, Universidade de São Paulo, São Paulo.

De acordo com o arcabouço teórico da microeconomia, as estruturas de mercado condicionam as empresas a se comportarem como formadoras ou tomadoras de preço principalmente em função das interações entre oferta e demanda. Além destes fatores externos, existem fatores internos que determinam a abordagem de preços utilizada pelas organizações, como por exemplo a estrutura organizacional e a estrutura de custos. As abordagens de preços são classificadas por diversos pesquisadores de marketing em três, a saber: preço baseado no custo; preço baseado na concorrência; e preço baseado no valor. A abordagem do valor se fundamenta nos benefícios esperados pelo consumidor, numa lógica completamente diferente das utilizadas nas abordagens que se baseiam nos preços da concorrência ou nos próprios custos, além de apresentar potencial de trazer ganhos para os fornecedores e para os consumidores. Considerando os benefícios indicados pela literatura, poder-se-ia esperar que as empresas adotassem as melhores técnicas e práticas disponíveis visando sua implementação; entretanto, pesquisas indicam que ela não é frequentemente aplicada no ambiente B2B. A fim de avaliar como se dá formação do preço de venda com base no valor em empresas formadoras e tomadoras de preço no ambiente B2B brasileiro, esta pesquisa realizou um estudo em determinantes de preço internos e externos de empresas da indústria eletroeletrônica associadas à ABINEE. Entre os determinantes internos, avaliou-se as características das margens utilizadas assim como as características da estrutura organizacional de preços. Entre os externos, avaliouse as características de empresas formadoras e tomadoras de preço, a intensidade de diferenciação e de competição no mercado. A coleta de dados foi realizada através de questionário aplicado aos gestores responsáveis pela determinação do preço de venda. Em função da sensibilidade do tema, a taxa de resposta de 13,6\% é considerada adequada, além de ser compatível com estudos anteriores. $\mathrm{O}$ instrumento da pesquisa foi submetido a um pré-teste de validade, além de basear-se no arcabouço teórico pertinente ao tema, partindo de constructos, indicadores e variáveis assemelhadas a outras utilizadas em estudos anteriores. $\mathrm{O}$ teste de confiabilidade resultou em um Alpha de Cronbach de 0,86. Análises de correspondências e estatísticas descritivas foram utilizadas como técnicas de análise dos dados. A pesquisa identificou que a determinação do preço de venda pela abordagem do valor apresenta características organizacionais distintas das demais abordagens. Percebe-se a existência de maior grau de formalização e de delegação da decisão de preços entre estas empresas, embora relata-se a baixa cooperação entre os atores organizacionais envolvidos com preço. Também houve indicação de menor envolvimento da alta gerência, o que pode estar relacionado à percepção de que a organização de preço nestas empresas já está suficientemente desenvolvida. Em relação ao comportamento de preços, percebe-se maior diferenciação dos produtos e dos serviços oferecidos pelas empresas que se comportam como formadoras de preço, da mesma maneira que relatam haver maior intensidade de competição. Nos aspectos organizacionais, os formadores de preço apresentam maior grau de formalização, cooperação, especialização e de envolvimento da alta gerência em relação aos tomadores de preço.

Palavras-chave: Valor (Administração). Preços. Organização (Administração). 


\begin{abstract}
Souza, A. A. (2018). The value-based pricing: A study in the Brazilian Business-to-Business market (Masters dissertation). Faculdade de Economia, Administração e Contabilidade, Universidade de São Paulo, São Paulo.
\end{abstract}

According to the microeconomic theory, firms can behave as price-makers or price-takers due to the interactions between market agents. In addition to these external factors, there are internal factors that determine the pricing approach used by organizations, such as organizational structure and cost structure. The pricing approaches are segregated, by several marketing researchers, into three, namely: cost-based price; competition-based price; and value-based price. The value-based approach is based on the benefits expected by the consumer, in a logic completely different from those used in approaches that are based on competition or on own costs, as well as presenting potential to bring gains to suppliers and consumers. Considering the benefits indicated by the literature, companies could be expected to adopt the best available techniques and practices for their implementation, however, researches indicate that it is not often applied in the B2B environment. In order to evaluate how value-based sales price is formed in Brazilian B2B environment, this research carried out a study on internal and external price determinants of companies in the electro-electronics industry associated with ABINEE. Among the internal determinants, the characteristics of the margins used as well as the characteristics of the organizational structure of prices were evaluated. Among the external ones, the characteristics of price-makers and price-takers, the intensity of differentiation and of competition in the market were evaluated. The data collection was done through a questionnaire applied to the managers responsible for determining the sale price. The response rate of $13.6 \%$ is considered adequate and it is compatible with previous studies about price. The research instrument was submitted to a validity pre-test, and it was based on the theoretical framework pertinent to the theme, with constructs, indicators and variables similar to those used in previous studies. The reliability test resulted in a Cronbach's Alpha of 0.86. Correspondence analysis and descriptive statistics were used as data analysis techniques. It was concluded that the valuebased price approach presents different organizational characteristics in relation to the other approaches. In the organizational aspect, the existence of a greater degree of formalization and delegation of price decision among these companies is noticed, although the low cooperation between the organizational actors involved with price is reported. There is also an indication of less involvement of the top management, which may be related to the perception that the price organization in these companies is already sufficiently developed. Regarding companies' behavior, it is possible to notice a greater differentiation of the products and services offered by the companies that behave as price-makers, in the same way that they perceive a greater intensity of competition. In the organizational aspects, the price-makers present a greater degree of formalization, cooperation, specialization and the involvement of top management compared to price takers.

Keywords: Value (Administration). Prices. Organization (Administration). 


\section{LISTA DE ILUSTRAÇÕES}

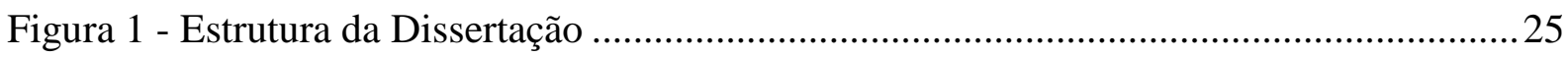

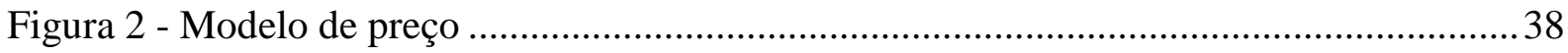

Figura 3 - Modelo utilizado para classificação do comportamento de preços .........................55

Figura 4 - Racional para classificação do comportamento de preço das empresas da amostra 


\section{LISTA DE GRÁFICOS}

Gráfico 1 - Mapa da distribuição geográfica da população pesquisada 46

Gráfico 2 - Representatividade das áreas em que se subdivide o setor eletroeletrônico (ABINEE) 46

Gráfico 3 - Faturamento do setor eletroeletrônico por área (em BiR \$) 47

Gráfico 4 - Efetivação da localização do responsável por determinação de preços de venda. 48

Gráfico 5 - Cargo ocupado pelos inicialmente contatados 51

Gráfico 6 - Classificação dos respondentes 52

Gráfico 7 - Divisão da amostra entre contato inicial e secundário 66

Gráfico 8 - Meio escolhido para resposta 66

Gráfico 9 - Respostas com e sem reiteração 67

Gráfico 10 - Distribuição geográfica da amostra 69

Gráfico 11 - Agrupamento por quantidade de funcionários da amostra 69

Gráfico 12 - Receita anual da amostra . 70

Gráfico 13 - Relação entre faturamento e porte 70

Gráfico 14 - Participação de exportadoras na amostra 71

Gráfico 15 - Área de atuação dos respondentes 71

Gráfico 16 - Cargos ocupados pelos respondentes 71

Gráfico 17 - Áreas em que atuam as empresas da amostra. 72

Gráfico 18 - Ambiente de atuação 73

Gráfico 19 - Comportamento de preços das empresas da amostra 75

Gráfico 20 - Mapa perceptual: comportamento de preço e diferencial percebida..... 76

Gráfico 21 - Mapa perceptual: comportamento de preço e facilidade de acesso ao preço da concorrência 77

Gráfico 22 - Forma de operacionalização do preço de venda. 79

Gráfico 23 - Abordagem de preços 81

Gráfico 24 - Mapa perceptual: abordagem de preço e essência valor 82

Gráfico 25 - Mapa perceptual: abordagem de preço e essência custo 83 


\section{LISTA DE TABELAS}

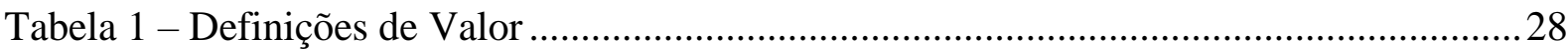

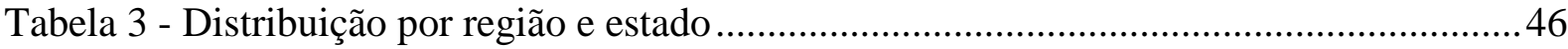

Tabela 4 - Justificativas alegadas pelos que não aceitaram participar da pesquisa.................. 48

Tabela 5 - Resultados dos Testes de Mann-Whitney para as questões em escala Likert ..........53

Tabela 6 - Constructos e seus respectivos indicadores de mensuração ....................................54

Tabela 7 - Variáveis relacionadas ao comportamento de preço .............................................55

Tabela 8 - Variáveis relacionadas à abordagem ...............................................................57

Tabela 9 - Variáveis relacionadas à estrutura organizacional de preços .................................59

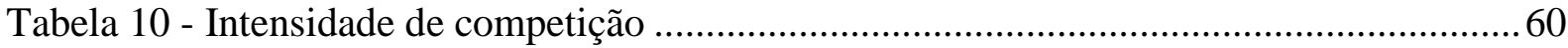

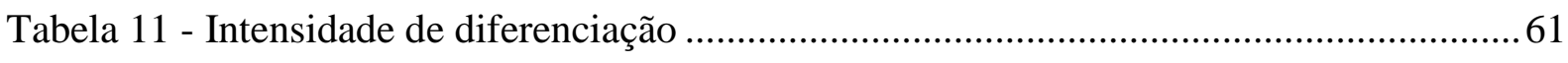

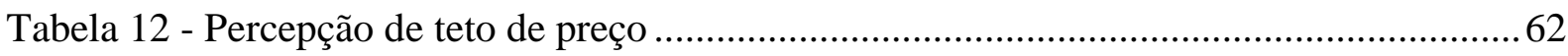

Tabela 13 - Facilidade de acesso aos dados da concorrência .................................................62 62

Tabela 14 - Forma de estabelecimento do preço de venda .................................................... 63

Tabela 15 - Estatística descritiva para as assertivas 26 e 27 ................................................. 74

Tabela 16 - Tabela de contingência: Comportamento de preço e diferenciação.......................75

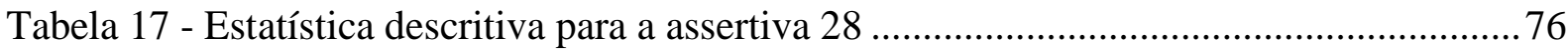

Tabela 18 - Tabela de contingência: comportamento de preço e facilidade de acesso a dados da

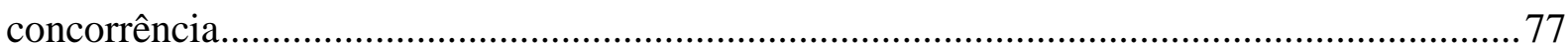

Tabela 19 - Estatística descritiva: intensidade de competição ............................................... 78

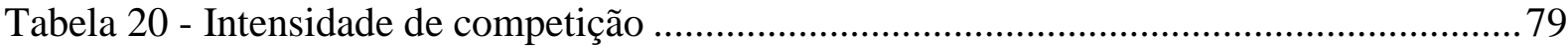

Tabela 21 - Análise da forma de estabelecimento de preço de venda .....................................80

Tabela 22 - Estatística descritiva: Abordagem de preços ..................................................... 81

Tabela 23 - Tabelas de contingência: Abordagem de preço e essência valor ......................... 82

Tabela 24 - Relação entre facilidade de acesso aos preços da concorrência e abordagens de

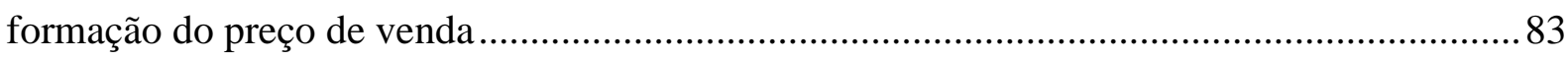

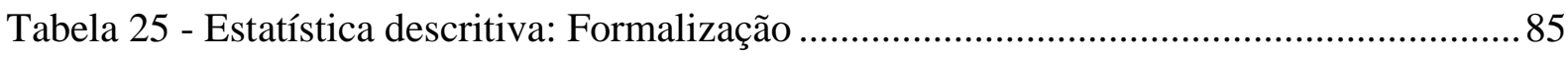

Tabela 26 - Relação entre formalização e abordagens de formação do preço de venda ...........85

Tabela 27 - Relação entre formalização e comportamento de preços ....................................... 86

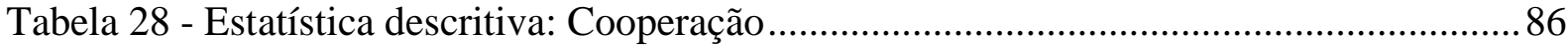

Tabela 29 - Relação entre cooperação e abordagens de formação do preço de venda..............87

Tabela 30 - Relação entre cooperação e comportamento de preços ......................................... 87 


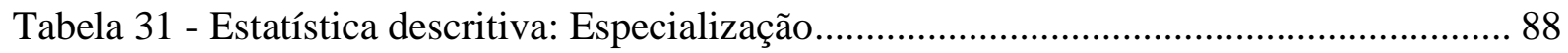

Tabela 32 - Relação entre especialização e abordagens de formação do preço de venda ........ 88

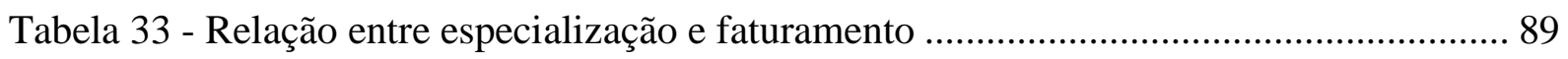

Tabela 34 - Relação entre especialização e quantidade de funcionários ................................. 89

Tabela 35 - Relação entre especialização e comportamento de preços ................................... 89

Tabela 36 - Estatística descritiva: Envolvimento da alta gerência......................................... 90

Tabela 37 - Relação entre envolvimento da alta gerência e abordagens de formação do preço de

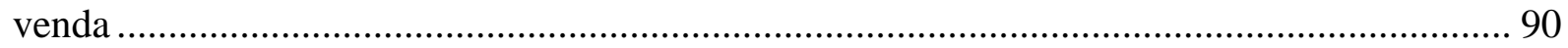

Tabela 38 - Relação entre envolvimento da alta gerência e comportamento de preços .......... 91

Tabela 39 - Estatística descritiva: Delegação vertical da autoridade de preços....................... 91

Tabela 40 - Relação entre delegação vertical da autoridade de preços e abordagens de formação

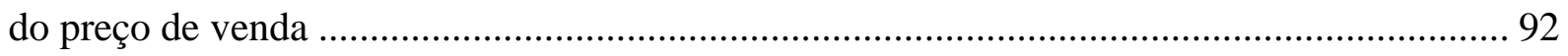

Tabela 41 - Relação entre delegação vertical e comportamento de preços ............................. 92 


\section{LISTA DE ABREVIATURAS E SIGLAS}

$\begin{array}{ll}\text { ABC } & \text { Activity Based Costing } \\ \text { ABINEE } & \text { Associação Brasileira da Indústria Elétrica e Eletrônica } \\ \text { APA } & \text { American Psychological Association } \\ \text { B2B } & \text { Business-to-Business } \\ \text { B2C } & \text { Business-to-Customer } \\ \text { FEA } & \text { Faculdade de Economia, Administração e Contabilidade } \\ \text { FIESP } & \text { Federação das Indústrias do Estado de São Paulo } \\ \text { KAM } & \text { Key Account Manager } \\ \text { RFP } & \text { Request for Proposal } \\ \text { USP } & \text { Universidade de São Paulo }\end{array}$





\section{SUMÁRIO}

1. INTRODUÇÃ

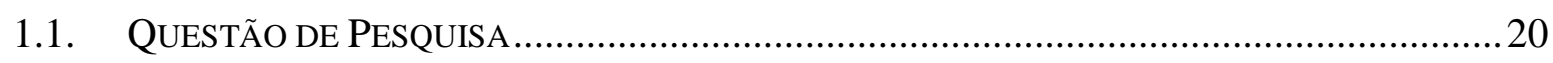

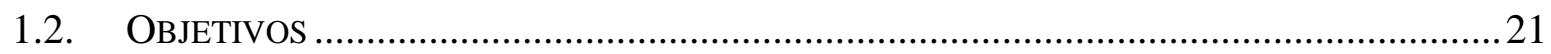

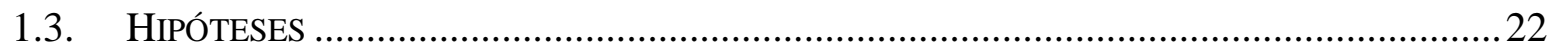

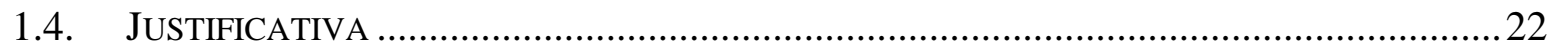

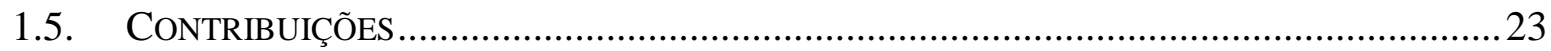

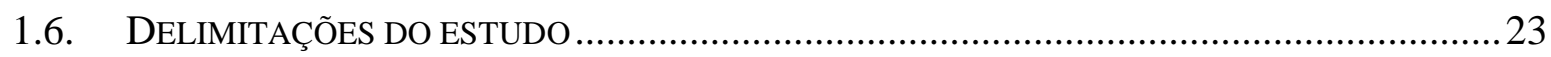

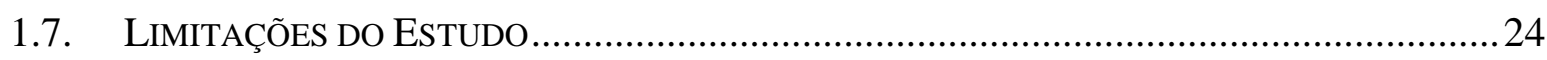

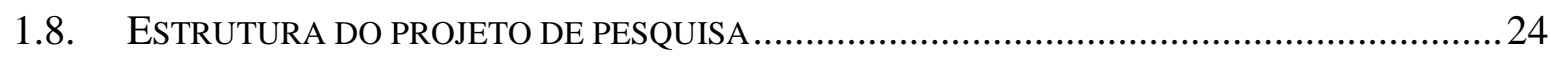

2. A ABORDAGEM DO VALOR: CARACTERÍSTICAS E DETERMINANTES.....27

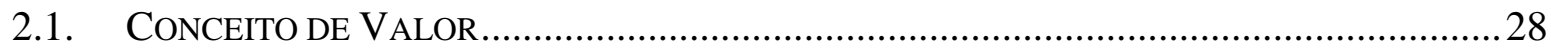

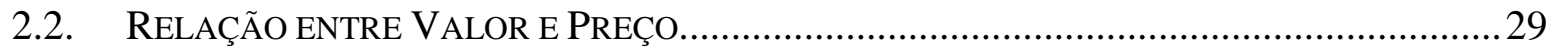

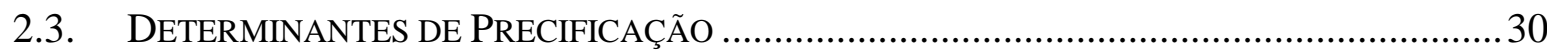

2.3.1. A influência da Demanda e da Concorrência no comportamento de preços:

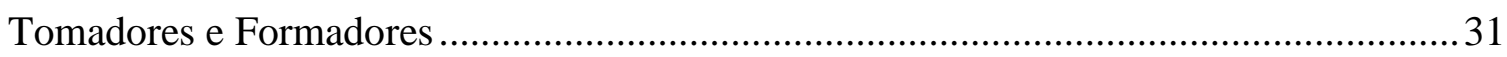

2.3.2. Estrutura organizacional de preços ................................................................... 34

2.4. Abordagens Alternativas de PreCificaÇão............................................................ 37

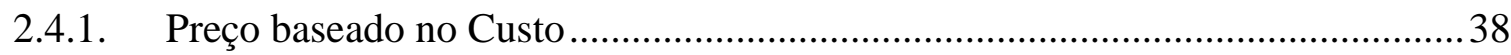

2.4.2. Preço baseado na Concorrência .............................................................................. 39

2.5. PaRTICULARIDADES DA FORMAÇÃO DE PREÇOS NO AMBIENTE B2B ............................ 40

3. DESENVOLVIMENTO DA PESQUISA.........................................................................45

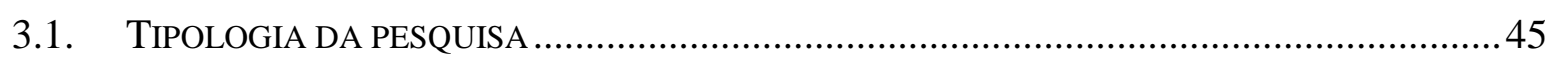

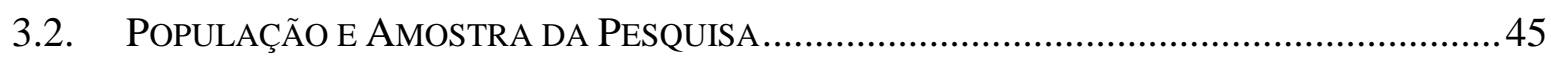

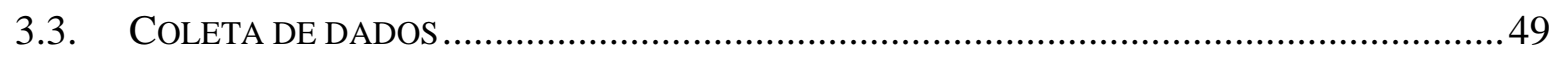

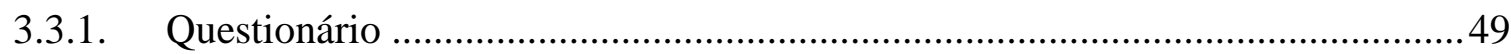

3.3.2. Seleção do respondente ……………………………………………………....5 50

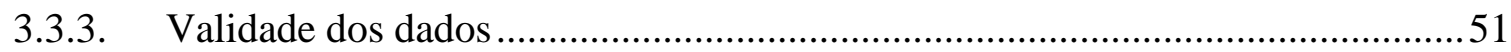

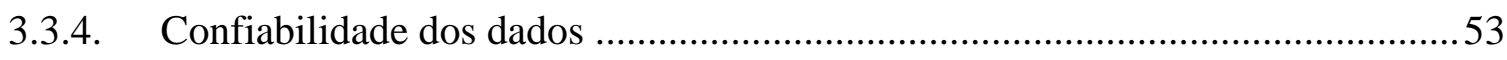

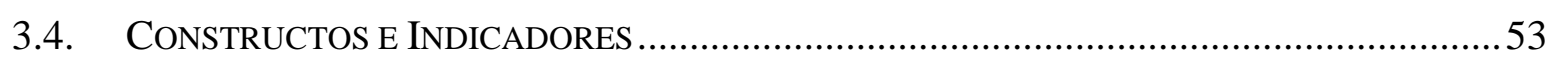

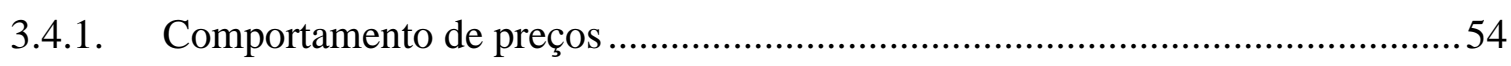

3.4.2. Abordagem de preços ……………………………………………………......56 


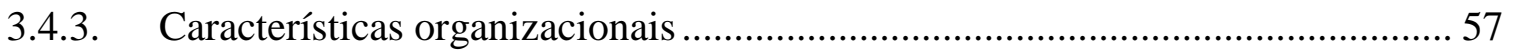

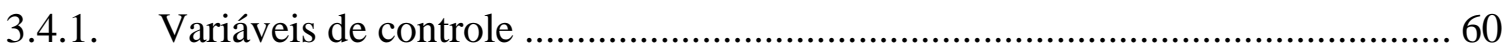

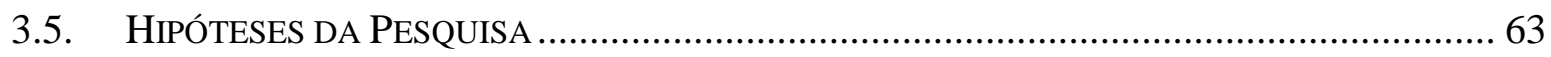

3.5.1. Hipótese 1 - Relação entre a abordagem e o comportamento de preço ............ 63

3.5.2. Hipótese 2 - Relação entre características da estrutura organizacional e a abordagem do valor

3.5.1. Hipótese 3 - Relação entre a características da estrutura organizacional e o

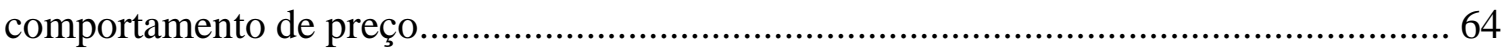

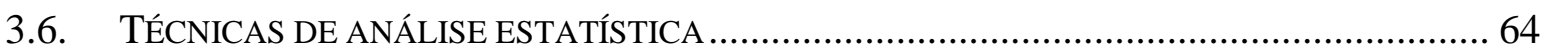

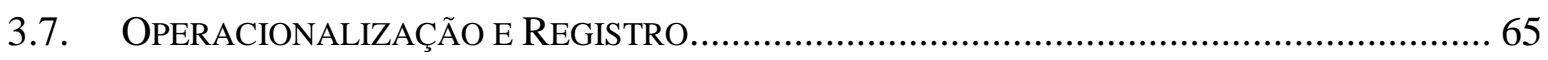

4. ANÁLISE E DISCUSSÃO DOS RESULTADOS........................................................ 69

4.1. DESCRIÇÃO DOS RESPONDENTES E DA AMOSTRA DA POPULAÇÃO PESQUISADA ........... 69

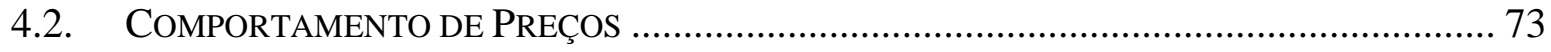

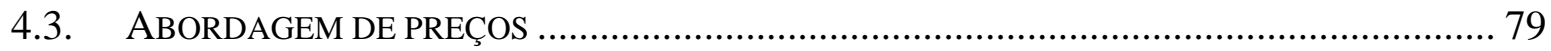

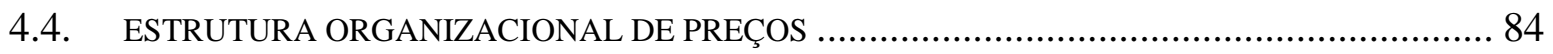

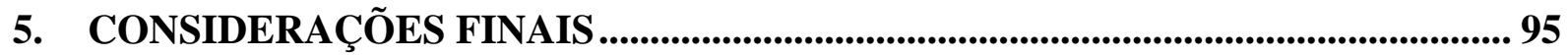

6. REFERÊNCIAS BIBLIOGRÁFICAS............................................................ 99

APÊNCIDE A - E-MAIL CONVITE ................................................................................. 109

APÊNDICE B - QUESTIONÁRIO DA PESQUISA (MODELO WORD) ..................... 110

APÊNCIDE C - E-MAIL DE AGRADECIMENTO ...................................................... 113

APÊNCIDE D - E-MAIL DE ENVIO DO RELATÓRIO INDIVIDUALIZADO......... 114

APÊNCIDE E - MODELO DO RELATÓRIO INDIVIDUALIZADO............................. 115 


\section{INTRODUÇÃO}

A formação do preço de venda tem recebido bastante atenção nas últimas décadas em função da sua importância para o lucro das organizações (Indounas \& Roth, 2012; Özer \& Phillips, 2012b). É um processo decisório que envolve diferentes áreas nas organizações (Özer \& Phillips, 2012b), revelando-se um campo de pesquisa fértil para diversas áreas de pesquisa, como economia, marketing e contabilidade (Hornby \& Macleod, 1996).

Apesar de ser um assunto muito pesquisado, ainda há certos pontos que precisam ser esclarecidos pela pesquisa acadêmica, dentre os quais se destaca a controvérsia sobre a ampla utilização da abordagem de custo em detrimento de abordagens consideradas mais vantajosas pela literatura econômica e pela literatura de marketing (P. T. M. Ingenbleek, 2007).

Diversos pesquisadores de marketing, como, por exemplo, Shipley e Jobber (2001), Ingenbleek et al. (2003), Avlonitis e Indounas (2006), Collins e Parsa (2006), Hinterhuber (2008), Indounas (2009), Hinterhuber e Liozu (2012), Calabrese e De Francesco (2014) e Campomar, (2017) segregam as abordagens de precificação em três grupos: (i) preço baseado no custo; (ii) preço baseado na concorrência e (iii) preço baseado no valor.

A abordagem do valor é a extensão pela qual as empresas usam informações sobre a percepção do cliente a respeito das vantagens oferecidas e sobre como os consumidores irão realizar o trade-off dessas vantagens com o preço a ser determinado (P. Ingenbleek, 2007). Esta abordagem se fundamenta nos benefícios esperados pelo consumidor, numa lógica completamente diferente das utilizadas nas abordagens que se baseiam nos preços da concorrência ou nos próprios custos (Shipley \& Jobber, 2001; Töytäri, Keränen, \& Rajala, 2017).

É caracterizada pela criação de valor, de maneira holística (Töytäri, Rajala, \& Alejandro, 2015), com potencial para trazer ganhos para o fornecedor e para o consumidor (J. Anderson \& Narus, 1998; Forbis \& Mehta, 1981; Hinterhuber, 2008a; P. T. M. Ingenbleek et al., 2003; Nagle \& Holden, 2003; Töytäri, Alejandro, Parvinen, Ollila, \& Rosendahl, 2011; Töytäri et al., 2017). Esta lógica exige que a simples venda de produtos e serviços dê lugar ao entendimento do cliente, desde seu modelo de negócios, passando pelos processos, direcionadores de negócios e culminando no entendimento do que o consumidor valoriza (Töytäri et al., 2017).

Considerando os benefícios indicados pela literatura (Liozu \& Hinterhuber, 2013), poder-se-ia esperar que as empresas adotassem as melhores técnicas e práticas disponíveis visando a implementação desta abordagem. Entretanto, o fato da abordagem do valor não ser 
frequentemente aplicada no ambiente B2B (Hinterhuber \& Liozu, 2012) sugere que existem barreiras à sua implementação (Hallberg, 2017; Provines, 2017).

Vários pesquisadores procuraram estudar os fatores que são determinantes para a formação do preço de venda, classificando-os em fatores externos e internos (Campomar, 2012; Shipley \& Jobber, 2001). No primeiro grupo, destacam-se características relacionadas tanto aos clientes quanto aos concorrentes. No segundo grupo, destacam-se os custos e as características organizacionais (Avlonitis \& Indounas, 2005; Forman \& Hunt, 2005; Shipley \& Jobber, 2001).

Entretanto, Töytäri, Keränen e Rajala, (2017) admitem que ainda se conhece pouco sobre os fatores que facilitam ou impedem a adoção da abordagem do valor no contexto industrial, assim como são poucos os estudos que analisam como as empresas se estruturam para as decisões de preço (Burkert, Ivens, Henneberg, \& Schradi, 2016).

Neste contexto, releva notar que estudos que abordam de forma integrada a escolha da abordagem da formação de preços, tanto em função do fator externo da estrutura de mercado quanto em função do fator interno da estrutura organizacional de preços não foram identificados. Além disso, ressalta-se que a pesquisa sobre preços no ambiente B2B é escassa (Sharma \& Iyer, 2011), assim como são escassos os trabalhos que procuram avaliar o processo de formação de preços de venda no mercado brasileiro (Campomar, 2017).

Afim de avaliar como se dá formação do preço de venda com base no valor em empresas formadoras e tomadoras de preço no ambiente $\mathrm{B} 2 \mathrm{~B}$ brasileiro, esta pesquisa realizou um estudo em determinantes de preço internos e externos de empresas da indústria eletroeletrônica associadas à ABINEE. Entre os determinantes internos, avaliou-se as características das margens utilizadas assim como as características da estrutura organizacional de preços. Entre os externos, avaliou-se as características de empresas formadoras e tomadoras de preço, a intensidade de diferenciação e de competição no mercado.

\subsection{Questão de Pesquisa}

Se a formação do preço com base no valor é a abordagem que resulta na maximização dos resultados, porque então não é a escolhida pela maioria das empresas? A chave para entender esta questão reside no entendimento dos fatores determinantes para formação do preço de venda. Se tais fatores não estão presentes em uma determinada organização, podem surgir verdadeiras barreiras para o estabelecimento de preço com base no valor. É neste contexto que surge a questão orientadora desta pesquisa: 


\section{Quais são as características de formação de preço com base no valor em empresas formadoras e tomadoras de preço no ambiente B2B brasileiro?}

Para responder esta questão, foi conduzida uma pesquisa empírica em empresas B2B brasileiras, após a análise da literatura relevante sobre o comportamento de preços e sobre os demais determinantes das abordagens de preço.

\subsection{OBJETIVOS}

Optou-se por dividir os objetivos entre geral e específicos a partir da concordância com os estudos de Gil (2002), Lakatos e Marconi (1992), que vinculam o objetivo geral de um trabalho científico ao tema de maneira abrangente. Já os objetivos específicos são vinculados ao tema de maneira particular, permitindo a aplicação do objetivo geral em situações específicas.

Diante do exposto, definiu-se o seguinte objetivo geral desta pesquisa:

Investigar quais as características das empresas, do ambiente B2B brasileiro, que estabelecem preços de venda utilizando a abordagem de valor, no contexto de formadoras e tomadoras de preço.

Como esta pesquisa trata-se de uma dissertação de mestrado, a variável tempo constitui um limitador importante para o estudo de todos os fatores determinantes da abordagem de valor. Desta forma, escolheu-se estudar determinantes fundamentais para a abordagem do valor que não diminuem a importância do trabalho e nem impedem o atingimento do objetivo geral proposto. Sendo assim, definharam-se os seguintes objetivos específicos desta pesquisa:

- Identificar a presença de empresas formadoras e tomadoras de preço no ambiente B2B brasileiro;

- Identificar as empresas que estabelecem preço de venda utilizando a abordagem de valor;

- Investigar a relação entre a abordagem do valor e as empresas formadoras e tomadoras de preço;

- Explorar a relação entre a abordagem do valor e características organizacionais. 


\subsection{HIPÓTESES}

As hipóteses são importantes para as pesquisas empírico-teóricas já que sua construção e teste fortalecem a consistência dos achados da pesquisa. (Martins \& Theóphilo, 2009, p. 31). Considerando que as hipóteses contextualizam a essência de um estudo científico, em conjunto com a questão e com os objetivos do estudo, estes autores recomendam construir e expor para teste algumas hipóteses "Após a formulação de um problema, delineamento da plataforma teórica e enunciado dos objetivos de uma pesquisa com abordagem empírico-analítica..." (Martins \& Theóphilo, 2009, p. 31).

Vale mencionar que são várias as conceituações sobre hipótese de pesquisa. Neste sentido, convém eleger aquela que mais se adequa às hipóteses apresentadas na presente pesquisa: "Conjectura, ou suposição, que enuncia um possível relacionamento entre duas, ou mais variáveis" (Martins \& Theóphilo, 2009, p. 31).

Assim, foram levantadas três hipóteses nesta pesquisa, cujas fundamentações teóricas serão expostas na seção 3.5 .

a) Hipótese 1: A abordagem do valor está associada positivamente ao comportamento de formadores de preço;

b) Hipótese 2: As características organizacionais das empresas que adotam a abordagem do valor são distintas das empresas que adotam as demais abordagens;

c) Hipótese 3: As características organizacionais das empresas que se comportam como formadoras de preço são distintas daquelas que atuam como tomadoras de preço.

\subsection{JUSTIFICATIVA}

Observa-se que nenhum dos estudos identificados na revisão de literatura abordou de forma integrada a escolha da abordagem da formação de preços, tanto em função do comportamento de preços (formador ou tomador) quanto em função da estrutura organizacional. Do mesmo modo, é importante ressaltar que a pesquisa sobre preços no ambiente B2B é escassa (Sharma \& Iyer, 2011), assim como são escassos os trabalhos que procuram avaliar o processo de formação de preços de venda no mercado brasileiro (Campomar, 2017). Özer e Phillips (2012a) acrescentam que há necessidade de mais pesquisas empíricas sobre a identificação de quais processos e quais organizações de preço são mais eficazes. 
Além disso, a literatura sobre valor percebido pelos clientes ainda está em desenvolvimento (Liozu, 2017), entretanto há um consenso de que esta abordagem traz benefícios significativos para as organizações (Töytäri et al., 2011).

Além do mais, Marn e Rosiello (1992), ao analisarem os números de 2.463 empresas, concluíram que a variação de $1 \%$ no preço resultaria, ceteris paribus, em $11 \%$ de aumento médio nos resultados operacionais. Ainda que o impacto no resultado dependa do grau de alavancagem operacional da empresa, a pesquisa indica uma significante sensibilidade do lucro em função do preço.

\subsection{CONTRIBUiÇÕeS}

Roll (2009) afirma que a geração de conhecimento tem valor intrínseco para os pesquisadores. Já para os gerentes das organizações, a geração de conhecimento só é valorizada se puder ser implementada e utilizada a um custo menor do que o benefício gerado (Roll, 2009). Levando em consideração estes dois diferentes pontos, a presente pesquisa atenderá as necessidades de ambos os públicos, já que além de fornecer um diagnóstico para as empresas participantes, também contribuirá para a literatura de formação de preços.

No aspecto acadêmico, é importante ressaltar que a literatura normativa tem enfatizado a abordagem do valor, entretanto pesquisas sugerem que a maioria das empresas toma decisões que não são consideradas ótimas pela literatura. Assim, este trabalho busca contribuir para a literatura ao oferecer um estudo empírico a respeito da relação entre fatores determinantes para a formação do preço de venda no ambiente B2B brasileiro.

Em relação ao público organizacional, a presente pesquisa pretende oferecer para cada participante um diagnóstico da situação encontrada na respectiva empresa, comparativamente com a encontrada em outras organizações. São particularmente importantes as questões que se debruçam na descrição de detalhes que ajudam na conversão de conhecimento privado em conhecimento público. Neste sentido, os procedimentos detalhados e cálculos que se não fossem compartilhados, por exemplo, ficariam limitados a um círculo restrito (Cooper \& Morgan, 2008).

\subsection{DELIMITAÇÕES DO ESTUDO}

Este trabalho está estruturado de forma a abordar os determinantes de precificação relacionados com aspectos organizacionais e ao conceito econômico de empresas formadoras e 
tomadoras de preço. Não faz parte do escopo deste trabalho pesquisar todos os fatores influenciadores de preço, em função do limite de tempo inerente a um trabalho de mestrado.

Ao mesmo tempo, com a finalidade de minimizar a influência de fatores poucos tangíveis, como necessidades socioculturais, este estudo tem foco nos produtos industriais e no comércio (B2B) já que compradores neste ambiente tendem a basear-se em objetivos profissionais da empresa, sendo menos influenciados por questões subjetivas (Forman \& Hunt, 2005).

Também releva notar que a presente dissertação não pretende apresentar uma visão normativa do que seria o melhor método ou modelo de formação do preço de venda, mas tão somente retratar e analisar as práticas atuais da população pesquisada.

Em relação à delimitação do universo de pesquisa, a população é formada por empresas de capital nacional e internacional que integram bens de capital, equipamentos e componentes eletroeletrônicos para modernização tecnológica de diversos setores da sociedade. Dessa forma, a delimitação geográfica abrange organizações instaladas no Brasil, independentemente da origem do capital. A delimitação temporal considera as empresas pertencente à associação no ano de 2017, o mesmo ano da coleta de dados.

\subsection{LIMITAÇÕES DO ESTUdO}

Ainda que a população do estudo seja relevante, o resultado desta pesquisa retratará as características da população pesquisada e não poderá representar a totalidade de empresas no Brasil.

\subsection{ESTRUTURA DO PROJETO DE PESQUISA}

O presente trabalho está estruturado em seções com a finalidade de facilitar o entendimento dos leitores. A primeira seção, Introdução, busca apresentar a caracterização do problema de pesquisa e da questão a ser investigada, assim como objetivos, hipóteses, justificativas, contribuições, delimitações e limitações, além da própria estrutura do trabalho.

A fim de identificar como as empresas estabelecem o preço de venda com base no valor é de fundamental importância o entendimento dos fatores que influenciam a determinação do preço de venda. Na segunda seção, revisaremos os fatores internos e externos que determinam a escolha de preços: inicialmente estudaremos como a demanda e a oferta se relacionam com do comportamento de tomadores e formadores de preço. Na sequência revisaremos os métodos 
de custeio, os métodos de precificação e a estrutura organizacional de preços, incluindo as particularidades da formação do preço de venda no ambiente B2B.

A terceira seção, desenvolvimento da pesquisa, apresenta os aspectos necessários ao entendimento do método utilizado, a saber: tipologia da pesquisa, delimitação da população pesquisada, técnica de coleta de dados, constructos, técnicas de análise dos dados e por fim, a operacionalização.

A quarta seção, análise e discussão dos resultados, apresentará dados da amostra e o contexto apresentados. Por fim, na quinta seção, conclusão, apresenta-se as contribuições e implicações para os pesquisadores e profissionais.

Figura 1 - Estrutura da Dissertação

Questão; Objetivos, Hipóteses; Justiticativa; Contribuições; Delimitação e Limitações

\section{A abordagem do valor: características e determinantes}

Conceitos de Valor e de Preço; Determinantes de precificação; Abordagens alternativas de precificação

Desenvolvimento da pesquisa

Tipologia; População; Coleta de dados; Constructos; Hipóteses; Análise de dados; Operacionalização

\section{Análise e discussão dos resultados}

Amostra; Comportamento de preços; Abordagem de preços; Estrutura organizacional 


\section{A ABORDAGEM DO VALOR: CARACTERÍSTICAS E DETERMINANTES}

A abordagem do valor é a extensão pela qual as empresas usam informação da percepção do cliente sobre as vantagens oferecidas e como os consumidores irão realizar o trade-off dessas vantagens com o preço a ser determinado (J. C. Anderson, Jain, \& Chintagunta, 1993; P. Ingenbleek, 2007). Esta abordagem se fundamenta nos benefícios esperados pelo consumidor, numa lógica completamente diferente da utilizada nas abordagens que se baseiam nos preços da concorrência ou nos próprios custos (Shipley \& Jobber, 2001; Töytäri et al., 2017).

Sendo caracterizada pela criação de valor, de maneira holística (Töytäri et al., 2015), esta abordagem requer o entendimento do cliente, desde seu modelo de negócios, passando pelos seus processos e direcionadores para finalmente culminar no entendimento do que o consumidor valoriza (Töytäri et al., 2017).

Apesar da literatura indicar que esta abordagem resulta na satisfação e na retenção do cliente assim como na maximização dos resultados (J. Anderson \& Narus, 1998; Forbis \& Mehta, 1981; Hinterhuber, 2008a; P. T. M. Ingenbleek et al., 2003; Liozu \& Hinterhuber, 2013; Nagle \& Holden, 2003; Töytäri et al., 2011, 2017), poder-se-ia esperar que as empresas adotassem as melhores técnicas e práticas disponíveis visando a implementação desta abordagem. Entretanto, o fato da abordagem do valor não ser frequentemente aplicada no ambiente B2B (Hinterhuber \& Liozu, 2012) sugere que existem barreiras à sua implementação (Hallberg, 2017).

A microeconomia tem como tema central a teoria de preços (Howe, 1978), que procura explicar a transferência de valor entre agentes econômicos, o que inclui a compra e a venda de produtos e serviços (Weber, 2012). Considerando a notória capacidade que os modelos econômicos têm de representar a realidade com elegância e simplicidade, não é exagerada a afirmação de N. Piercy (2014) de que é praticamente inevitável começar um estudo sobre preços por eles. Sendo assim, após a breve apresentação das definições de valor e de preço (subseções 2.1 e 2.2 respectivamente), será abordada na subseção 2.3 .1 a influência da demanda e da concorrência no comportamento de preços das empresas.

Ainda que os modelos econômicos sejam inegavelmente úteis para o estudo de preços, as premissas consideradas e as variáveis que são mantidas constates em seus modelos não são suficientes para o entendimento completo das questões enfrentadas pelos profissionais de 
precificação, o que leva os profissionais de administração, contabilidade e de marketing a se debruçarem sobre este assunto. A subseção 2.3.2 revisará a estrutura organizacional no contexto da precificação. Por fim, serão apresentadas as abordagens de precificação alternativas à abordagem do valor (subseções 2.4).

\subsection{CONCEITO DE VALOR}

O termo valor é geralmente conceituado como um trade-off entre a percepção dos benefícios e a percepção dos sacrifícios gerados pela aquisição de um bem, como pode ser observado nas definições de valor realizadas por diferentes pesquisadores nas últimas quatro décadas e consolidadas na Tabela 1 a seguir.

Tabela 1 - Definições de Valor

\begin{tabular}{|c|c|}
\hline Definições & Fontes \\
\hline $\begin{array}{l}\text { Valor é a avaliação geral do consumidor sobre a utilidade de um produto, baseado } \\
\text { nas percepções sobre o que é recebido e o que dado. }\end{array}$ & $\begin{array}{l}\text { Zeithaml } \\
\text { (1988) }\end{array}$ \\
\hline $\begin{array}{l}\text { Valor é a preferência percebida pelo consumidor e a sua avaliação sobre os atributos } \\
\text { dos produtos e da consequente facilitação (ou bloqueio) do atingimento dos } \\
\text { objetivos e propósitos do consumidor em situação de uso. }\end{array}$ & $\begin{array}{l}\text { Woodruff } \\
\text { (1997) }\end{array}$ \\
\hline $\begin{array}{l}\text { Valor é um trade-off entre produto, serviço, conhecimento, tempestividade de } \\
\text { mercado e benefícios sociais, assim como preço e custos de processamento num } \\
\text { relacionamento de fornecimento, como percebidos pelos decisores principais na } \\
\text { organização dos clientes, levando em consideração os relacionamentos alternativos } \\
\text { disponíveis com outros fornecedores. }\end{array}$ & $\begin{array}{l}\text { Ulaga \& } \\
\text { Eggert (2005) }\end{array}$ \\
\hline $\begin{array}{l}\text { Valor é definido pela extensão pela qual uma empresa utiliza informação no } \\
\text { processo de determinação de preço sobre as vantagens relativas percebidas da oferta } \\
\text { e como os clientes vão realizar o trade-off entre estas vantagens e o preço que ainda } \\
\text { será determinado. }\end{array}$ & $\begin{array}{l}\text { (P. T. M. } \\
\text { Ingenbleek, } \\
\text { 2007) }\end{array}$ \\
\hline $\begin{array}{l}\text { Valor é a diferença entre a percepção dos benefícios recebidos e a percepção dos } \\
\text { sacrifícios feitos pelo consumidor. Tanto os benefícios quanto os sacrifícios são } \\
\text { conceitos multidimensionais, combinando dimensões operacionais, estratégicas, } \\
\text { sociais e simbólicas. }\end{array}$ & $\begin{array}{l}\text { Töytäri, } \\
\text { Rajala, \& } \\
\text { Alejandro } \\
(2015)\end{array}$ \\
\hline
\end{tabular}


Pesquisas anteriores apresentam o valor como dinâmico (Flint \& Woodruff, 2001), dimensional e situacional (Holbrook, 1996; Ravald \& Grönroos, 1996), já que a maneira como é percebido varia em função do contexto em que o consumidor está inserido. Nesse sentido, a percepção de valor depende da perspectiva temporal, geográfica (Woodruff, 1997) e das alternativas apresentadas pela concorrência (Liozu, Hinterhuber, Boland, \& Perelli, 2012). Além disso, Eggert e Ulaga (2002) sugerem que o valor percebido pelo consumidor é subjetivo, sendo apontado por Vargo e Lusch (2004) como baseado nos julgamentos e preferências individuais.

Sendo por vezes percebido como ambíguo (Munnukka \& Järvi, 2012) e multifacetado (P. T. M. Ingenbleek, 2007), por receber diversas classificações (Parasuraman, 1997) em diferentes contextos (Woodruff, 1997), a determinação do preço de venda baseado no valor é vista como um desafio que pode depender de soluções contextualizadas e específicas (Rajala, Töytäri, \& Hervonen, 2015).

Entretanto, o entendimento do conceito de valor por parte dos gestores parece estar relacionado com a adoção da abordagem do valor pelas empresas: Liozu et al. (2012) identificaram em seu estudo que os gerentes de empresas que adotam a abordagem do valor apresentaram um bom entendimento do conceito exposto pela literatura, ao contrário dos gerentes de empresas que adotam abordagens alternativas.

\subsection{RelaÇão entre VAlor e Preço}

A relação entre valor e preço foi estudada por diversos pesquisadores, que, por exemplo, procuraram entender como o preço é utilizado para a inferência de qualidade pelos consumidores (Levin \& Johnson, 1984; Zeithaml, 1988), para reduzir riscos em cenários de informação incompleta (Tellis \& Gaeth, 1990) e para influenciar a percepção de valor em consumidores - através de descontos em preços de lista por exemplo (Grewal, Monroe, \& Krishnan, 1998).

Do ponto de vista econômico, Adam Smith (1776) procurou explicar a relação entre valor e preço, fazendo a seguinte observação:

a palavra valor, deve ser observado, tem dois diferentes significados, e algumas vezes expressa a utilidade de um objeto particular, e em outras vezes o poder de comprar outros 
bens que a posse desse objeto suporta. O primeiro pode ser chamado de 'valor de uso'; o outro, 'valor de troca' (p.17) ${ }^{1}$

De acordo com sua teoria, o trabalho seria a unidade do valor de troca de um bem que, assim, determinaria o seu preço "real". Considerando que é mais trabalhoso obter um quilograma de diamante do que um quilograma de água, o seu preço elevado refletiria a quantidade de trabalho desprendida em sua obtenção.

Baseado em outra teoria, a da utilidade marginal, Menger $^{2}$ (1871, apud Weber, 2012) considera que, apesar da água ser fundamental para a sobrevivência, ela não é mais cara do que o diamante porque as primeiras unidades de água são críticas para a sobrevivência, mas a utilidade das unidades adicionais cai rapidamente. Neste sentido, o preço de um bem tende a cair quando há mais oferta do que demanda (Weber, 2012).

\subsection{Determinantes de PrecificaÇão}

A revisão da literatura indica que um conjunto de condições de mercado, da concorrência e da empresa determinam a escolha da abordagem do valor. Diamantopoulos e Mathews (1994) classificam esse conjunto como "ambiente de precificação", no qual as decisões de preço são tomadas (Noble \& Gruca, 1999).

Shipley e Jobber (2001) segregam estas condições entre fatores externos e internos. Forman e Hunt (2005) corroboram a segregação ressaltando que os fatores externos estão estabelecidos na literatura econômica, dos quais se destacam a demanda e a concorrência.

A demanda é economicamente relacionada às quantidades ótimas de cada um dos bens que os consumidores escolhem em função de sua renda e dos preços (Varian, 2012). Do ponto de vista da concorrência, entende-se que os produtores escolhem o plano de produção que maximiza seus lucros, em função das restrições do mercado e da natureza (Varian, 2012). Diante deste cenário de escolhas de consumidores e de produtores, existem algumas condições que resultam no comportamento de preços das empresas, a saber: quantidade de empresas ofertantes; quantidade de consumidores; nível diferenciação dos produtos ofertados; barreiras de entrada e saída do mercado (Varian, 2012). Em função das diversas associações destas características, o mercado estrutura-se de tal forma que condiciona as empresas a se

\footnotetext{
${ }^{1}$ Tradução livre do autor. No original: "the word value, it is to be observed, has two different meanings, and sometimes expresses the utility of some particular object, and sometimes the power of purchasing other goods which the possession of that object conveys. The one may be called "value in use"; the other, "value in exchange." (p.17) Vienna, Austria.

Menger, C. (1871) Grundsatze der Volkswirthschaftslehre: Erster, Allgemeiner Theil, W. Braumuller,
} 
comportarem como formadoras ou como tomadoras de preços, justamente o que será abordado na subseção 2.3.1.

Do ponto de vista da estrutura organizacional, ainda que se sejam poucos os estudos que analisam como as empresas se estruturam para as decisões de preço (Burkert et al., 2016), a subseção 2.3.2 abordará evidências de que a organização de preços pode facilitar a implementação da abordagem do valor, assim como pode impor barreiras para a adoção deste método (Hallberg, 2017; Töytäri et al., 2015).

\subsubsection{A influência da Demanda e da Concorrência no comportamento de preços: Tomadores e Formadores}

Na teoria econômica, quando o mercado contém elevado número de consumidores e de empresas ofertando produtos sem diferenciação, a interação entre as escolhas ótimas dos

consumidores e das empresas as leva a se comportarem como tomadoras de preços. É o que será abordado na subseção 2.3.1.1.

Por outro lado, em outras condições de mercado as empresas não consideram os preços como dados, ao contrário, elas têm o poder de decidir o preço que maximiza seus lucros. $\mathrm{O}$ comportamento e escolha dos formadores de preços serão abordados na subseção 2.3.1.2.

\subsubsection{Comportamento e escolha de Tomadores de preços}

Um dos pontos mais fundamentais da economia é o fato de que os preços não são números arbitrários, mas "indicadores do valor marginal que as pessoas atribuem às coisas" (Varian, 2012, cap. 5.5, parágrafo 10). Para entender este ponto fundamental é necessário compreender que a taxa marginal de substituição entre um bem $\mathrm{x}_{1}$ e um bem $\mathrm{x}_{2}$ é a mesma da divisão entre o preço de $\mathrm{x}_{1}$ e o preço de $\mathrm{x}_{2}$. Isso significa que se o preço de $\mathrm{x}_{1}$ é de $\mathrm{R} \$ 1,00$ e o de $\mathrm{x}_{2}$ é de $\mathrm{R} \$ 2,00$, a taxa de substituição para todos os agentes que consomem $\mathrm{x}_{1}$ e $\mathrm{x}_{2}$ tem que ser 2: para compensar a desistência de uma unidade de $\mathrm{x}_{2}$, é necessário ter duas unidades de $\mathrm{x}_{1}$ e vice-versa (Varian, 2012).

É importante destacar o fato de que a taxa marginal de substituição para um agente econômico chamado João, seria a mesma taxa para um outro agente econômico chamado Maria, ainda que sua renda e preferências fossem diferentes (Weber, 2012): "Portanto, todos os que consumirem ambos os bens atribuirão valor a uma variação marginal em consumo do mesmo modo" (Varian, 2012, cap. 5.5, parágrafo 07). 
A teoria do consumidor - e neste caso nos referimos tanto às pessoas físicas quanto às pessoas jurídicas - pode ser resumida num exemplo simples oferecido por Weber (2012): Imaginemos um agente econômico com uma riqueza $w$ que pode ser gasta numa cesta $x$ contendo bens consumíveis na economia. Dado que cada bem da cesta tem um preço, o agente econômico maximiza sua utilidade ${ }^{3}$ até o limite em que o valor total do seu consumo não ultrapasse sua riqueza. No mesmo sentido, Varian (2012) apresenta o conceito de cesta demandada, que se refere à "escolha ótima num determinado conjunto de preços e de renda... Para cada conjunto de preços e de renda, haverá um composição de bens que corresponderá à escolha ótima" (Varian, 2012, cap. 5.2, parágrafo 01).

As quantidades ótimas de um bem em função da renda e dos preços disponíveis é chamada função de demanda. A somatória das funções demandas individuais dos consumidores resulta na demanda de mercado. A sensibilidade da variação da demanda em função de variações no preço é chamada de elasticidade. A demanda inelástica é aquela que não varia em função do preço, já a demanda elástica é aquela que apresenta variação em função das alterações de preço. A elasticidade-preço da demanda, é definida "como uma variação percentual na quantidade dividida pela variação percentual no preço" (Varian, 2012, cap. 15.2, parágrafo 03).

Uma vez entendido o comportamento do lado do consumo, passaremos ao comportamento da oferta para que seja possível estudar o equilíbrio resultante de interação de ambos.

$\mathrm{Na}$ teoria da produção, o estudo do comportamento das empresas passa pelo entendimento das restrições impostas pelo mercado - representado tanto pelos consumidores quanto pelos concorrentes - e pela natureza (Varian, 2012). Nesta última categoria, estão incluídos os insumos de produção, por sua vez constituídos pela terra, pelo trabalho, pelas matérias-primas e pelo capital físico (máquinas, prédios etc.). Somente certa combinação de insumos viabiliza a produção de certa quantidade de bens, sendo que em função das limitações dos recursos finitos as empresas estabelecem planos de produção factíveis (Varian, 2012).

Ainda que as empresas elaborem planos de produção factíveis, é de fundamental importância que os consumidores queiram comprar os produtos disponibilizados aos preços ofertados. A curva de demanda do mercado indicaria as restrições de mercado enfrentadas por

${ }^{3}$ Utilidade é um conceito econômico. "Os filósofos e economistas da era vitoriana referiam-se alegremente à 'utilidade' como um indicador do bem-estar geral de uma pessoa" (cap.04, parágrafo 01). Gradualmente o conceito foi sendo adaptado para o que se admite hoje no ambiente econômico: "A função utilidade é um modo de atribuir um número a cada possível cesta de consumo, de modo que se atribuam às cestas mais preferidas números maiores que os atribuídos às cestas menos preferidas" (Varian, 2012, cap. 04, parágrafo $06)$. 
uma empresa que possui todo o mercado, entretanto, se houver concorrentes, a empresa terá que considerar o comportamento da concorrência (Varian, 2012).

Em um mercado competitivo, cada consumidor ou produtor representa uma pequena parcela do mercado total, de tal forma que cada um deles tem efeito insignificante sobre os preços de mercado (Varian, 2012). Considerando que o preço de um bem está fora do controle dos agentes econômicos, tanto do ponto de vista do consumo quanto do ponto de vista da oferta, os agentes econômicos apenas determinam sua melhor resposta em função dos preços disponíveis no mercado. É por isso que neste ambiente de mercado, os agentes econômicos são chamados de tomadores de preço. (Varian, 2012).

Existem duas premissas que são de fundamental importância para o entendimento da decisão de oferta de uma empresa que atua em um ambiente de mercado competitivo: (i) os agentes econômicos se comportam racionalmente no sentido de que suas preferências são estáveis e; (ii) suas escolhas podem ser maximizadas (Weber, 2012). A partir destas duas premissas, os modelos econômicos consideram que a empresa escolhe o plano de produção que maximiza os lucros (Varian, 2012). A maximização dos lucros, neste contexto, ocorre quando "a receita marginal for igual ao custo marginal - onde a receita extra recebida por uma unidade adicional produzida iguala-se ao custo extra de produzir uma unidade a mais (Varian, 2012, cap. 23.3, parágrafo 03).

A somatória das funções de oferta individuais das empresas resulta na curva de oferta do mercado. É na intersecção desta curva com a curva de demanda que ocorre o equilíbrio de mercado. Em termos econômicos, equilíbrio "é a situação em que todos os agentes econômicos escolhem a melhor ação possível de acordo com sus próprios interesses e em que o comportamento de cada pessoa é coerente com o de todas as outras" (Varian, 2012, cap. 16.2, parágrafo 07).

O preço de equilíbrio é atingido no ponto de encontro das curvas que representam as escolhas ótimas dos agentes econômicos: as curvas de oferta e demanda. Em outras palavras, “o preço de equilíbrio é determinado ao se encontrar a quantidade na qual o preço que os demandantes estão dispostos a pagar para consumi-la é igual ao preço que os ofertantes querem receber para oferta-la" (Varian, 2012, cap. 16.4, parágrafo 02).

\subsubsection{Comportamento e escolha de Formadores de preços}

Uma empresa que atua isoladamente no mercado não considera os preços como dados, ao contrário, tem o poder de decidir o preço que maximixa seus lucros. É por essa razão que 
este contexto leva as empresas a se comportarem como formadoras de preços. Ainda que a empresa esteja livre de restrições da concorrência, ela ainda enfrentas as restrições da "natureza" e dos consumidores. Neste sentido, o "comportamento da demanda dos consumidores restringirá a escolha do monopolista no que tange ao preço e à quantidade" (Varian, 2012, cap. 25, parágrafo 03). Nesta estrutura de mercado, o monopólio, a decisão de preço que maximiza o lucro ocorre no ponto em que a receita marginal se iguala ao custo marginal (Varian, 2012).

Os modelos de competição perfeita e o de monopólio são exemplos extremos. O mercado de competição monopolista é um composto de monopólio e de competição perfeita, no qual há diferenciação de produtos, de maneira que todas as empresas têm algum grau de poder de monopólio, entretanto a entrada no mercado é livre, o que leva os lucros a zero no longo prazo. Neste mercado, a diferenciação dá alguma liberdade para a fixação de preços, fazendo que as empresas se comportem como formadoras de preços no curto prazo. Nestas condições, a decisão de preço que maximiza o lucro ocorre no ponto em que a receita marginal se iguala ao custo marginal (Varian, 2012).

A estrutura de oligopólio é caracterizada por um mercado com poucas empresas em função da existência de barreiras de entrada. Como existem poucas empresas, elas reconhecem a interdependência das decisões que são tomadas. Há várias formas possíveis de comportamento para os oligopólios, dependendo da natureza exata de suas interações (Varian, 2012).

\subsubsection{Estrutura organizacional de preços}

O conhecimento sobre o impacto das influências organizacionais nas estratégias e nas abordagens utilizadas pelas empresas no estabelecimento de preços ainda é limitado (Roll, 2009), o que oferece um grande potencial para pesquisas (Hallberg, 2017; Noble \& Gruca, 1999), principalmente no ambiente B2B (Roll, 2009). Além disso, há indícios que os profissionais do mercado também entendem haver um grande potencial nesta área: em um estudo com profissionais de toda a Europa, a organização de gestão de preços foi apontada como uma das três maiores prioridades para os gestores (Roll, 2009).

Töytäri et al. (2017) apontam que ainda se conhece pouco sobre os fatores que facilitam ou impedem a adoção da abordagem do valor no contexto industrial, assim como são poucos os estudos que analisam como as empresas se estruturam para as decisões de preço (Burkert et al., 2016). Entretanto, há evidência de que a estrutura organizacional pode facilitar a 
implementação da abordagem do valor (Dutta, Zbaracki, \& Bergen, 2003; Johansson, Keränen, Hinterhuber, Liozu, \& Andersson, 2015; Töytäri \& Rajala, 2015) assim como pode constituir barreira para este método (Hallberg, 2017; Töytäri et al., 2015).

No que se refere às barreiras para a implementação da abordagem do valor, aponta-se que a excessiva delegação das decisões de preços, a maneira como força de vendas é gerida, assim como a forma que o controle organizacional é realizado, podem prejudicar a implementação da precificação baseada no valor (Hallberg, 2017).

Do ponto de vista da literatura que investiga a influência dos indivíduos nas capacidades organizacionais, a adoção da abordagem do valor pode ser dificultada em função da crenças e dos hábitos individuais (Töytäri et al., 2017). Nesse sentido, encontra-se no ambiente B2B, e notadamente nos representantes de vendas, a percepção de que as abordagens que se baseiam no custo e na competição são mais justas do que a abordagem do valor (Töytäri et al., 2017). A pressão do cliente por descontos soma-se a essa percepção, o que pode resultar em reduções de preços míopes (Homburg \& Jensen, 2007).

Além disso, as ferramentas corporativas, por vezes, podem estar desenvolvidas de tal forma que estimulam a adoção de abordagens alternativas à do valor, principalmente no que se refere ao programa de incentivos de vendas e às ferramentas de governança corporativa (Töytäri et al., 2017).

No que se refere aos fatores que facilitam a implementação da abordagem do valor, a literatura sugere que empresas que desenvolvem recursos organizacionais voltados à precificação facilitam o caminho para a adoção da abordagem do valor (Dutta et al., 2003; Johansson et al., 2015; Töytäri \& Rajala, 2015). A clara definição das responsabilidades e dos papeis de cada agente do processo de determinação do preço de venda está relacionada com organizações de preços maduras (Carricano, Trinquecoste, \& Mondejar, 2010) em função da capacidade de facilitar relacionamentos colaborativos e congruentes no contexto organizacional (Vlaar, Van Den Bosch, \& Volberda, 2006).

No ambiente B2B, um conhecido problema reside na dúvida acerca dos benefícios ou malefícios da delegação da autoridade de preços aos representantes de vendas (Bhardwaj, 2001). Defensores da delegação de preços para os representantes de venda costumam se embasar na linha de pesquisa econômica para a qual a decisão de preços deve ser feita pelo agente com maior quantidade de informação disponível (Frenzen, Hansen, Krafft, Mantrala, \& Schmidt, 2010).

Assim, em função da proximidade com o mercado, os representantes de vendas estariam melhor informados sobre as condições, necessidades e disposição a pagar dos clientes locais 
(Frenzen et al., 2010) que os permitiria estabelecer preços pela abordagem do valor. Políticas de incentivo de vendas baseadas em margens de contribuição parecem mitigar o conflito de agência existente nas situações de delegação de preços vertical (Homburg, Jensen, \& Hahn, 2012). Em relação à experiência, os profissionais sêniores que decidem preço em situações de informação incompleta e alta complexidade podem facilitar a adoção da abordagem do valor, principalmente no cenário industrial de preços customizados (Hallberg, 2017).

Por outro lado, empresas e profissionais parecem pouco confiantes em adotar esta prática: Hansen, Joseph, e Krafft (2008) identificaram que apenas $11 \%$ das empresas respondentes delegavam as decisões de preço, em consonância com a pesquisa de Stephenson, Cron, e Frazier (1979) que identificou que apenas 23\% das empresas respondentes delegavam a determinação de preços para os representantes de vendas, enquanto $48 \%$ delegavam parcialmente, dentro de uma determinada faixa de preços, e $29 \%$ não delegavam.

A literatura de organização normalmente considera especialistas os profissionais que lidam exclusivamente com preços (Burkert, Ivens, Henneberg, \& Schradi, 2017), em diferentes níveis hierárquicos, como analistas ou gerentes. Nos E.U.A o especialista em preços surgiu oficialmente na década de 1990 em empresas que buscavam investir em recursos e capacitações para a otimização das decisões de preço (Carricano et al., 2010). Ainda que seja uma especialização relativamente nova, 62\% das empresas dos E.U.A cujas vendas superam 1 bilhão de dólares contam com gerentes de preços (Carricano et al., 2010).

O papel da alta gerência no contexto da precificação tem sido apontado como de elevada importância em função da capacidade de desenvolver atividades e profissionais que lidam com preços, já que sua posição confere envergadura única para estabelecer objetivos claros, influenciar o comportamento dos profissionais e para estruturar a organização de preços (Burkert et al., 2017).

Do ponto de vista da teoria institucional, estratégias de sensibilização da equipe de vendas para a utilização da abordagem do valor foram identificadas em pesquisa empírica (Töytäri et al., 2017): programas internos que identificam o valor gerado em casos recentes e o divulgam internamente (J. C. Anderson \& Wynstra, 2010); treinamentos que oferecem argumentos de vendas focados no valor; e o desenvolvimento de ferramentas que permitem o cálculo rápido do valor relacionado a uma oferta.

Nesse sentido, Liozu, Hinterhuber, Boland, e Perelli (2012) argumentam que líderes de preço devem se responsabilizar pela internalização da precificação baseada no valor, assim como pela transformação organizacional necessária. 


\subsection{Abordagens Alternativas de PrecificaÇão}

As abordagens de precificação - muitas vezes chamadas de Práticas ou de Métodos de Precificação (P. T. M. Ingenbleek \& van der Lans, 2013) - podem ser definidas como os passos ou procedimentos explícitos através dos quais empresas chegam ao preço (Avlonitis \& Indounas, 2005). É importante ressaltar que as abordagens de precificação constituem o conjunto de atividades executadas pelas organizações que levam à decisão de preços, diferentemente da estratégia de precificação que oferece o meio pelo qual a empresa pode atingir seus objetivos de preço no mercado (P. T. M. Ingenbleek \& van der Lans, 2013). Para estes autores, as estratégias de precificação “... estão visíveis no mercado, enquanto práticas de estabelecimento de preços estão escondidas atrás das fronteiras de uma organização" (P. T. M. Ingenbleek \& van der Lans, 2013) em tradução livre.

Diversos pesquisadores de marketing, como, por exemplo, Shipley e Jobber (2001), Ingenbleek et al. (2003), Avlonitis e Indounas (2006), Collins e Parsa (2006), Hinterhuber (2008), Indounas (2009), Hinterhuber e Liozu (2012), Calabrese e De Francesco (2014) e Campomar (2017) segregam as abordagens de precificação em três grupos: (i) preço baseado no custo; (ii) preço baseado na concorrência e (iii) preço baseado no valor.

O preço baseado no custo tem como fundamento o cálculo dos custos internos sobre os quais se adiciona um margem para a definição do preço (Töytäri et al., 2017). Já o preço baseado na concorrência tem como fundamento o preço de mercado de ofertas equivalentes, a partir do qual o preço é determinado em função das características da oferta comparativamente ao da concorrência (Liozu et al., 2012).

Estes métodos são predominantes em mercados comoditizados e maduros, com características de redução de custos e preços baixos. São características destes mercados o alto poder de barganha e a liderança das negociações pelos compradores, além da baixa percepção de valor (Töytäri et al., 2017).

O modelo de discrição de preços proposto por Monroe (2003) ajuda a visualizar as três fronteiras que naturalmente delimitam o alcance das referidas abordagens. O teto é delimitado pelo valor percebido pelo consumidor e o piso é definido pelos custos. Num mercado competitivo, de tomadores de preço, o preço da concorrência se torna o teto de preços, já que se o preço for estabelecido acima deste ponto, os consumidores preferirão adquirir o produto da concorrência. Num mercado de concorrência monopolística, em que há diferenciação de suficiente para que as empresas tenham alguma liberdade para o estabelecimento de preços, o 
preço da concorrência se torna um ponto de referência, como pode ser observado na figura a seguir.

Figura 2 - Modelo de preço

\section{Valor para os consumidores}

\section{Teto de preço}

\section{Preço da concorrência}

Piso de preço

Fonte: adaptado de Monroe (2013)

Preços estabelecidos próximo ao teto são previstos de serem atingidos através da abordagem do valor, já os preços que acompanham o da concorrência são previstos de serem atingidos através da abordagem da concorrência, e por fim, preços próximos ao piso são previstos de serem atingidos pela abordagem do custo (P. T. M. Ingenbleek \& van der Lans, 2013).

\subsubsection{Preço baseado no Custo}

Este método de precificação baseia-se, como o próprio nome revela, nos custos dos produtos e dos serviços (Hinterhuber, 2008a). Uma vez que o custo tenha sido determinado, é adicionada uma margem que deriva no preço de venda. Em função da existência de diferentes métodos de custeio, que resultam em diferentes custos, Sizer (1966) aponta que a contabilidade tem um papel importante no fornecimento de informações úteis para os tomadores de decisão.

Pesquisadores de diversos países sugerem a partir de pesquisas empíricas que a abordagem de custo constitui o método mais utilizado pelas empresas (Avlonitis \& Indounas, 2004, 2005, 2006a, 2006b, 2007a, 2007b; Fabiani et al., 2005; Guilding, Drury, \& Tayles, 2005; 
Indounas, 2008, 2009, Indounas \& Avlonitis, 2009, 2011; Noble \& Gruca, 1999; Shipley \& Jobber, 2001).

Entre as explicações dadas por gerentes pela escolha deste método estão a simplicidade, a ampla utilização pela concorrência (Shipley \& Jobber, 2001) e segurança de cobrir os custos (Piercy, 2014).

Como problemas deste método, Skinner (1970) aponta que a estimativa do volume de vendas dificilmente poderia ser obtida independentemente do preço e independentemente dos preços e volumes da concorrência. Além disso, o volume de vendas depende do valor percebido e da capacidade de pagamento dos consumidores do produto ofertado. Shipley e Jobber (2001) apontam que a sua utilização pode levar a inúmeros erros se não forem consideradas as variáveis internas e externas. Dessa maneira, N. Piercy (2014) afirma que o papel dos custos na precificação seria o de indicar a rentabilidade das várias possibilidade de preço.

Lucas (2003) acredita que algumas pesquisas simplificam demasiadamente as abordagens de precificação, e que isso pode ter criado uma ilusão de que a abordagem de custo é a mais utilizada. No mesmo sentido Skinner (1970) aponta evidências empíricas de que empresas que declaram utilizar o método de custo o utilizam como ponto de partida, para ao final, realizarem ajustes em função da concorrência e da demanda.

No mesmo sentido destes autores, Amaral (2017) indica que algumas pesquisas empíricas simplificaram em demasia a identificação das abordagens de precificação: a fórmula matemática utilizada para o cálculo de preços usualmente considera informações de custo, entretanto, o uso desta fórmula não indica necessariamente a adoção da abordagem de custos (Amaral, 2017; Guerreiro \& Amaral, 2018).

$$
\text { Preço de venda }=\text { Custo }+ \text { Margem }
$$

\subsubsection{Preço baseado na Concorrência}

Este método de precificação baseia-se em informações de preços dos concorrentes, podendo ser o mesmo preço praticado pelo competição ou ligeiramente diferente (Hinterhuber, 2008a). Diversas fontes de informação podem ser utilizadas para a obtenção dos preços dos concorrentes, como por exemplo, propagandas, clientes, distribuidores, feiras de negócios entre outros (Shipley \& Jobber, 2001).

Entretanto, Garda (1991) aponta a dificuldade de conhecer o preço real ofertado pela concorrência em certos mercados, já que o preço visível, de lista, não é o preço final, após 
descontos e rebates. Além disso, aponta como tática para confundir a concorrência, o estabelecimento de um preço alto para um consumidor que sabidamente transparece preços para os concorrentes.

No mesmo sentido, Dutta et al. (2003) destacaram, em sua pesquisa empírica, a dificuldade da obtenção de correta informação do preço da concorrência em função da grande quantidade de itens vendáveis e da prática adotada pelo mercado de trabalhar com descontos e rebates sobre a lista de preços. Os autores recomendam a criação de times multifuncionais para gerar, armazenar e comparar informações de produtos equivalentes da concorrência.

Recomendação semelhante é feita por Roll (2009), num estudo que entrevistou 81 profissionais responsáveis por preço na Europa:

...é muito difícil ter informações acuradas da concorrência, atualizadas e disponíveis para todos. Por um lado, este pode ser um problema técnico, por exemplo, instalando uma base de dados; por outro lado este pode ser um problema de recurso e processo. A empresa precisa de diretrizes claras para preencher e atualizar a base de dados, assim como para distribuir o conhecimento armazenado na empresa" (p. 397) .

Entre os argumentos para utilização deste método estão (Hinterhuber, 2008a; Shipley \& Jobber, 2001):

a) A administração é simples e geralmente de custo baixo;

b) Permite ao seguidor aproveitar os mesmo reajustes de preço;

c) Pode evitar uma guerra de preços;

d) Disponibilidade de informação.

Entre os problemas desta abordagem, estão (Shipley \& Jobber, 2001):

a) Ignora oportunidade de ganho decorrentes de ajuste de preços;

b) Ignora os custos internos e diferenciais;

c) Dificuldade de obtenção do preço exatamente praticado pela concorrencia em função de negociações e descontos não visíveis.

\subsection{Particularidades da FORMaÇão de PREÇOS NO AMBIENTE B2B}

4 Tradução livre do autor. No original: "it is very difficult to have the competitor information accurate, up to date and available to everyone. On the one hand, this can be a technical problem, for example, installing a database; on the other hand it can be resource and process problem. The company needs clear guidelines for filling and updating the database, as well as for distributing the gathered knowledge in the company" (Roll, 2009). 
Os termos B2B e B2C são acrônimos já bastante difundidos, e referem-se respectivamente ao comércio industrial e ao comércio destinado ao consumidor final, seja ele baseado ou não na internet (Secomandi \& Johnson, 2007). O processo de criação de valor e de relacionamento no ambiente $\mathrm{B} 2 \mathrm{~B}$ tem complexidades que requerem ao mesmo tempo profunda e ampla atenção (Albadvi \& Hosseini, 2011).

Diversos pesquisadores apontam que a determinação do preço de venda no ambiente B2B - no qual produtos e serviços são ofertados a produtores, revendedores, governos e entidades não governamentais - apresenta algumas diferenças se comparada ao ambiente B2C (Hinterhuber, 2008b), já que os preços podem variar entre os clientes e durante o processo de compras dentro de um mesmo cliente (Frenzen et al., 2010). Forman e Lancioni (2002) apontam as três principais diferenças entre estes dois ambientes, a saber:

a) a relação entre qualidade e preço é mais importante no ambiente B2B;

b) os compradores deste ambiente são menos sensíveis à preço;

c) os compradores deste ambiente são especialistas e detêm mais conhecimento do que os consumidores do ambiente B2C.

No mesmo sentido, Secomandi e Johnson (2007) se apoiam nos princípios microeconômicos para ressaltear que, ao invés da maximização da utilidade do indivíduo estar relacionada a restrições orçamentárias, o modelo B2B é o de maximização do lucro em função das restrições de capacidade no curto prazo. Em outras palavras, para o consumidor B2C, as preferências individuais e sua capacidade de compra determinam a avaliação de um produto, enquanto que para o consumidor B2B, a capacidade de geração de lucro determina a avaliação de um produto (Secomandi \& Johnson, 2007).

Do ponto de vista da tomada de decisão, Hinterhuber (2008b) reforça o fato de que no ambiente B2B o consumidor não é um indivíduo, e sim uma empresa. Neste contexto, no ambiente B2C o decisor normalmente é um único indivíduo, ainda que a família ou amigos possam opinar no processo. Ao contrário, no ambiente B2B a decisão de compra é normalmente realizada por um grupo de funcionários (Plank \& Dempsey, 1980) que devem seguir processos documentados assim como devem respeitar a dinâmica organizacional (Secomandi \& Johnson, 2007).

Em grandes compradores do ambiente B2B é comum encontrar processos de compras coordenados por gerentes seniores com o envolvimento de equipes multifuncionais (Homburg, Workman Jr., \& Jensen, 2000), comumente chamadas de centro de compras (Bonoma, 2006). Estas equipes podem ser compostas por pessoas com posições opostas (Arslanagic-Kalajdzic \& Zabkar, 2015), exercendo papeis distintos no processo de compras (Bonoma, 2006), a saber: 
a) O iniciador, que identifica a necessidade de compra de um bem ou serviço;

b) O decisor, que tem a palavra final sobre o processo de compra;

c) O influenciador, que tem voz ativa sobre o processo de compra;

d) O comprador, que executa o processo de compra;

e) O controller, que compara as necessidades de compra com as ofertas;

f) O usuário do bem ou serviço.

Percebe-se no ambiente B2B uma cultura que busca a redução de preços no curto prazo, em detrimento da avaliação do impacto no negócio e do valor de uso das ofertas (Töytäri et al., 2017). O desenvolvimento de sofisticadas técnicas de compras (Aloini, Dulmin, \& Mininno, 2012), associadas ao frequentemente elevado poder de barganha dos compradores costumam resultar em redução dos preços efetivamente pagos aos fornecedores pela sua contribuição na cadeia de valor do seguimento (Hinterhuber \& Liozu, 2012; P. T. M. Ingenbleek \& van der Lans, 2013).

Em resposta a este cenário, empresas tem adotado a abordagem do valor para proteger suas margens (Keränen \& Jalkala, 2014), o que envolve a adoção de contratos baseados em resultados (Liinamaa et al., 2016) e a criação de ações para influenciar a percepção de valor dos decisores nos estágios iniciais do processo de compras (Töytäri et al., 2017).

A partir do reconhecimento de que o processo de venda envolve relacionamento interpessoal com os vários membros do centro de compras, surgiram processos normativos no sentido de indicar a construção de relacionamentos produtivos com os clientes através do tempo (Brooksbank, 1995; Decormier \& Jobber, 1993; Moncrief \& Marshall, 2005), contando inclusive com o apoio de ferramentas e sistemas (Borg \& Young, 2014).

Alguns profissionais de marketing estão partindo da perspectiva relacional para propor que a criação de valor, antes considerada intrínseca aos bens vendidos, pode ser alcançada no próprio relacionamento (Haas, Snehota, \& Corsaro, 2012). Considerando que o relacionamento vendedor-comprador é um ativo que gera valor, ele precisa ser administrado, gerenciado e utilizado, principalmente no processo de venda realizado no ambiente B2B, já que este costuma demandar vendas recorrentes e relacionamento de longo prazo (Borg \& Freytag, 2012).

Apesar dos custos associados ao processo de obter informação, avaliar, assessorar e influenciar o cliente (Töytäri et al., 2017), há indícios de que o investimento é vantajoso: os pesquisadores Homburg, Droll, e Totzek (2008) identificaram que a priorização de clientes com maior potencial de vendas está associada a maiores receitas e a maiores níveis nos indicadores de satisfação dos consumidores selecionados. Além disso, clientes não prioritários não apresentaram impacto negativo nos indicadores de satisfação. Dessa forma, há indícios que a 
maior aplicação de recursos para a venda baseada no valor destinada a clientes chave é vantajosa para as organizações (Grönroos, 2008; Moncrief \& Marshall, 2005).

Neste sentido, o gerente de conta chave (Key Account Manager) atua como guardião do relacionamento com o cliente, passando do simples papel de realizar vendas consultivas para também atuar gerenciando o relacionamento com o cliente, coordenando as entregas e a rentabilidade do relacionamento (Storbacka, Ryals, Davies, \& Nenonen, 2009). Além disso, cabe destacar o importante papel de reconstruir valor em situações que necessitam de reparo no relacionamento B2B (Liu, Leach, \& Chugh, 2015).

No que se refere às decisões de preço, o KAM coordena equipes multifuncionais, assim como a equipe de venda, sendo responsável por acessar o cliente em maiores níveis hierárquicos (Homburg et al., 2000). A literatura que investiga a precificação de relacionamento (relationship pricing) sugere que a celebração de contratos de longo prazo, com foco em indicadores de qualidade, evita a adoção de precificação baseada no custo, a redução de preços e a concessão de descontos em massa (Argouslidis \& Indounas, 2010).

No ambiente B2B, existe uma modalidade de precificação chamada de preço customizado. Trata-se de uma modalidade através da qual o vendedor tem a habilidade de estabelecer o preço de venda com base em algum conhecimento expresso pelo cliente, sendo amplamente utilizados no ambiente B2B. Nesta modalidade, o processo de compra é normalmente iniciado quando o cliente solicita uma proposta (Request for Proposal - RFP) para um ou mais competidores, com descrição detalhada das necessidades a serem atendidas. Se o fornecedor decidir responder a solicitação, ele deve decidir o preço a ser estabelecido (Phillips, 2012).

Cada solicitação do cliente pode ter características específicas, já que podem variar desde fornecimentos de itens sob medida a fornecimentos de itens não customizados (Megliorini, 2003), entretanto o preço customizado é comumente encontrado em itens que são também altamente customizáveis (Phillips, 2012).

Pesquisas demonstraram o impacto positivo da customização na satisfação dos clientes (Fornell, Johnson, Anderson, \& Bryant, 1996), o que pode ser associado a uma maior percepção do valor entregue aos clientes nas situações de customização de produtos e serviços (Homburg et al., 2008).

O problema da precificação nestes casos, é que no limite, o fornecedor tem que definir um preço a cada pedido. Por outro lado, a customização oferece a possibilidade de segmentar os produtos para várias demandas e, consequentemente, permite a prática da diferenciação de preços (Phillips, 2012). 


\section{DESENVOLVIMENTO DA PESQUISA}

Esta seção tem o objetivo de apresentar a tipologia, delimitação da população, os métodos, técnicas, fontes, instrumentos de coleta de dados, variáveis de interesse e o delineamento do tratamento dos dados. Convém informar que o presente trabalho seguiu o padrão de formatação da American Psychological Association (APA) e as diretrizes para apresentação de dissertações e teses da Universidade de São Paulo (USP) (Pestana et al., 2016).

\subsection{TIPOLOGIA DA PESQUISA}

Quanto à abordagem do problema, a presente pesquisa enquadra-se como aplicada tendo em vista que será realizada com a finalidade de coletar informações das empresas escolhidas.

Em relação à natureza do problema essa pesquisa pode ser vista sob a ótica quantitativa, haja vista se tratar de survey, envolvendo a coleta de dados por meio de questionários aplicados a gestores da área das empresas, da população definida.

No que tange os objetivos, reserva-se para a presente pesquisa a descritiva, haja vista que os fenômenos e suas relações são observados, sem a interferência do pesquisador.

\subsection{População e Amostra da Pesquisa}

No início deste trabalho, pensou-se idealmente em estudar a população formada por todas as indústrias brasileiras já que fabricantes costumam estar presentes no ambiente B2B e em estruturas de mercado propícias tanto a formadores quanto a tomadores de preço.

Entretanto, uma pesquisa em todas as indústrias brasileiras se mostrou inviável, para o presente pesquisador, em função da existência de mais de 2 milhões de indústrias com cadastro ativo no Brasil (FIESP, 2017).

Sendo assim, optou-se por delimitar esta pesquisa em uma população industrial menor do que toda a brasileira. Por conveniência, a presente pesquisa definiu como população aquela formada por empresas de capital nacional e internacional que integram bens de capital, equipamentos e componentes eletroeletrônicos para modernização tecnológica de diversos setores da sociedade associados à Associação Brasileira da Indústria Elétrica e Eletrônica (ABINEE). Vale lembrar que o conceito de população pode ser definido como um conjunto de 
indivíduos que apresentam determinadas características em comum (Martins \& Theóphilo, 2009, p. 118).

A ABINEE foi fundada em 1963 e possui mais de trezentos e oitenta empresas associadas de diversos tamanhos e segmentos, presentes em diversos estados do país, conforme indicado no mapa. O gráfico a seguir indica as onze áreas em que atuam as associadas, assim como a representatividade de cada área no setor eletroeletrônico, tomado o número de empresas registradas na associação em 2017.

Gráfico 1 - Mapa da distribuição geográfica da população pesquisada

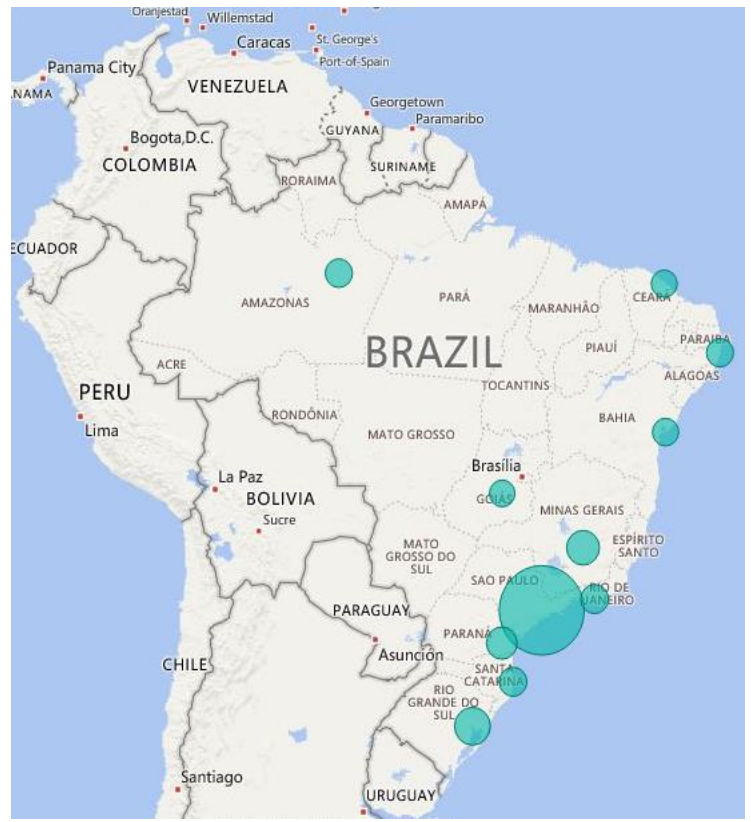

Fonte: produção do autor
Tabela 2 - Distribuição por região e estado

\begin{tabular}{ccc}
\hline Região & Estado & Qtde \\
\hline Sudeste & SP & 242 \\
& MG & 31 \\
& RJ & 10 \\
\hline Sudeste Total & & $\mathbf{2 8 3}$ \\
\hline Nordeste & PE & 7 \\
& BA & 4 \\
& CE & 3 \\
\hline Nordeste Total & & $\mathbf{1 4}$ \\
\hline Sul & RS & 43 \\
& PR & 22 \\
& SC & 10 \\
\hline Sul Total & & $\mathbf{7 5}$ \\
\hline Norte & AM & 8 \\
\hline Norte Total & & $\mathbf{8}$ \\
\hline Centro-Oeste & GO & 1 \\
\hline Centro-Oeste Total & & $\mathbf{1}$ \\
\hline Total Geral & & $\mathbf{3 8 1}$ \\
\hline
\end{tabular}

Fonte: produção do autor

Gráfico 2 - Representatividade das áreas em que se subdivide o setor eletroeletrônico (ABINEE)

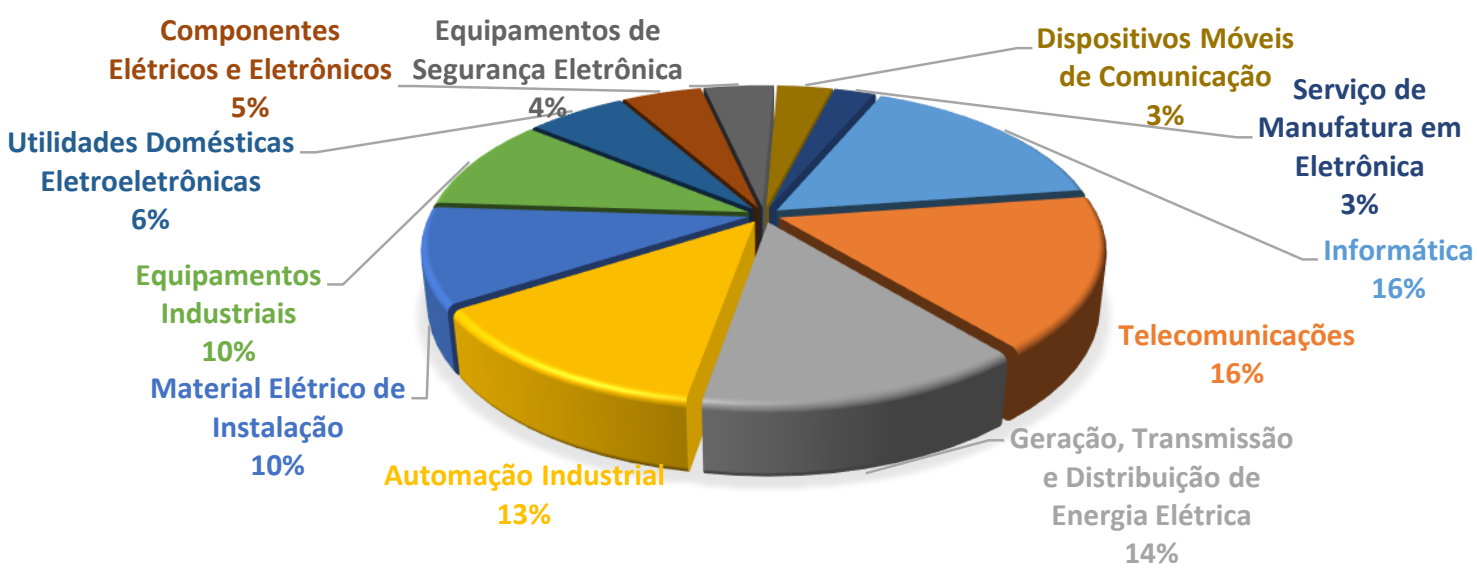

Fonte: produção do autor 
As empresas da população pesquisada faturaram no ano de 2016 mais de 129 bilhões de Reais com estimativa de encerrar o ano de 2017 com crescimento de 5\%, atingindo 136 bilhões de Reais. Cerca de $15 \%$ do faturamento do setor é destinado às exportações para diversos países do mundo, com destaque para os E.U.A. (19,3\%), Argentina (18,3\%) e países da União Europeia (12\%). As áreas de telecomunicações, equipamentos industriais e informática, representam mais de $57 \%$ do faturamento do setor.

Gráfico 3 - Faturamento do setor eletroeletrônico por área (em BiR\$)

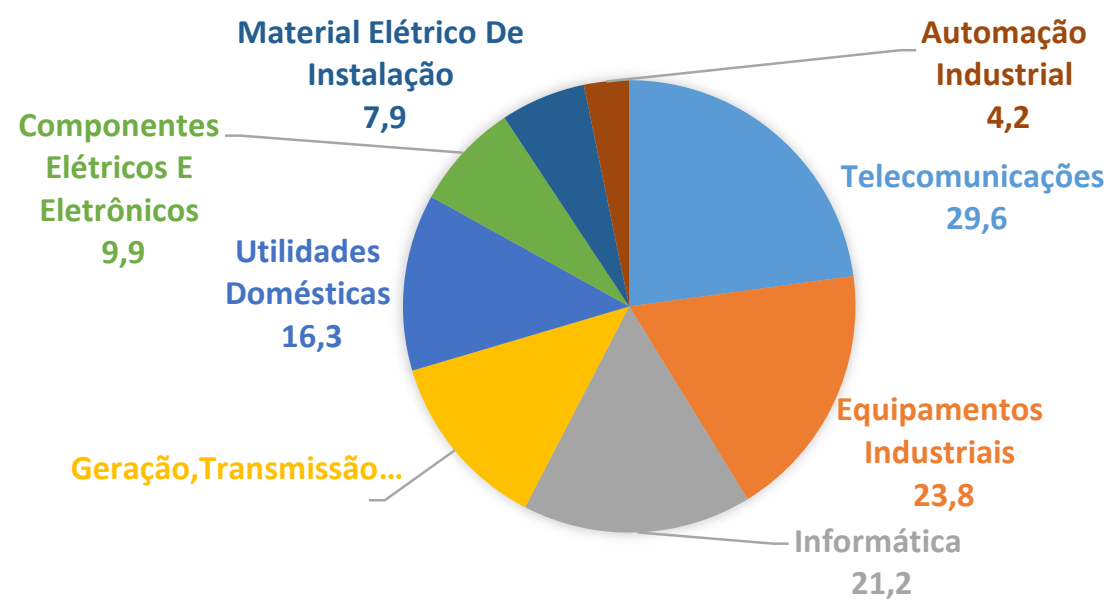

Fonte: produção do autor

Amostra pode ser definida como um subconjunto da população e foi composta, nesta pesquisa, por empresas que participaram do estudo de maneira espontânea, de tal forma que esta amostra não é aleatória e tão pouco probabilística (Martins \& Theóphilo, 2009).

Da população de 381 empresas, constatou-se que algumas delas pertenciam ao mesmo grupo e poderiam gerar resultados duplicados. Por esta razão a população foi ajustada para 372 empresas.

Não foi possível estabelecer contato com o responsável pela determinação dos preços de venda em 107 empresas. Destas, 56 não foram localizados em razão de chamadas nunca atendidas ou completadas, mesmo em diversas tentativas. Nas outras 51 empresas, o contato foi realizado, mas o responsável pela precificação não foi disponibilizado ou localizado pelo atendente. 
Gráfico 4 - Efetivação da localização do responsável por determinação de preços de venda

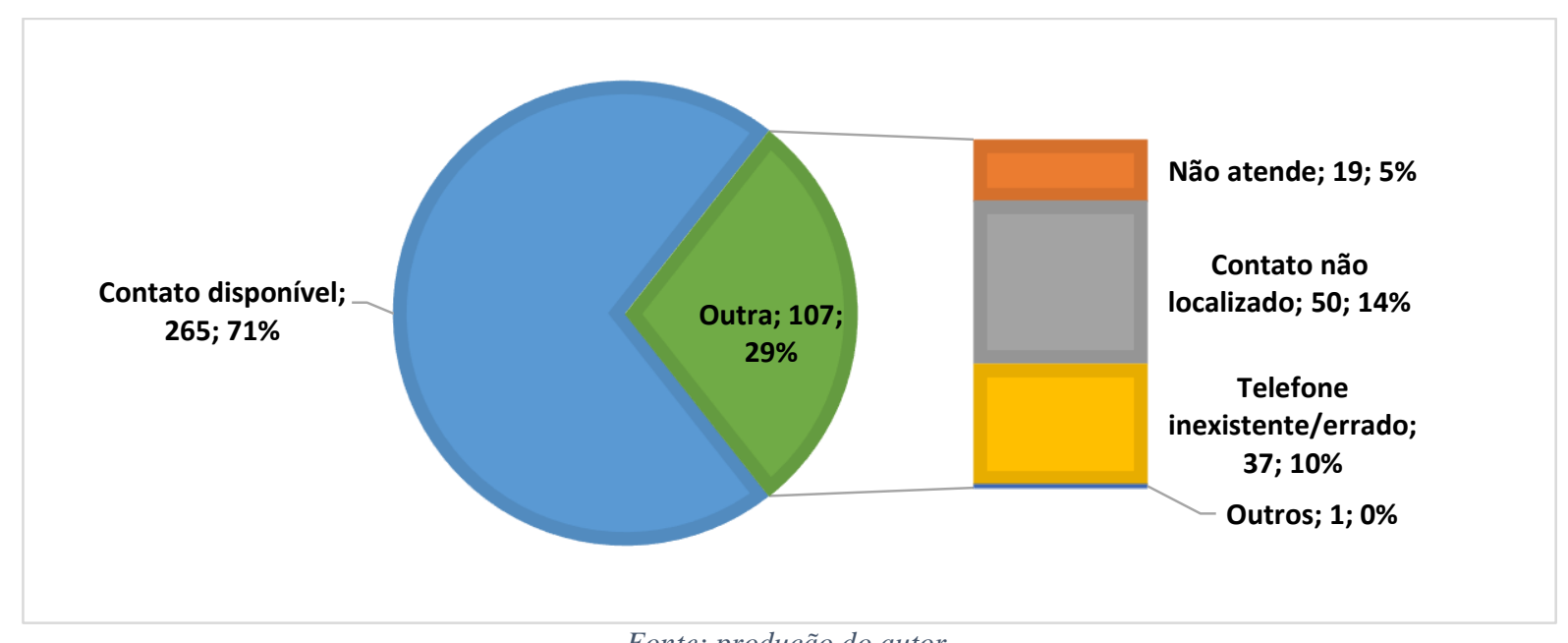

Fonte: produção do autor

Dez profissionais preferiram não participar da pesquisa em função das razões indicadas a seguir.

Tabela 3 - Justificativas alegadas pelos que não aceitaram participar da pesquisa

\begin{tabular}{|lc|}
\hline Justificativa & Qtde \\
\hline A empresa não fornece informações sobre preço & 3 \\
Preços são decididos fora do país & 3 \\
Não tem tempo ou interesse & 4 \\
\hline Total & $\mathbf{1 0}$ \\
\hline \multicolumn{1}{c}{ Fonte: produção do autor }
\end{tabular}

Por fim, a presente pesquisa contou com uma amostra de 36 empresas respondentes, o equivalente a 9,7\% da população total, mas equivalente a uma taxa de resposta 13,6\% daqueles que efetivamente foram contatados. Apesar da promessa de confidencialidade dos dados, devese levar em consideração a sensibilidade do tema sobre formação do preço de venda quando se avalia a taxa de resposta. Além disso, o percentual obtido na presente pesquisa está condizente com o obtido em pesquisas anteriores: em torno de treze por cento (Burkert et al., 2017; Forman \& Lancioni, 2002; P. T. M. Ingenbleek \& van der Lans, 2013). 


\subsection{Coleta de dados}

As diferentes maneiras de abordar e analisar dados empíricos no contexto das ciências sociais aplicadas podem ser chamadas de estratégias de pesquisa (Martins \& Theóphilo, 2009, p. 53). Na presente dissertação, foram utilizadas as seguintes estratégias:

a) Pesquisa bibliográfica e;

b) Levantamento.

A pesquisa bibliográfica é considerada indispensável para qualquer pesquisa científica já que “...busca conhecer, analisar e explicar contribuições sobre um determinado assunto... com base em referências publicadas em livros, periódicos, revistas... etc." (Martins \& Theóphilo, 2009, p. 54).

O levantamento é apropriado para situações em que o pesquisador deseja estudar relações entre características de grupos em situações naturais, demandando coleta de dados da população ou amostra da população. Embora ressalta-se que os levantamentos possam identificar correlação entre variáveis que não são indicativas de causa e efeito, eles emprestam "crédito a uma hipótese causal envolvendo variáveis. Cada um desses casos envolvendo correlação funciona como um teste de hipóteses que poderia refutar a hipótese causal" (Martins \& Theóphilo, 2009, p. 61).

\subsubsection{Questionário}

Considerado um popular instrumento para pesquisa social, o questionário é “... um conjunto ordenado e consistente de perguntas a respeito de variáveis e situações que se deseja medir ou descrever" (Martins \& Theóphilo, 2009, p. 93) e foi utilizado como ferramenta para o levantamento desta pesquisa.

O questionário foi enviado por e-mail, com duas opções de preenchimento: em MS Word ou através de link para o Google Forms. Esta plataforma de pesquisa foi utilizada por oferecer um questionário eletrônico, baseado na web, amigável, econômico e rápido. A opção em Word foi fornecida para aqueles que eventualmente se sentissem inseguros em utilizar a versão do Google Form acessada através de link.

A mensagem incluída no corpo do e-mail continha a ratificação do propósito da pesquisa, a finalidade, os benefícios ao respondente e a garantia, aos participantes, do anonimato e confidencialidade dos dados individuais (M. Smith, 2015, p. 252). A reprodução da mensagem pode ser visualizada no apêndice. 
O instrumento desta pesquisa é composto de perguntas fechadas em escala Likert, elaboradas para que sejam claras, compreensíveis e para que não induzam respostas (Martins \& Theóphilo, 2009, p. 94). Optou-se pela escolha de um número ímpar que fornece um ponto médio ou neutro, o que eleva a taxa de resposta, ainda que não haja consenso sobre a quantidade adequada de pontos para este tipo de escala (M. Smith, 2015, p. 131).

Com a intenção de manter o interesse e a motivação dos respondentes, objetivou-se construir um instrumento que pode ser preenchido em menos de vinte minutos.

O questionário está conceitualmente dividido em cinco seções, a saber:

a) Seção A: composta por questões destinadas a coletar informações da estrutura organizacional;

b) Seção B: composta por questões destinadas a identificar o comportamento de preços;

c) Seção C: composta por questões destinadas a identificar a abordagem de formação de preços.

d) Seção D: composta por questões destinadas a identificar características dos respondentes;

\subsubsection{Seleção do respondente}

Pesquisas anteriores indicam que os responsáveis pela determinação do preço de venda nem sempre são especialistas na função (Carricano et al., 2010): além de Gerentes de Preço, outros profissionais aparecem como responsáveis pela decisão de preços, como Vicepresidentes, Diretores e Gerentes. Além disso, estes profissionais costumam pertencer a diversos departamentos, como Marketing e Vendas (Abratt \& Pitt, 1985).

Em função disso, objetivou-se contatar o profissional com condições de oferecer informações confiáveis, independentemente da área e do cargo do profissional, seguindo a estratégia utilizada por Ingenbleek et al. (2003) e por Amaral (2017).

Com o objetivo de identificar o profissional responsável por preços em melhor condição de responder o questionário, esta pesquisa adotou a estratégia de contatar preferencialmente os maiores níveis hierárquicos possíveis. A lista de contatos era composta majoritariamente por sócios, diretores e presidentes das empresas (52\%) e por gerentes de diversas áreas (24\%), conforme pode ser observado no gráfico a seguir. 
Gráfico 5 - Cargo ocupado pelos inicialmente contatados

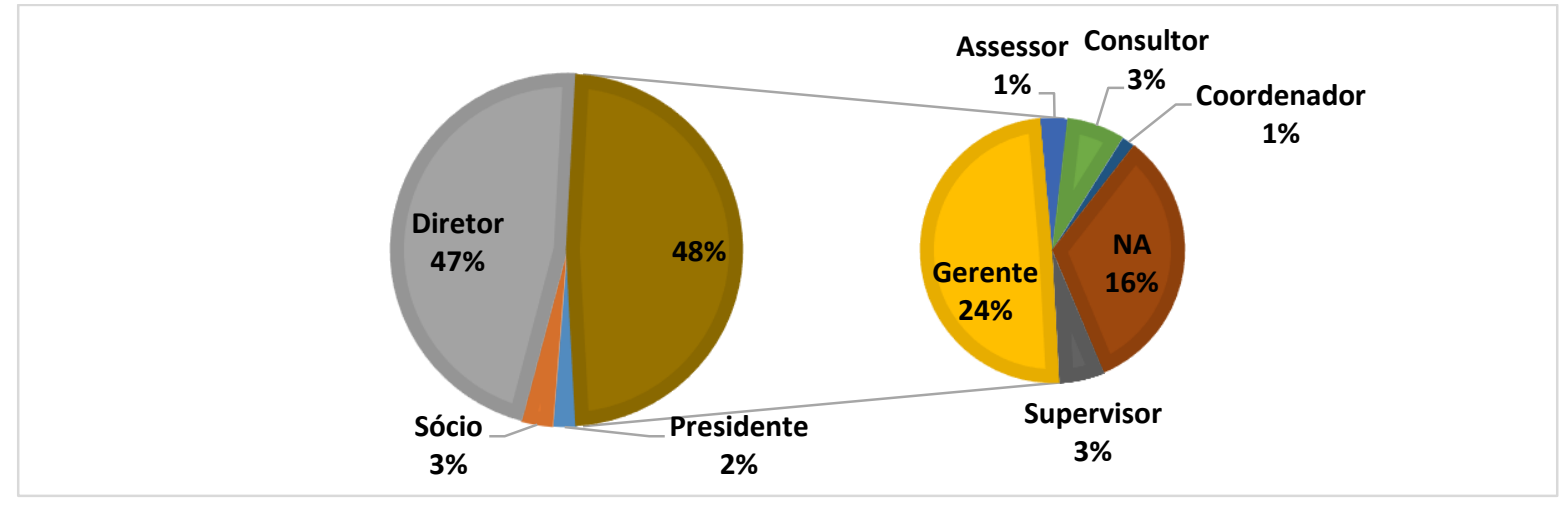

Fonte: produção do autor

\subsubsection{Validade dos dados}

Um dos dois critérios considerados fundamentais para avaliar se um instrumento de pesquisa atinge o objetivo de medir o que se propõe é o de validade (Martins \& Theóphilo, 2009).

Para estes autores existem algumas técnicas que identificam a validade do instrumento de pesquisa, e que usamos como guia nesta pesquisa. A primeira é a da validade aparente, e se refere à relevância e à adequação do instrumento aos olhos dos respondes da pesquisa. Apesar de parecer simples, avaliar o questionário com os olhos dos respondentes pode evitar o comprometimento dos dados no caso do instrumento ser considerado inadequado pelos respondentes. $\mathrm{O}$ instrumento desta pesquisa foi avaliado por um pesquisador e por um profissional responsável por precificação de uma empresa atuante no ambiente B2B.

Durante a avaliação do pré-teste, foi sugerida a simplificação do formato do questionário, a eliminação de seções indicativas dos constructos a que se referiam as questões e a eliminação das questões 5 e 21 por parecerem redundantes para os avaliadores. A simplificação do formato visou à elevação da taxa de resposta. A eliminação de seções e divisões indicativas dos constructos buscou eliminar a possível influência nas respostas dos pesquisados.

A segunda técnica é a da validade de conteúdo e pode ser descrita como “... o grau em que a medição representa o conceito que se pretende medir" (Martins \& Theóphilo, 2009, p. 16). Para esses autores, uma revisão sistemática do conteúdo deve ser realizada antes da construção do questionário para que este tenha garantia de cobrir adequadamente a área a ser testada, sugestão seguida nesta pesquisa. Além disso, os constructos desta pesquisa já foram 
utilizados por outros pesquisadores, como Amaral (2017), Burkert et al. (2017) e Monroe (2003), o que indica a validade de conteúdo de acordo com G. de A. Martins e Theóphilo (2009).

A terceira técnica é a da validade do constructo que "... se refere ao grau em que um instrumento de medidas se relaciona consistentemente com outras medições assemelhadas...” (G. de A. Martins \& Theóphilo, 2009, p. 18). A validade do constructo é construída por vários estudos investigativos sustentados por teorias que o suportem em relação a outras G. de A. Martins e Theóphilo (2009). A presente pesquisa baseou-se no arcabouço teórico pertinente ao tema, partindo de constructos, indicadores e variáveis assemelhadas a outras utilizadas em estudos anteriores.

Além das técnicas citadas, optou-se por avaliar um eventual viés de não resposta através da comparação das médias das respostas dos respondentes tardios com as dos respondentes não tardios (Armstrong \& Overton, 1977). Este método parte do princípio de que os respondentes tardios se assemelham aos não respondentes. Considerou-se tardios aqueles respondentes que precisaram de mais de um dia para responder o questionário. Aqueles que responderam à pesquisa em até um dia foram classificados como imediatos. A figura a seguir indica a divisão dos dois grupos.

Gráfico 6 - Classificação dos respondentes

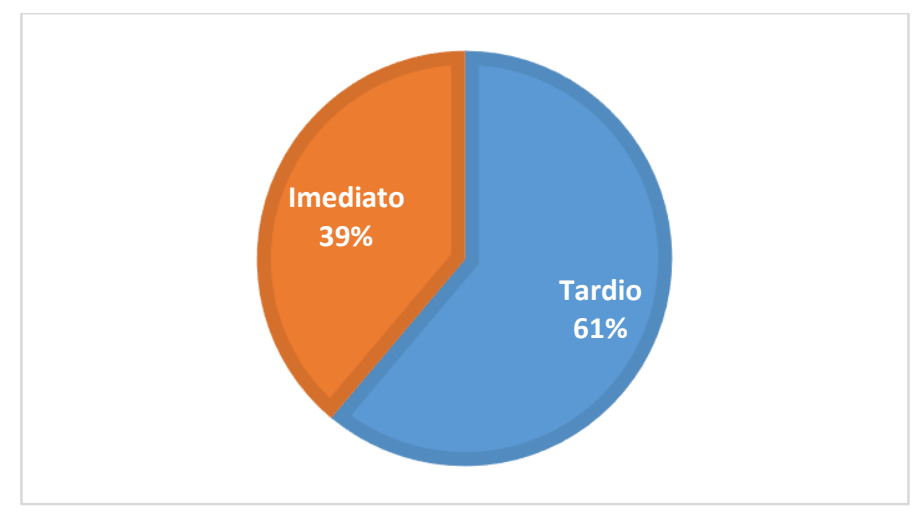

Fonte: produção do autor

As trinta e seis respostas relacionadas à escala Likert foram comparadas entre os dois grupos com uso do programa R Studio. O teste de Mann-Whitney é um teste não paramétrico que não exige nenhuma hipótese sobre distribuições populacionais e suas variâncias, podendo ser aplicado para variáveis ordinais (Martins \& Theóphilo, 2009), sendo uma excelente alternativa ao paramétrico teste $\mathrm{t}$ (Teetor, 2011).

O teste verifica se a frequência relativa dos dois grupos são significativamente diferentes (Teetor, 2011). A hipótese a ser testada é $\mathrm{H}_{0}$ : não há diferença entre os grupos, contra a hipótese alternativa $\mathrm{H}_{1}$ : há diferença entre os grupos. Os resultados apurados nos testes estão listados na 
tabela a seguir e indicam a não rejeição da hipótese nula, ou seja, de que não há diferença entre os grupos tardio e imediato.

O fato de que não foram encontradas diferenças significativas entre os respondentes tardios e os não tardios indica que não há um viés importante de não resposta.

Tabela 4 - Resultados dos Testes de Mann-Whitney para as questões em escala Likert

\begin{tabular}{|l|c|c|c|c|c|c|c|c|c|}
\hline Questões & $\mathbf{1}$ & $\mathbf{2}$ & $\mathbf{3}$ & $\mathbf{4}$ & $\mathbf{6}$ & $\mathbf{7}$ & $\mathbf{8}$ & $\mathbf{9}$ & $\mathbf{1 0}$ \\
\hline P-valores & 0,4506 & 0,6654 & 0,3976 & 0,5947 & 0,5192 & 0,5258 & 0,3961 & 0,8315 & 0,4564 \\
\hline
\end{tabular}

\begin{tabular}{|l|c|c|c|c|c|c|c|c|c|}
\hline Questões & 11 & 12 & 13 & 14 & 15 & 16 & 17 & 18 & 19 \\
\hline P-valores & 0,2749 & 0,1706 & 0,1049 & 1,0000 & 0,3824 & 0,4592 & 0,4578 & 0,4606 & 0,8288 \\
\hline
\end{tabular}

\begin{tabular}{|l|c|c|c|c|c|c|c|c|c|}
\hline Questões & $\mathbf{2 0}$ & $\mathbf{2 2}$ & $\mathbf{2 3}$ & $\mathbf{2 4}$ & $\mathbf{2 5}$ & $\mathbf{2 6}$ & $\mathbf{2 7}$ & $\mathbf{2 8}$ & $\mathbf{2 9}$ \\
\hline P-valores & 0,8325 & 1,0000 & 0,5947 & 0,5245 & 0,3443 & 0,5232 & 0,2858 & 0,5165 & 0,3383 \\
\hline
\end{tabular}

\begin{tabular}{|l|c|c|c|c|c|c|c|}
\hline Questões & $\mathbf{3 0}$ & $\mathbf{3 1}$ & $\mathbf{3 2}$ & $\mathbf{3 3}$ & $\mathbf{3 4}$ & $\mathbf{3 5}$ & $\mathbf{3 6}$ \\
\hline P-valores & 0,2873 & 0,5284 & 0,6723 & 0,4578 & 0,4564 & 0,1049 & 0,3947 \\
\hline
\end{tabular}

Fonte: produção do autor a partir dos cálculos obtidos através do programa R Studio

\subsubsection{Confiabilidade dos dados}

A confiabilidade de um questionário se refere ao grau de confiança que o mesmo inspira na medição realizada. De acordo com G. de A. Martins \& Theóphilo (2009) a confiança é atingida pelo nível de estabilidade da medição e pode ser determinada por diversas técnicas, como a do coeficiente Alfa de Cronbach.

O Alfa de Cronbach é a média dos coeficientes de correlação linear de Pearson entre o valor de cada item e o valor total dos demais itens. Requer apenas única aplicação do instrumento de medição, resultando em valores situados no intervalo entre $0 \%$ e $100 \%$, sendo que o atingimento superior a 0,70 é considerado suficiente para garantir a confiabilidade das medidas (Martins \& Theóphilo, 2009). Com o auxílio do programa R Studio, foi calculado o Alfa de Cronbach no valor de 0,86 para as trinta e quatro questões com escala Likert, o que indica a confiabilidade do instrumento.

\subsection{CONSTRUCTOS E INDICADORES}

Conceitos são ideias não observáveis ou mensuráveis diretamente. O constructo é uma medição indireta do conceito e é geralmente apresentado na forma de questões múltiplas (M. 
Smith, 2015) e visa representar empiricamente um conceito dentro de um quadro teórico: "Para explorar empiricamente um conceito teórico, o pesquisador precisa traduzir a assertiva genérica do conceito em uma relação com o mundo real, baseada em variáveis e fenômenos observáveis e mensuráveis" (Martins \& Theóphilo, 2009, p. 35). Dessa forma, nas ciências sociais, como a contabilidade, o pesquisador deve elaborar constructos que sejam operacionalizáveis e viabilizem o teste empírico (M. Smith, 2015).

Na sequência, apresentam-se os constructos e indicadores presentes na pesquisa.

Tabela 5 - Constructos e seus respectivos indicadores de mensuração

\begin{tabular}{|c|c|c|c|}
\hline Classificação & Constructo & Indicador & Referência (adaptada) \\
\hline $\begin{array}{l}\text { Comportamento de } \\
\text { preço }\end{array}$ & Comportamento de preço & $\begin{array}{l}\text { Assertivas } \\
26 \text { e } 27\end{array}$ & (Amaral, 2017) \\
\hline $\begin{array}{l}\text { Abordagem de } \\
\text { preços }\end{array}$ & Abordagem de preço & $\begin{array}{l}\text { Assertivas } \\
29,31,32 \\
33,34,35 \text { e } \\
36\end{array}$ & (Amaral, 2017; Hinterhuber, 2008a) \\
\hline \multirow[t]{5}{*}{$\begin{array}{l}\text { Características } \\
\text { organizacionais }\end{array}$} & Formalização & $\begin{array}{l}\text { Assertivas } 1 \\
2,3 \text { e } 4\end{array}$ & $\begin{array}{l}\text { (Argouslidis \& Indounas, 2010; Burkert } \\
\text { et al., 2017; Workman, Homburg, \& } \\
\text { Jensen, 2003) }\end{array}$ \\
\hline & Cooperação & $\begin{array}{l}\text { Assertivas } 6 \\
7,8,9 \text { e } 10\end{array}$ & $\begin{array}{l}\text { (Burkert et al., 2017; Homburg \& } \\
\text { Jensen, 2007) }\end{array}$ \\
\hline & Especialização & $\begin{array}{l}\text { Assertivas } \\
11,12 \mathrm{e} 13 \\
\end{array}$ & $\begin{array}{l}\text { (Burkert et al., 2017; Olson, Slater, \& } \\
\text { Hult, 2005; Vorhies \& Morgan, 2003) }\end{array}$ \\
\hline & $\begin{array}{l}\text { Delegação vertical da } \\
\text { autoridade de preços }\end{array}$ & $\begin{array}{l}\text { Assertivas } \\
14,15,16 \mathrm{e} \\
17\end{array}$ & $\begin{array}{l}\text { (Burkert et al., 2017; Cadogan, } \\
\text { Sundqvist, Salminen, \& Puumalainen, } \\
\text { 2005; Frenzen et al., 2010; Menon, } \\
\text { Jaworski, \& Kohli, 1997) }\end{array}$ \\
\hline & $\begin{array}{l}\text { Envolvimento da alta } \\
\text { gerência }\end{array}$ & $\begin{array}{l}\text { Assertivas } \\
18,19 \text { e } 20\end{array}$ & $\begin{array}{l}\text { (Burkert et al., 2017; Cadogan et al., } \\
\text { 2005; Verhoef \& Leeflang, 2009) }\end{array}$ \\
\hline \multirow[t]{5}{*}{$\begin{array}{l}\text { Variáveis de } \\
\text { controle }\end{array}$} & Intensidade de competição & $\begin{array}{l}\text { Assertivas } \\
22,23 \text { e } 25 .\end{array}$ & $\begin{array}{l}\text { (Burkert et al., 2017; Jaworski \& Kohli, } \\
\text { 1993; Workman et al., 2003) }\end{array}$ \\
\hline & $\begin{array}{l}\text { Intensidade de } \\
\text { diferenciação }\end{array}$ & $\begin{array}{l}\text { Assertivas } \\
24,26 \text { e } 27\end{array}$ & (Amaral, 2017) \\
\hline & Percepção de teto de preço & Assertiva 30 & (Monroe, 2003) \\
\hline & $\begin{array}{l}\text { Facilidade de acesso aos } \\
\text { dados da concorrência }\end{array}$ & Assertiva 28 & (Amaral, 2017) \\
\hline & $\begin{array}{l}\text { Forma do estabelecimento } \\
\text { do preço de venda }\end{array}$ & Assertiva 37 & (Amaral, 2017) \\
\hline
\end{tabular}

Fonte: produção do autor

\subsubsection{Comportamento de preços}

A revisão da literatura indica que a interação entre demanda, oferta e concorrência determinam o comportamento de preços das empresas: formador ou tomador de preços. Além disso, Amaral (2017) indicou a importância de classificar as empresas em relação ao 
comportamento de preços em função das características inerentes a cada comportamento de preço.

Com o objetivo de identificar o comportamento de preços das empresas da população pesquisada, dois indicadores foram escolhidos, a saber: nível de diferenciação percebida pelos clientes em relação aos produtos ofertados e pela ausência de necessidade de estabelecer os preços pela concorrência. A diferenciação de produtos dá alguma liberdade para fixação de preços, fazendo com que as empresas se comportem como Formadoras de Preço (Varian, 2012). Entretanto, é preciso considerar se, apesar da diferenciação, a empresa necessita estabelecer o preço de venda de acordo com a competição. Neste caso, a diferenciação não seria grande o suficiente para que empresa se comporte como formadora de preço.

Tabela 6 - Variáveis relacionadas ao comportamento de preço

\begin{tabular}{|l|l|c|l|}
\hline \multicolumn{1}{|c|}{ Indicador } & \multicolumn{1}{|c|}{ Item } & $\begin{array}{c}\mathbf{N}^{\mathbf{0}} \\
\text { Identificação }\end{array}$ & $\begin{array}{l}\text { Referência } \\
\text { (adaptada) }\end{array}$ \\
\hline Diferenciação & $\begin{array}{l}\text { Os clientes consideram que nossos produtos } \\
\text { são diferentes dos produtos oferecidos pelos } \\
\text { nossos concorrentes. }\end{array}$ & 26 & $\begin{array}{l}\text { (Amaral, } \\
2017)\end{array}$ \\
\hline $\begin{array}{l}\text { Ausência de } \\
\text { necessidade de } \\
\text { precificar pela } \\
\text { concorrência }\end{array}$ & $\begin{array}{l}\text { Como nossos produtos são diferenciados, } \\
\text { não precisamos colocar preços exatamente } \\
\text { iguais aos preços dos nossos concorrentes. }\end{array}$ & 27 & (Amaral, \\
\hline
\end{tabular}

Fonte: produção do autor

O comportamento de preços foi obtido a partir dos pontos indicados na escala Likert, presente nas assertivas de número 26 e de número 27, seguindo o racional utilizado por Amaral (2017) e ilustrado na figura a seguir.

Figura 3 - Modelo utilizado para classificação do comportamento de preços

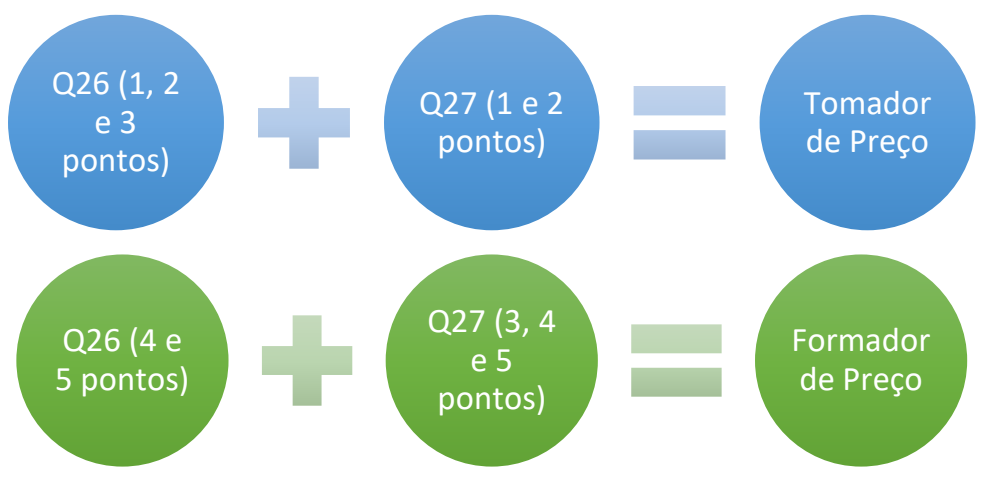




\subsubsection{Abordagem de preços}

As abordagens de precificação por serem definidas como os passos ou procedimentos explícitos através dos quais empresas chegam ao preço (Avlonitis \& Indounas, 2005) e costumam ser classificas em três grupos, a saber: preço baseado no custo, preço baseado na concorrência e preço baseado no valor.

O preço baseado no custo tem como fundamento o cálculo dos custos internos sobre os quais se adiciona um margem para a definição do preço (Töytäri et al., 2017). Com o objetivo de identificar as empresas que adotam esta abordagem, as questões do indicador essência custo visam identificar a ausência de avaliação de características do cliente, do produto e da concorrência para a determinação do preço de venda. No cenário de margens uniformes, tanto para diferentes produtos quanto para diferentes clientes, a revisão da literatura indica que a abordagem de custo estaria sendo utilizada pela empresa.

O preço baseado na concorrência tem como fundamento o uso de informações de preços dos concorrentes (Hinterhuber, 2008a). A assertiva 29 visa acessar diretamente o uso desta abordagem pelo respondente.

O preço baseado no valor pode ser definido como a extensão pela qual as empresas usam informação da percepção do cliente sobre as vantagens oferecidas e como os consumidores irão realizar o trade-off dessas vantagens com o preço a ser determinado (P. Ingenbleek, 2007). A utilização desta abordagem requer o conhecimento das características da oferta, da concorrência e do consumidor, de tal forma que a definição da margem deve apresentar variações em função dos produtos, dos clientes e da percepção de valor pelo consumidor. Desta maneira, os indicadores presentes no indicador essência valor têm a intenção de capturar justamente estes fatores.

A tabela demonstra as questões relacionadas aos indicadores, assim como a fonte de referência de cada uma delas. As respostas deveriam ser enquadradas na escala Likert de 5 pontos rotulada nos extremos como um (1) equivalendo a "discordo totalmente" e cinco (5) equivalendo a "concordo totalmente". 
Tabela 7 - Variáveis relacionadas à abordagem

\begin{tabular}{|c|c|c|c|}
\hline Indicadores & Itens & $\mathbf{N}^{\mathbf{o}}$ & $\begin{array}{l}\text { Referência } \\
\text { adaptada }\end{array}$ \\
\hline $\begin{array}{l}\text { Abordagem da } \\
\text { Concorrência }\end{array}$ & $\begin{array}{l}\text { Nós determinamos o nosso preço de acordo com } \\
\text { o preço dos concorrentes. }\end{array}$ & 29 & $\begin{array}{l}\text { (Hinterhuber, } \\
\text { 2008a) }\end{array}$ \\
\hline \multirow[t]{3}{*}{ Essência Custo } & $\begin{array}{l}\text { A margem colocada sobre os custos é definida } \\
\text { isoladamente pelo departamento financeiro. }\end{array}$ & 31 & \multirow{3}{*}{ (Amaral, 2017) } \\
\hline & $\begin{array}{l}\text { Todos os nossos produtos têm margens } \\
\text { parecidas. }\end{array}$ & 32 & \\
\hline & $\begin{array}{l}\text { Todos os nossos segmentos de clientes têm } \\
\text { margens parecidas. }\end{array}$ & 33 & \\
\hline \multirow[t]{3}{*}{ Essência Valor } & $\begin{array}{l}\text { A definição da margem independe da } \\
\text { consideração de características específicas dos } \\
\text { produtos (por exemplo, a margem de produtos } \\
\text { simples é similar à margem de produtos } \\
\text { sofisticados) }\end{array}$ & 34 & (Amaral, 2017) \\
\hline & $\begin{array}{l}\text { A definição da margem independe da } \\
\text { consideração de características específicas dos } \\
\text { clientes, como porte e localidade }\end{array}$ & 35 & (Amaral, 2017) \\
\hline & $\begin{array}{l}\text { A definição da margem independe da } \\
\text { consideração da importância que os clientes } \\
\text { veem nos produtos }\end{array}$ & 36 & (Amaral, 2017) \\
\hline
\end{tabular}

Fonte: produção do autor

\subsubsection{Características organizacionais}

A precificação está ligada às escolhas do desenho organizacional das empresas, sendo importante aspecto das práticas de precificação (Dutta et al., 2003). As perguntas deste constructo serão baseadas nas variáveis do instrumento de pesquisa de Burkert, Ivens, Henneberg e Schradi (2017), que considera os seguintes indicadores: (i) formalização; (ii) cooperação; (iii) especialização; (iv) centralização; (v) envolvimento da alta gerência. Nesta pesquisa, decidimos excluir os indicadores de adaptabilidade e eficiência, já que não se referem diretamente à dimensão organizacional.

A Formalização é a extensão pela qual regras formais e procedimentos padrões permeiam o processo de determinação do preço de venda (Burkert et al., 2017). É considerada parte importante do processo de precificação e envolve a definição clara das responsabilidades e dos papeis de cada agente do processo (Carricano et al., 2010). 
Há indícios de que a formalização atua como facilitador de relacionamentos colaborativos e congruentes no contexto organizacional (Vlaar et al., 2006). Uma organização que possui um processo de precificação pouco formal, pode desprender energia com conflitos entre agentes que pretendem influir no preço, o que pode resultar em decisões de preço inconsistentes (Burkert et al., 2017).

O processo de precificação costuma envolver diversos atores de diferentes departamentos (Homburg et al., 2012; Homburg, Workman Jr., \& Krohmer, 1999). A qualidade da Cooperação desses atores, procura identificar em que medida os atores envolvidos no processo de precificação colaboram mutuamente a fim de atingir a decisão de preços (Burkert et al., 2017), já que o sistema político interno das organizações costuma ser afetado por ela (Lancioni, Schaur, \& Smith, 2005).

O Envolvimento da alta gerência tem sido relacionado ao desenvolvimento da cultura de preços na organização, sendo apontado como um direcionador importante para a geração de valor (Burkert et al., 2017; Liozu et al., 2012).

Já a Especialização, se refere ao grau de existência de profissionais dedicados exclusivamente à precificação (Burkert et al., 2017).

Apesar da literatura ter se debruçado sobre as vantagens e desvantagens da chamada Delegação vertical da autoridade de preço, os resultados são esparsos e conflitantes (Homburg et al., 2012), e a sua relação com a abordagem do valor ainda é escassa. Por essa razão, pesquisas empíricas que buscam entender os fatores favoráveis a maior ou menor delegação da autoridade de preços são necessárias (Frenzen et al., 2010).

A tabela demonstra as questões relacionadas aos indicadores, assim como a fonte de referência de cada uma delas. As respostas deveriam ser enquadradas na escala Likert de 5 pontos rotulada nos extremos como um (1) equivalendo a "discordo totalmente" e cinco (5) equivalendo a "concordo totalmente". O total de pontos indica o nível de cada respondente em cada indicador. 
Tabela 8 - Variáveis relacionadas à estrutura organizacional de preços

\begin{tabular}{|c|c|c|c|}
\hline Indicadores & Itens & $\mathbf{N}^{\mathbf{o}}$ & Referências \\
\hline \multirow{4}{*}{ Formalização } & $\begin{array}{l}\text { A responsabilidade pelas decisões de preços foi } \\
\text { claramente atribuída aos indivíduos } \\
\text { organizacionais em nossa empresa. }\end{array}$ & 1 & \multirow{4}{*}{$\begin{array}{l}\text { (Argouslidis \& } \\
\text { Indounas, 2010; } \\
\text { Burkert et al., } \\
\text { 2017; Workman et } \\
\text { al., 2003) }\end{array}$} \\
\hline & $\begin{array}{l}\text { Dentro da nossa organização, os canais formais } \\
\text { de comunicação interna são seguidos quando se } \\
\text { trabalha em preços. }\end{array}$ & 2 & \\
\hline & $\begin{array}{l}\text { Em nossa empresa, o raciocínio para as decisões } \\
\text { de preços está bem documentado e arquivado } \\
\text { para referência futura }\end{array}$ & 3 & \\
\hline & $\begin{array}{l}\text { Para coordenar as partes de nossa organização } \\
\text { que trabalham em preços, procedimentos } \\
\text { operacionais padrão foram estabelecidos. }\end{array}$ & 4 & \\
\hline \multirow{6}{*}{ Cooperação } & $\begin{array}{l}\text { Na gestão de preços, os departamentos } \\
\text { envolvidos... }\end{array}$ & & \multirow{6}{*}{$\begin{array}{l}\text { (Burkert et al., } \\
\text { 2017; Homburg \& } \\
\text { Jensen, 2007) }\end{array}$} \\
\hline & ... colaboram sem atrito. & 6 & \\
\hline & ... agem em conjunto. & 7 & \\
\hline & ... têm poucos problemas na sua cooperação. & 8 & \\
\hline & ... atingem os seus objetivos comuns. & 9 & \\
\hline & ... confiam um no outro. & 10 & \\
\hline \multirow{3}{*}{ Especialização } & $\begin{array}{l}\mathrm{Na} \text { nossa organização há "especialistas em } \\
\text { preços" que direcionam seus esforços para a } \\
\text { gestão de precos. }\end{array}$ & 11 & \multirow{3}{*}{$\begin{array}{l}\text { (Burkert et al., } \\
\text { 2017; Olson et al., } \\
\text { 2005; Vorhies \& } \\
\text { Morgan, 2003) }\end{array}$} \\
\hline & $\begin{array}{l}\text { Há treinamentos padronizados para cargos que } \\
\text { envolvem atividades de preços. }\end{array}$ & 12 & \\
\hline & $\begin{array}{l}\text { Há descrição escrita das atividades, funções e } \\
\text { objetivos esperados dos especialistas de preços. }\end{array}$ & 13 & \\
\hline \multirow{3}{*}{$\begin{array}{l}\text { Envolvimento da alta } \\
\text { gerência }\end{array}$} & $\begin{array}{l}\text { Nossa alta gerência considera os esforços para } \\
\text { melhorar a gestão de preços como um valioso } \\
\text { investimento de recursos. }\end{array}$ & 18 & \multirow{3}{*}{$\begin{array}{l}\text { (Burkert et al., } \\
\text { 2017; Cadogan et } \\
\text { al., 2005; Verhoef } \\
\text { \& Leeflang, 2009) }\end{array}$} \\
\hline & $\begin{array}{l}\text { Nossa alta gerência considera nossas atividades } \\
\text { de preços como um fator crítico de sucesso. }\end{array}$ & 19 & \\
\hline & $\begin{array}{l}\text { Nossa alta administração pretende aumentar a } \\
\text { conscientização de preços da empresa. }\end{array}$ & 20 & \\
\hline \multirow[t]{4}{*}{$\begin{array}{l}\text { Delegação vertical da } \\
\text { autoridade de preços }\end{array}$} & $\begin{array}{l}\text { As decisões importantes de preços devem ser } \\
\text { submetidas a nível hierárquico acima para a } \\
\text { resposta final. }\end{array}$ & 14 & \multirow{4}{*}{$\begin{array}{l}\text { (Burkert et al., } \\
\text { 2017; Cadogan et } \\
\text { al., 2005; Frenzen } \\
\text { et al., 2010; Menon } \\
\text { et al., 1997) }\end{array}$} \\
\hline & $\begin{array}{l}\text { Pessoas envolvidas em importantes decisões de } \\
\text { preços têm de perguntar ao seu superior antes } \\
\text { de fazerem quase tudo. }\end{array}$ & 15 & \\
\hline & $\begin{array}{l}\text { Os funcionários que tomam decisões } \\
\text { importantes de preços precisam ter a aprovação } \\
\text { do chefe em primeiro lugar. }\end{array}$ & 16 & \\
\hline & $\begin{array}{l}\text { Os gerentes geralmente tomam decisões } \\
\text { importantes de preços apenas depois de } \\
\text { verificá-los com alguém da equipe gerencial. }\end{array}$ & 17 & \\
\hline
\end{tabular}




\subsubsection{Variáveis de controle}

Com o objetivo de aumentar a validade do instrumento, algumas variáveis de controle foram levantadas a partir da revisão de literatura.

\subsubsection{Ambiente de atuação}

Os termos B2B e B2C são acrônimos já bastante difundidos, e referem-se respectivamente ao comércio industrial e ao comércio destinado ao consumidor final, seja ele baseado ou não na internet (Secomandi \& Johnson, 2007). O processo de criação de valor e de relacionamento no ambiente $\mathrm{B} 2 \mathrm{~B}$ tem complexidades que requerem ao mesmo tempo profunda e ampla atenção (Albadvi \& Hosseini, 2011). Obtida através da pesquisa minuciosa da área de atuação e do mercado a que se destinam os produtos ofertados.

\subsubsection{Intensidade de competição}

Apesar da literatura ter se debruçado sobre o impacto da intensidade de competição na abordagem de preços, os resultados são conflitantes (Amaral, 2017), e sua relação com a abordagem do valor ainda é escassa. Por essa razão, pesquisas empíricas que buscam entender a influência da intensidade de competição na determinação do preço de venda são necessárias (Amaral, 2017).

Obtida através do nível de intensidade percebida pela empresa. Para o indicador foram aplicadas questões fechadas às quais foram atribuídos pontos de um a cinco. $\mathrm{O}$ total de pontos indica o nível de cada respondente em cada item.

Tabela 9 - Intensidade de competição

\begin{tabular}{|c|c|c|c|}
\hline Indicadores & Itens & $\mathbf{N}^{\mathbf{o}}$ & Referências \\
\hline \multirow{3}{*}{$\begin{array}{l}\text { Intensidade de } \\
\text { competição no } \\
\text { mercado }\end{array}$} & A concorrência na nossa indústria é intensa. & 22 & \multirow{3}{*}{$\begin{array}{l}\text { (Burkert et al., 2017; } \\
\text { Jaworski \& Kohli, } \\
\text { 1993; Workman et } \\
\text { al., 2003) }\end{array}$} \\
\hline & $\begin{array}{l}\text { Há muitas "guerras de promoção" em nossa } \\
\text { indústria. }\end{array}$ & 23 & \\
\hline & $\begin{array}{l}\text { Qualquer diferencial que um competidor pode } \\
\text { oferecer, outros podem oferecer prontamente. }\end{array}$ & 25 & \\
\hline
\end{tabular}




\subsubsection{Intensidade de diferenciação}

A diferenciação de produtos dá alguma liberdade para fixação de preços, fazendo com que as empresas se comportem como Formadoras de Preço (Varian, 2012). Assim, o indicador Intensidade de diferenciação tem o objetivo de identificar a existência de diferenciação dos produtos. Espera-se encontrar uma associação positiva entre intensidade de diferenciação e formadores de preço.

Obtida através do nível de intensidade percebida pela empresa. Foram aplicadas questões fechadas às quais foram atribuídos pontos de um a cinco. $\mathrm{O}$ total de pontos indica $\mathrm{o}$ nível de cada respondente em cada item.

Tabela 10 - Intensidade de diferenciação

\begin{tabular}{|l|l|l|l|}
\hline Indicadores & Itens & $\mathbf{N}^{\mathbf{0}}$ & $\begin{array}{l}\text { Referências } \\
\text { adaptadas }\end{array}$ \\
\hline \multirow{5}{*}{$\begin{array}{l}\text { Intensidade de } \\
\text { diferenciação }\end{array}$} & $\begin{array}{l}\text { Os atributos e funcionalidades dos nossos } \\
\text { produtos são diferentes dos atributos e } \\
\text { funcionalidades dos produtos dos nossos } \\
\text { concorrentes. }\end{array}$ & $\begin{array}{l}\text { Os clientes consideram que nossos produtos são } \\
\text { diferentes dos produtos oferecidos pelos nossos } \\
\text { concorrentes. }\end{array}$ & \multirow{2}{*}{ (Amaral, 2017) } \\
\cline { 2 - 3 } & $\begin{array}{l}\text { Como nossos produtos são diferenciados, não } \\
\text { precisamos colocar preços exatamente iguais } \\
\text { aos preços dos nossos concorrentes. }\end{array}$ & \multirow{2}{*}{27} & \\
\hline
\end{tabular}

Fonte: produção do autor

\subsubsection{Percepção de teto de preço}

Obtida através da percepção da existência de um teto de preço, limitido pela precificação da concorrência. Foi aplicada uma questão fechada à qual se atribuiu pontos de um a cinco. $\mathrm{O}$ total de pontos indica o nível de cada respondente no indicador. É esperada a associação negativa entre percepção de teto de preço e abordagem do valor. 
Tabela 11 - Percepção de teto de preço

\begin{tabular}{|l|l|l|l|}
\hline Indicador & Item & $\mathbf{N}^{\mathbf{0}}$ & Referência \\
\hline $\begin{array}{l}\text { Percepção de teto } \\
\text { de preço }\end{array}$ & $\begin{array}{l}\text { No nosso mercado, não é possível } \\
\text { estabelecer o preço acima dos praticados } \\
\text { pela concorrência. }\end{array}$ & 30 & Monroe (2003) \\
\hline
\end{tabular}

Fonte: produção do autor

\subsubsection{Facilidade de acesso aos dados dos concorrentes}

Diversas fontes de informação podem ser utilizadas para obtenção dos preços dos concorrentes, como por exemplo, propagandas, clientes, distribuidores, feiras de negócios entre outros (Shipley \& Jobber, 2001); entretanto, diversos autores apontam a dificuldade de obter o preço real ofertado pela concorrência (Dutta et al., 2003; Garda, 1991; Roll, 2009).

Obtida através do nível de facilidade de acessar dados de preço da concorrencia. Foi aplicada uma questão fechada, à qual se atribuiu pontos de um a cinco. $\mathrm{O}$ total de pontos indica o nível de cada respondente no indicador.

Tabela 12 - Facilidade de acesso aos dados da concorrência

\begin{tabular}{|l|l|l|l|}
\hline Indicador & Item & $\mathbf{N}^{\mathbf{0}}$ & $\begin{array}{l}\text { Referência } \\
\text { adaptada }\end{array}$ \\
\hline $\begin{array}{l}\text { Facilidade de acesso } \\
\text { aos dados da } \\
\text { concorrência }\end{array}$ & $\begin{array}{l}\text { Temos facilidade em identificar os preços } \\
\text { cobrados pelos nossos concorrentes (é ampla a } \\
\text { divulgação prévia dos preços em catálogos por } \\
\text { exemplo). }\end{array}$ & 28 & (Amaral, 2017) \\
\hline
\end{tabular}

Fonte: produção do autor

\subsubsection{Forma de estabelecimento do preço de venda}

A maior parte dos estudos empíricos que buscou identificar a abordagem de formação de preços através da forma em que a abordagem é utilizada (Amaral, 2017). Foi obtida através da indicação da principal forma de operacionalização do estabelecimento de preços. 
Tabela 13 - Forma de estabelecimento do preço de venda

\begin{tabular}{|l|l|l|l|}
\hline Indicador & Item & $\mathbf{N}^{\mathbf{0}}$ & Referência \\
\hline $\begin{array}{l}\text { Forma do } \\
\text { estabelecimento de } \\
\text { preço }\end{array}$ & $\begin{array}{l}\text { Indique a principal forma de operacionalização } \\
\text { do estabelecimento de preços. }\end{array}$ & 37 & (Amaral, 2017) \\
\hline
\end{tabular}

Fonte: produção do autor

\subsection{Hipóteses da PeSQuisa}

A presente pesquisa testou três hipóteses que serão expostas nas subseções seguintes.

\subsubsection{Hipótese 1 - Relação entre a abordagem e o comportamento de preço}

De acordo com os princípios econômicos, em um mercado com elevada quantidade de empresas e de consumidores e sem barreiras de entrada e de saída, empresas que não oferecem diferenciação dos produtos se comportam como tomadoras de preços do mercado. Nestas condições, a interação entre as escolhas ótimas dos consumidores e das empresas resulta numa condição de equilíbrio em que o preço que maximiza o lucro se dá no ponto em que a receita marginal (dada pelo mercado) se iguala ao custo marginal (Varian, 2012).

Sendo assim, os tomadores de preços fornecem bens com baixa diferenciação, em um ambiente repleto de concorrentes fornecendo produtos iguais ou semelhantes a preços similares e facilmente visíveis no mercado. Este contexto parece oferecer um ambiente hostil à abordagem do valor, já que se fundamenta nos benefícios esperados peço consumidor, numa lógica completamente diferente da utilizada nas abordagens que se baseiam nos preços da concorrência ou nos próprios custos, (Shipley \& Jobber, 2001; Töytäri et al., 2017).

A partir destas considerações, propõe-se testar a Hipótese 1: A escolha da abordagem do valor está associada positivamente ao comportamento das formadoras de preços.

\subsubsection{Hipótese 2 - Relação entre características da estrutura organizacional e a abordagem do valor}

A adoção da abordagem do valor não é fácil (Töytäri et al., 2017) e não ocorre sem custos (Dutta et al., 2003), entretanto uma estrutura organizacional de preços madura pode facilitar a implementação da abordagem do valor (Dutta et al., 2003; Johansson et al., 2015; Töytäri \& Rajala, 2015). 
Espera-se de uma organização de preços madura, a presença de profissionais especializados em preços (Burkert et al., 2017), além de uma clara definição das responsabilidades e dos papeis de cada agente do processo (Carricano et al., 2010), assim como a presença de relacionamentos colaborativos e congruentes no contexto organizacional (Vlaar et al., 2006).

Além disso, o papel da alta gerência no contexto da precificação tem sido apontado como de elevada importância em função da capacidade de desenvolver atividades e profissionais que lidam com preços, já que sua posição confere envergadura única para estabelecer objetivos claros, influenciar o comportamento dos profissionais e para estruturar a organização de preços (Burkert et al., 2017).

Em função do exposto, esta pesquisa se propõe a testar a Hipótese 2: As características da organização de preços das empresas que adotam a abordagem do valor são distintas das empresas que adotam as demais abordagens;

\subsubsection{Hipótese 3 - Relação entre a características da estrutura organizacional e o comportamento de preço}

As empresas que se comportam como tomadoras de preço utilizam menos informações de valor para o cliente, e mais informações de custo e da concorrência no processo de estabelecimento de preços (Amaral, 2017). Já as formadoras de preços, por apresentarem maior diferenciação em seus produtos, apresentam dificuldade em obter as informações de preço da concorrência, utilizando com maior intensidade os dados de custo e de valor oferecido aos clientes (Amaral, 2017). Neste contexto, espera-se que as formadoras de preço dispendam maior energia no processo de estabelecimento de preços, o que pode estar associado a um maior nível de maturidade da estrutura organizacional de preços.

Face ao exposto, a presente pesquisa propõe-se a testar a Hipótese 3: As características da organização de preços das empresas que se comportam como formadoras de preço são distintas daquelas que atuam como tomadoras de preço.

\subsection{TÉCNICAS DE ANÁLISE ESTATÍSTICA}

No que diz respeito ao instrumental estatístico utilizado para tratamento, análise e interpretação dos dados, foram utilizadas estatísticas descritivas e a análise de correspondência. 
A estatística descritiva, como o próprio nome sugere se refere à “organização, sumarização e descrição de um conjunto de dados” (Martins \& Theóphilo, 2009, p. 108).

A análise de correspondência "é uma técnica de interdependência que tem se tornado cada vez mais popular para a redução dimensional e o mapeamento perceptual" (Hair, Jr.,

Anderson, Tathan, \& Black, 2005, p. 441). É uma técnica composicional que retrata “a 'correspondência' de categorias variáveis, particularmente aquelas medidas em escalas nominais" (Hair, Jr., Anderson, Tathan, \& Black, 2005, p. 441).

Os detalhes de utilização de cada técnica estão descritos na seção de análise e discussão dos resultados.

\subsection{OPERACIONALIZAÇÃo E REGISTRO}

Nesta seção será exposta a operacionalização da pesquisa, contendo a descrição dos contatos com a população pesquisada assim como a descrição dos arquivos armazenados como documentos de pesquisa.

Uma vez definida a população a ser pesquisada, as informações das empresas e dos respectivos contatos foram tabuladas. Por questões de confidencialidade, a lista de contatos não foi divulgada no trabalho impresso, mas está armazenada em meio eletrônico como documento da pesquisa.

As empresas foram contatadas inicialmente por telefone e convidadas a participar deste projeto após a exposição tanto do objetivo da pesquisa quanto da retribuição pela participação na mesma. A cada contato era solicitada a indicação do profissional mais habilitado a respondela. Cerca de $50 \%$ das respostas foram realizadas pelo contatado inicialmente, o que indica que a estratégia de contatar inicialmente o maior nível hierárquico possível foi interessante por corresponder ao próprio responsável pela decisão de preços em metade dos casos. 
Gráfico 7 - Divisão da amostra entre contato inicial e secundário

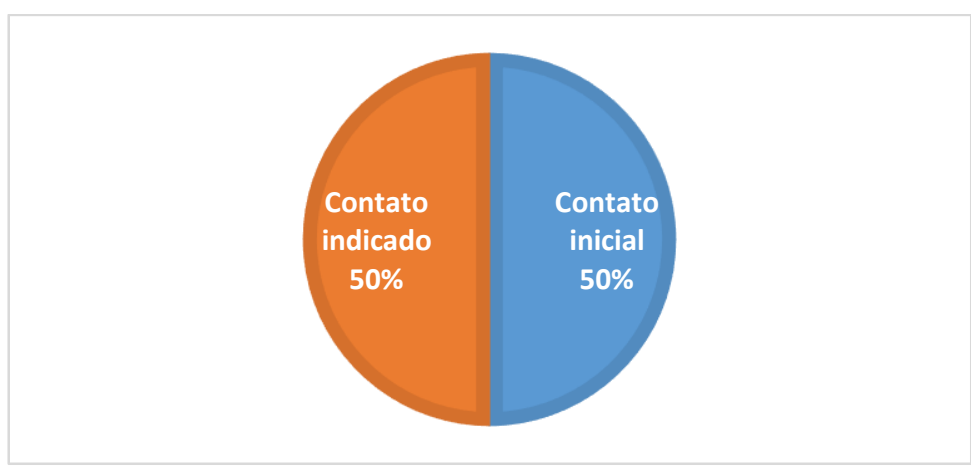

Fonte: produção do autor

Após as ligações efetivamente concretizadas, uma mensagem eletrônica (e-mail) com explicações sobre a pesquisa e com o questionário foi enviada. O modelo do e-mail está no Apêndice A; no Apêndice B encontra-se o questionário enviado como anexo em todas as mensagens em versão MS Word. Alternativamente existia a indicação do caminho (link) para a versão eletrônica no Google Forms. Todas as mensagens enviadas estão armazenadas no Webmail USP como documento da pesquisa.

A mensagem de agradecimento - Apêndice $\mathrm{C}$ - foi enviada para os respondentes depois do recebimento dos questionários, independentemente do meio escolhido para a resposta. Dos questionários recebidos, $50 \%$ foram enviados em MS Word e os demais pelo Google Forms.

Gráfico 8 - Meio escolhido para resposta

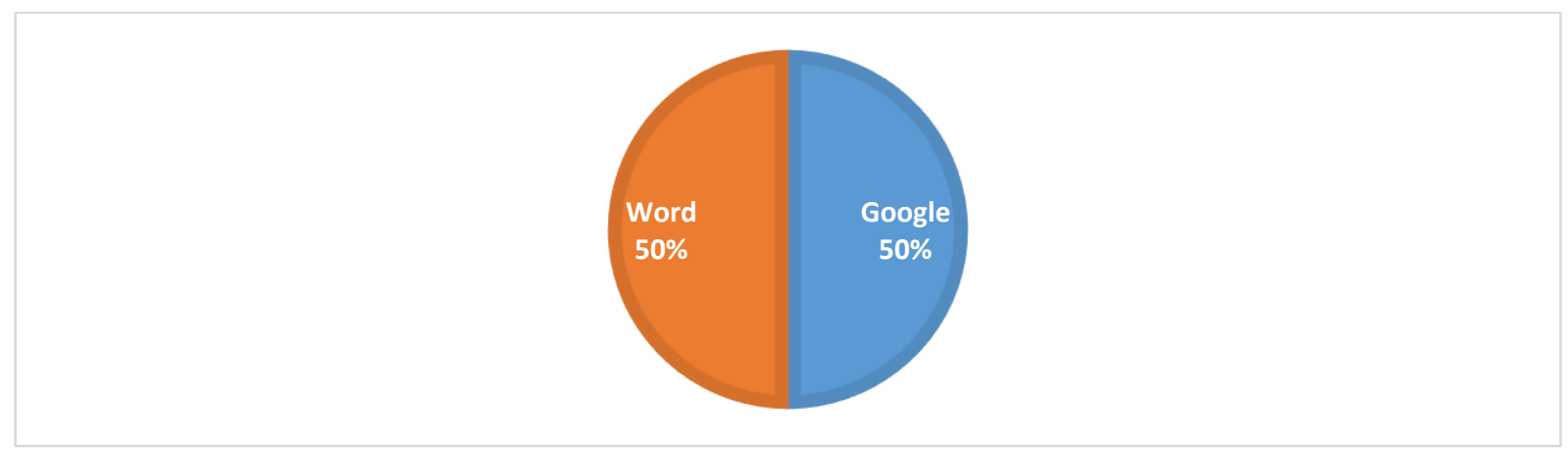

Fonte: produção do autor

Após a data combinada para a resposta, uma mensagem de reforço foi enviada com o mesmo conteúdo da mensagem original. Em alguns casos foi efetuado um novo contato telefônico. Cerca de $75 \%$ dos respondentes preencheram o questionário após o primeiro contato, $19 \%$ após o segundo contato e $6 \%$ após o terceiro contato. 
Gráfico 9 - Respostas com e sem reiteração

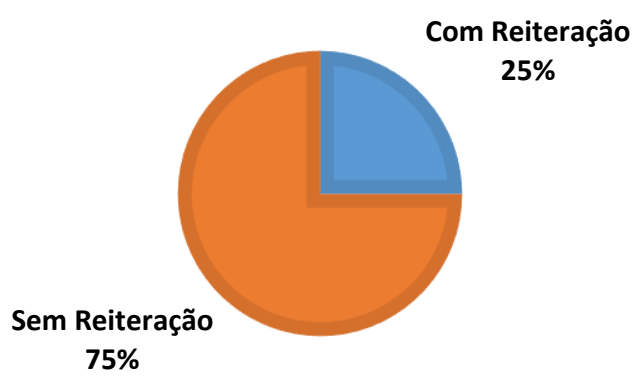

Fonte: produção do autor

Após o termino da etapa de coleta de dados, o relatório individualizado foi elaborado e será enviado a cada um dos respondentes, contendo a comparação entre as respostas realizadas pelo respondente com as respostas médias da amostra. A mensagem de envio do relatório está contida no Apêndice D e o modelo do relatório está contido no Apêndice E.

4. 


\section{ANÁLISE E DISCUSSÃO DOS RESULTADOS}

Esta seção tem o objetivo de analisar as observações da pesquisa empírica à luz do arcabouço teórico levantado nas seções anteriores. Inicialmente apresenta-se a característica da amostra, seguida da apresentação dos resultados mensurados a partir do questionário.

\subsection{DESCRIÇÃO DOS RESPONDENTES E DA AMOSTRA DA POPULAÇÃO PESQUISADA}

Nesta seção são apresentadas as características das empresas e dos respondentes que compõem a amostra. A tabela a seguir indica a distribuição geográfica, com aproximadamente $69 \%$ das empresas da amostra localizadas na região sudeste, similarmente ao percentual da população ABINEE, de $74 \%$.

Gráfico 10 - Distribuição geográfica da amostra

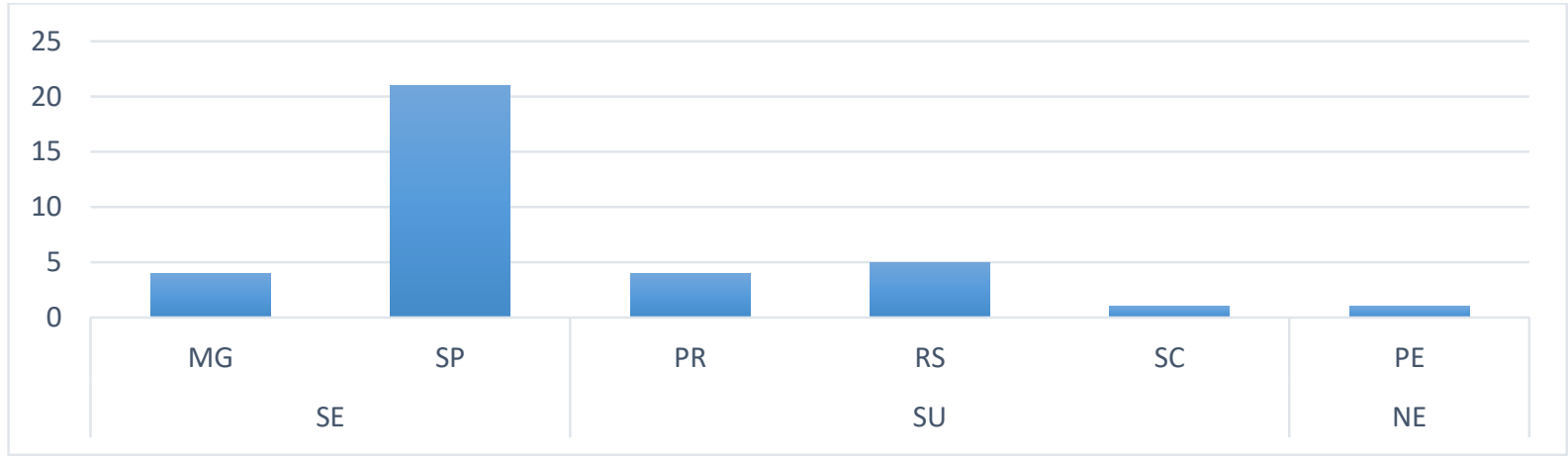

Fonte: produção do autor

Quando se adota o critério de quantidade de funcionários, a amostra é composta tanto por empresas de grande (25\%) e médio porte $(39 \%)$ quanto por micro (8\%) e pequenas empresas (28\%), conforme pode ser observado no gráfico a seguir.

Gráfico 11 - Agrupamento por quantidade de funcionários da amostra

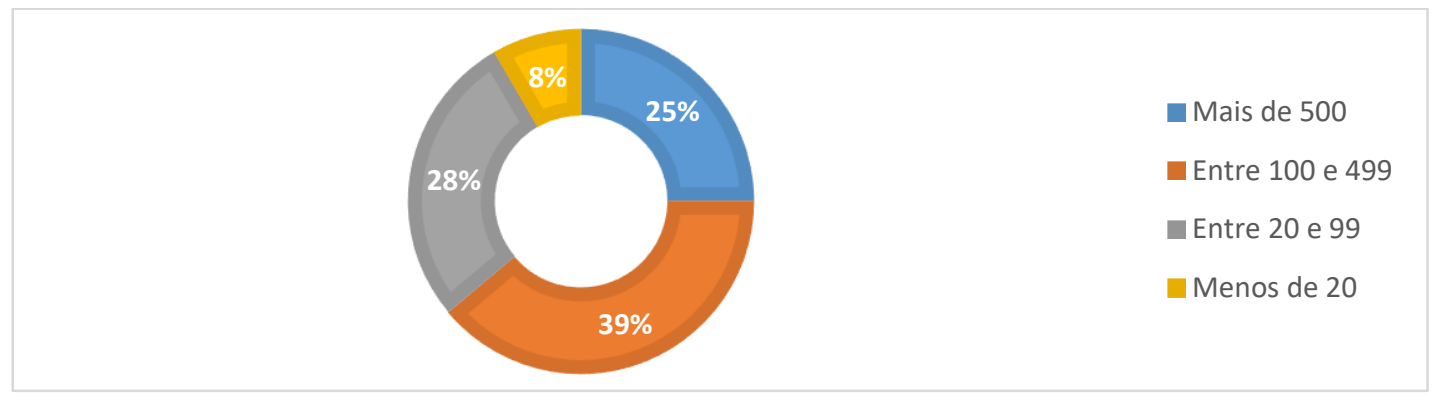

Fonte: produção do autor 
Em relação ao faturamento anual, $72 \%$ da amostra é composta por empresas que faturam até 250 milhões de reais, $11 \%$ que faturam entre 250 e 499 milhões de reais, $6 \%$ entre 500 e 999 milhões de reais e $11 \%$ acima de 1 bilhão de reais, conforme indicado no gráfico a seguir.

Gráfico 12 - Receita anual da amostra

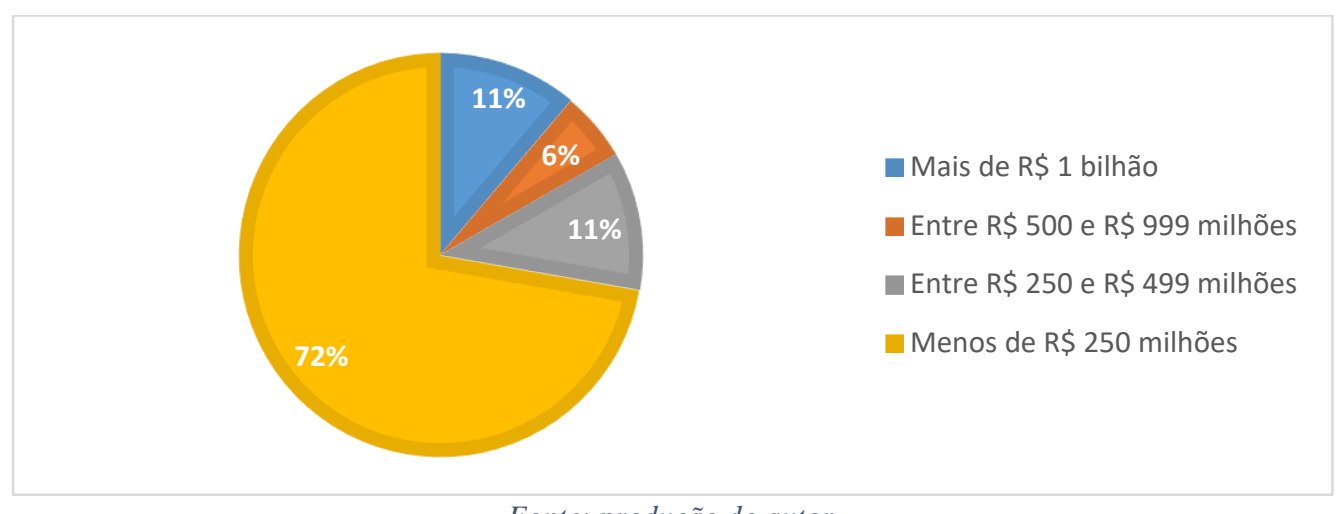

Fonte: produção do autor

A relação entre porte e faturamento é indicada no gráfico a seguir, no qual se observa a associação gráfica entre pequenas e médias empresas com faturamento de até 500 milhões de Reais.

Gráfico 13 - Relação entre faturamento e porte

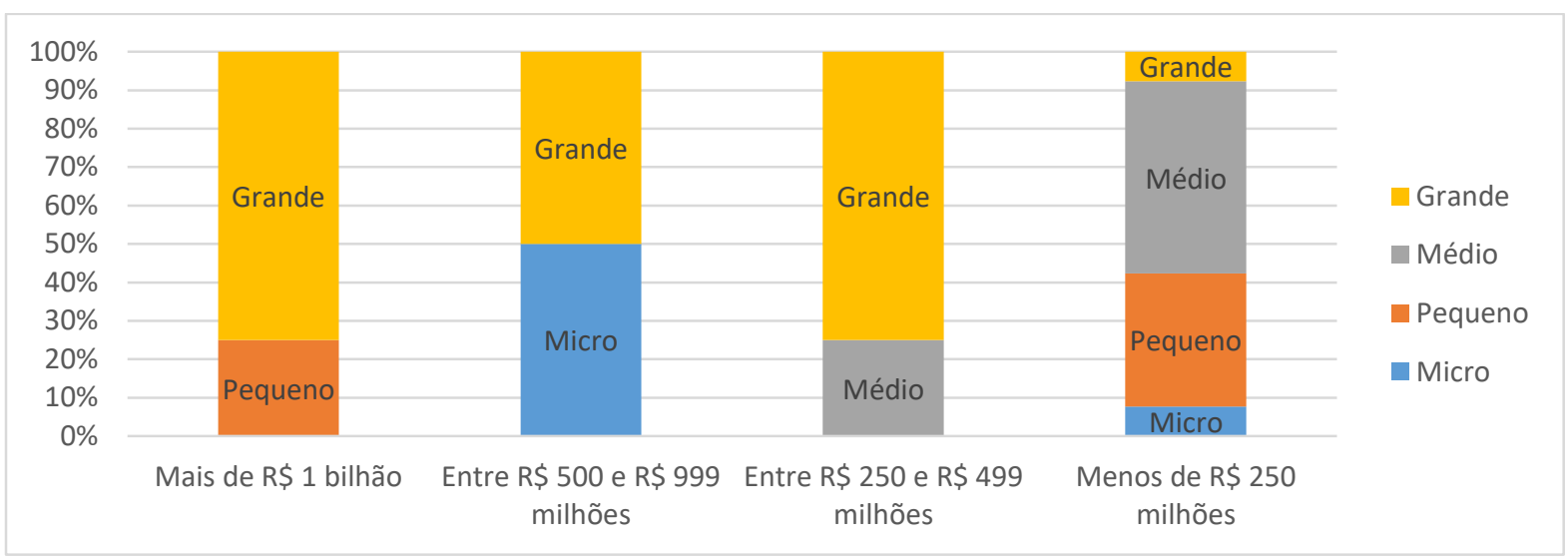

Fonte: produção do autor

Além disso, observa-se que $31 \%$ são classificadas como exportadoras. 
Gráfico 14 - Participação de exportadoras na amostra

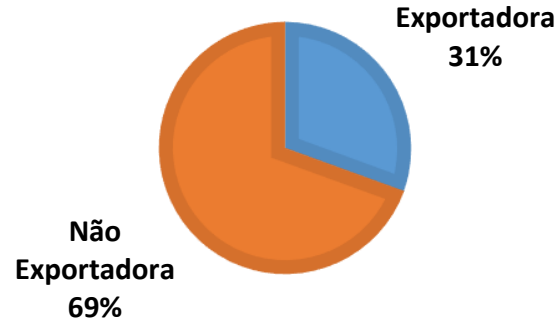

Fonte: produção do autor

Em relação a área de atuação dos respondentes, observa-se maior concentração de profissionais nas área de vendas, marketing e controladoria, embora seja relevante a participação de outras áreas, conforme apontam estudos anteriores (Abratt \& Pitt, 1985).

Gráfico 15 - Área de atuação dos respondentes

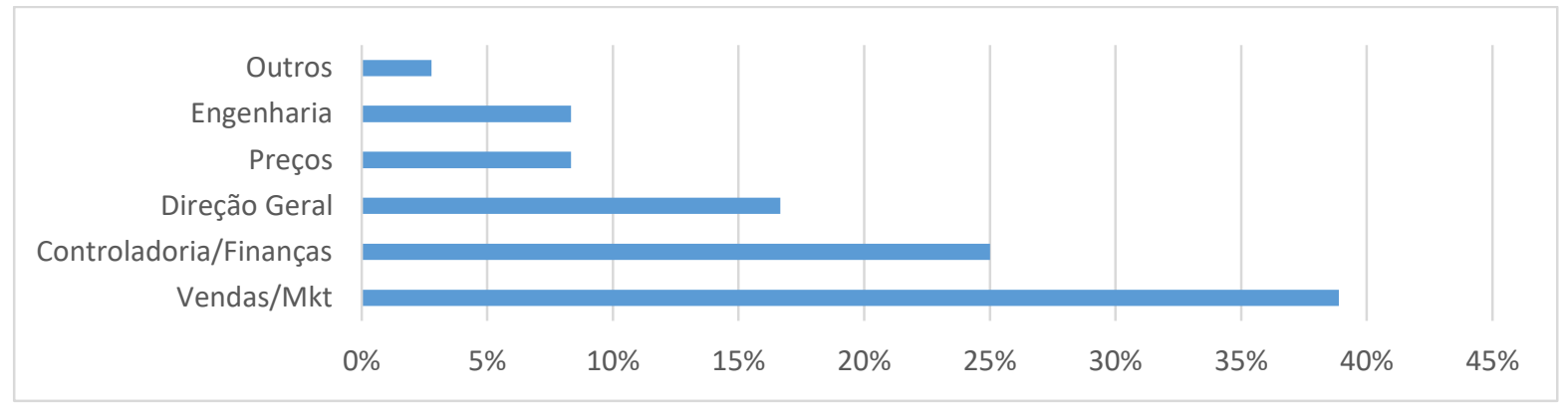

Fonte: produção do autor

Em relação ao cargo ocupado, percebe-se uma significante participação de presidentes e diretores, possivelmente em função da relevância do tema, conforme observa-se a seguir.

Gráfico 16 - Cargos ocupados pelos respondentes

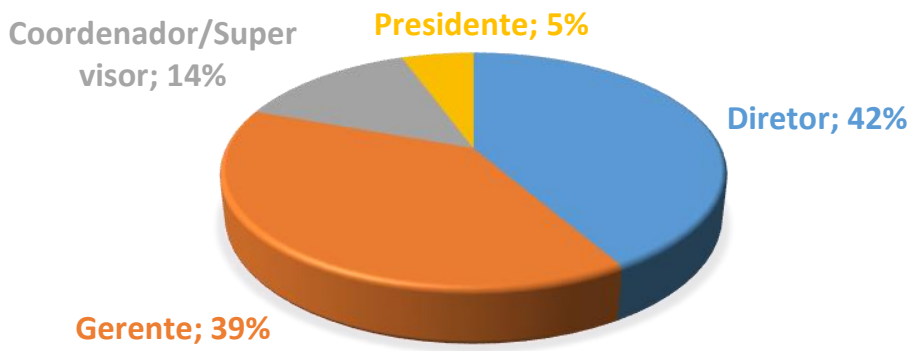

Fonte: produção do autor 
Em relação à área de atuação, 50\% da amostra é composta por empresas atuantes em automação industrial, materiais elétricos e equipamentos industriais, seguindo a classificação da ABINEE. O gráfico com a participação percentual de cada área de atuação é mostrado a seguir.

Gráfico 17 - Áreas em que atuam as empresas da amostra

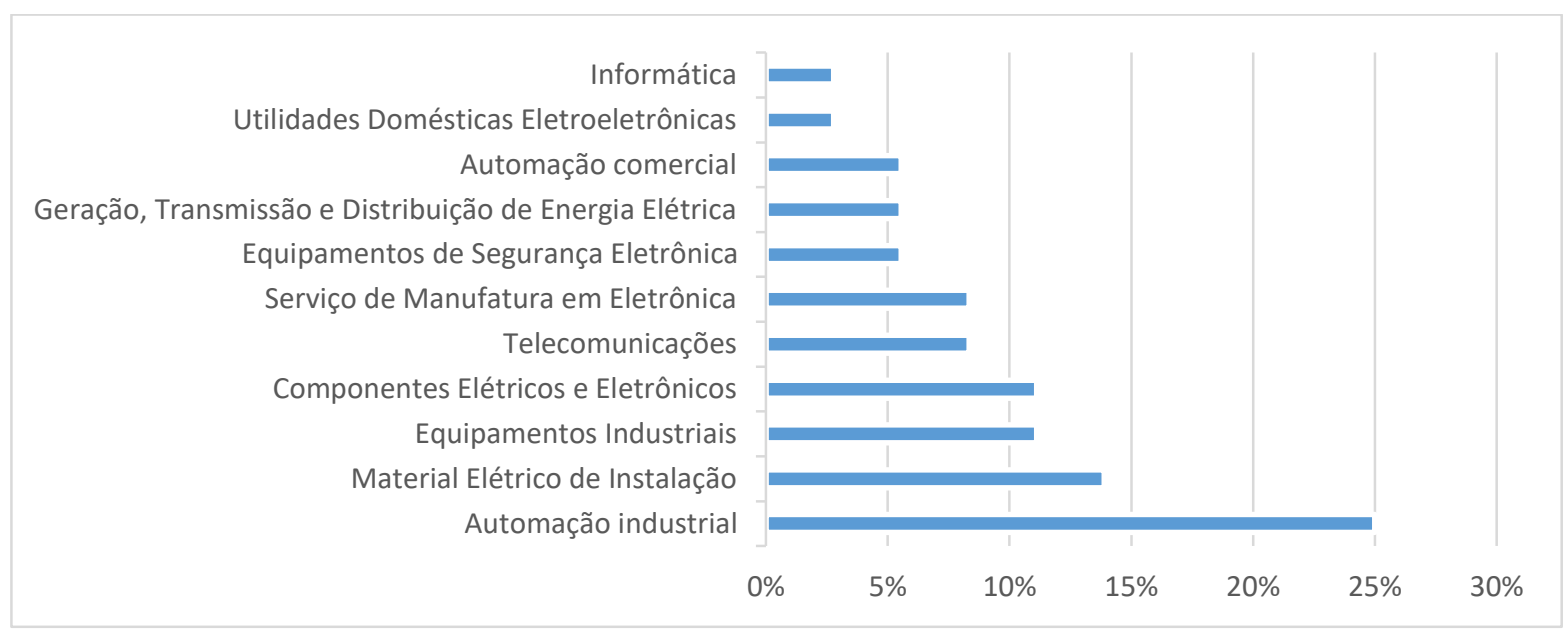

Fonte: produção do autor

Como exposto em seções anteriores, as empresas do ambiente B2B vendem seus produtos a outras empresas, em contraposição àquelas pertencentes ao ambiente $\mathrm{B} 2 \mathrm{C}$, que os vendem ao consumidor final. Entretanto, é importante considerar o argumento de que existem empresas que pertencem às duas categorias (Gummesson, 2004). Uma empresa pode vender o mesmo produto diretamente para o consumidor final assim como pode vender para outras empresas, como a europeia Ikea faz (Gummesson, 2004). Além disso, ainda que haja indústrias que vendem apenas para revendedores, seu produtos podem ser claramente destinados ao consumidor não empresarial (Gummesson, 2004).

Sendo assim, a pesquisa fez a classificação de acordo com uma pesquisa minuciosa dos produtos e serviços ofertados e do mercado a que se destinam. O resultado pode ser conferido no gráfico a seguir. 
Gráfico 18 - Ambiente de atuação

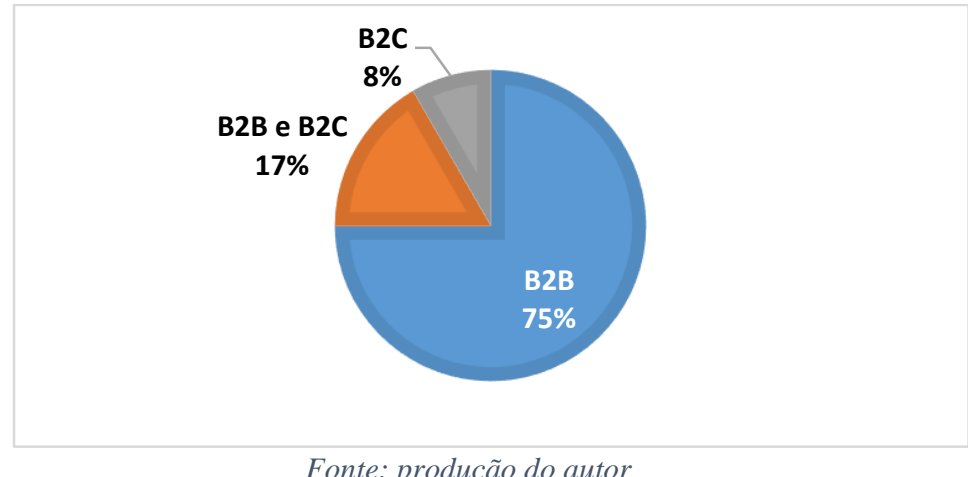

Fonte: produção do autor

É possível observar a predominância de empresas atuantes exclusivamente no ambiente B2B (75\%), resultado esperado para a amostra da indústria eletroeletrônica.

Em resumo, a amostra é composta majoritariamente por empresas da região sudeste (69\%), não exportadoras (69\%), atuantes nas áreas de automação industrial (25\%), materiais elétricos $(\sim 15 \%)$ e equipamentos industriais $(\sim 10 \%)$, que faturam até 250 milhões de Reais $(72 \%)$ e possuem até 499 funcionários $(75 \%)$.

Em relação aos profissionais respondentes, houve uma expressiva participação de presidentes (5\%) e diretores (42\%), assim como de profissionais atuantes nas áreas de vendas e marketing $(\sim 40 \%)$ e controladoria e finanças $(25 \%)$.

\subsection{Comportamento de Preços}

No que se refere ao comportamento de preços, foram escolhidos dois indicadores para classificar as empresas entre formadoras e tomadoras de preço. O primeiro se refere à diferenciação dos produtos ofertados, representado pela assertiva de número 26 , e o segundo se refere à efetividade da diferenciação no comportamento de preços, representado na assertiva de número 27. As estatísticas descritivas de ambas as assertivas estão disponíveis na tabela a seguir. 
Tabela 14 - Estatística descritiva para as assertivas 26 e 27

\begin{tabular}{|c|c|c|c|c|c|c|c|c|c|c|}
\hline \multirow[b]{3}{*}{ Assertiva } & \multirow[b]{3}{*}{$\#$} & \multicolumn{6}{|c|}{1 - > Discordo totalmente } & \multicolumn{3}{|c|}{5 -> Concordo totalmente } \\
\hline & & \multicolumn{2}{|c|}{ Concordância } & \multicolumn{5}{|c|}{ Frequência Absoluta e (Relativa) das Respostas } & \multirow{2}{*}{ Mediana } & \multirow{2}{*}{ Moda } \\
\hline & & $\begin{array}{c}\text { Não } \\
\text { Concorda }\end{array}$ & Concorda & 1 & 2 & 3 & 4 & 5 & & \\
\hline $\begin{array}{l}\text { Os clientes consideram que nossos produtos são } \\
\text { diferentes dos produtos oferecidos pelos nossos } \\
\text { concorrentes. }\end{array}$ & 26 & $17 \%$ & $53 \%$ & $2(5,6 \%)$ & $4(11,1 \%)$ & $11(30,6 \%)$ & $13(36,1 \%)$ & $6(16,7 \%)$ & 4 & 4 \\
\hline $\begin{array}{l}\text { Como nossos produtos são diferenciados, não } \\
\text { precisamos colocar preços exatamente iguais aos } \\
\text { preços dos nossos concorrentes. }\end{array}$ & 27 & $39 \%$ & $33 \%$ & $4(11,1 \%)$ & $10(27,8 \%)$ & $10(27,8 \%)$ & $9(25,0 \%)$ & $3(8,3 \%)$ & 3 & 3 \\
\hline
\end{tabular}

Fonte: produção do autor

A figura a seguir ilustra o raciocínio utilizado para classificar a amostra entre Formadores e Tomadores de Preço, inspirado no procedimento utilizado por Amaral (2017).

Figura 4 - Racional para classificação do comportamento de preço das empresas da amostra

\section{Amostra (100\%)}

$53 \%$ concordam com a assertiva 26: O clientes consideram que nossos produtos são diferentes dos produtos oferecidos pelos nossos concorrentes

$47 \%$ não discordam da assertiva 27: Como nossos produtos são diferenciados,

não precisamos colocar preços exatamente igauis aos

preços dos nossos concorrentes.

Formador de Preço (47\%) $\mathbf{5 \%}$ não concordam com

a assertiva 27: Como

nossos produtos são

diferenciados, não

precisamos colocar preços

exatamente igauis aos preços

dos nossos concorrentes.

Tomador de Preço (5\%)

Fonte: produção do autor
$47 \%$ não concordam com a assertiva 26: $\mathrm{O}$ clientes consideram que nossos produtos são diferentes dos produtos oferecidos pelos nossos concorrentes

\section{Tomador de Preço (47\%)}

Dessa maneira, observa-se que a amostra é composta majoritariamente por formadores de preço: 
Gráfico 19 - Comportamento de preços das empresas da amostra

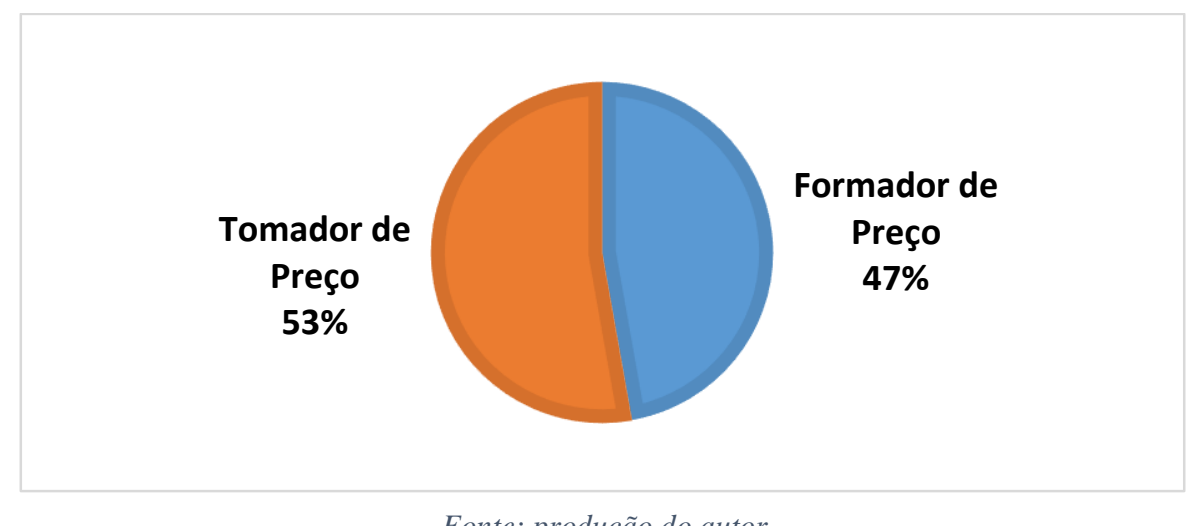

Fonte: produção do autor

Com a amostra classificada, passou-se para a investigação da relação entre o comportamento de preço e a intensidade de diferenciação, composta pelos pontos indicados nas assertivas 24, 26 e 27. O teste Qui-Quadrado foi realizado para testar a hipótese nula de independência das variáveis, com a conclusão de que as variáveis são dependentes com p-valor de 0,001 e valor 34,8230 .

A análise de correspondência examina as relações entre as categorias de dados em uma tabela de contingência, que pode ser visualizada a seguir. Percebe-se que os formadores de preço apresentam alta intensidade de diferenciação, enquanto os tomadores apresentam baixa intensidade de diferenciação.

Tabela 15 - Tabela de contingência: Comportamento de preço e diferenciação

\begin{tabular}{|lccrr|}
\cline { 2 - 5 } \multicolumn{1}{c|}{} & \multicolumn{3}{c|}{ Intensidade de diferenciação } \\
\hline Comportamento & Baixa & Média & Alta & Total \\
\hline Tomador de Preço B2C & 1 & & & 1 \\
Tomador de Preço B2B e B2C & & 1 & & 1 \\
Tomador de Preço B2B & 13 & 2 & 2 & 17 \\
Formador de Preço B2C & & & 2 & 2 \\
Formador de Preço B2B e B2C & & & 5 & 5 \\
Formador de Preço B2B & & 1 & 9 & 10 \\
Total Geral & $\mathbf{1 4}$ & $\mathbf{4}$ & $\mathbf{1 8}$ & $\mathbf{3 6}$ \\
\hline
\end{tabular}

A partir da utilização do pacote "ANACOR" (Leeuw \& Mair, 2009) do programa $R$ Studio, foi gerado o mapa perceptual da relação entre comportamento de preço e intensidade de diferenciação. Optou-se por avaliar separadamente os formadores e tomadores preço de acordo com o ambiente de atuação (B2B e B2C). Percebe-se que a maior diferenciação percebida pelas empresas (“Alta”, em vermelho) está associada ao comportamento de formadores de preço (F) 
e que as empresas que percebem menor diferenciação ("Baixa", em vermelho) estão associadas ao comportamento de tomadoras de preço $(\mathrm{T})$.

Gráfico 20 - Mapa perceptual: comportamento de preço e diferencial percebida

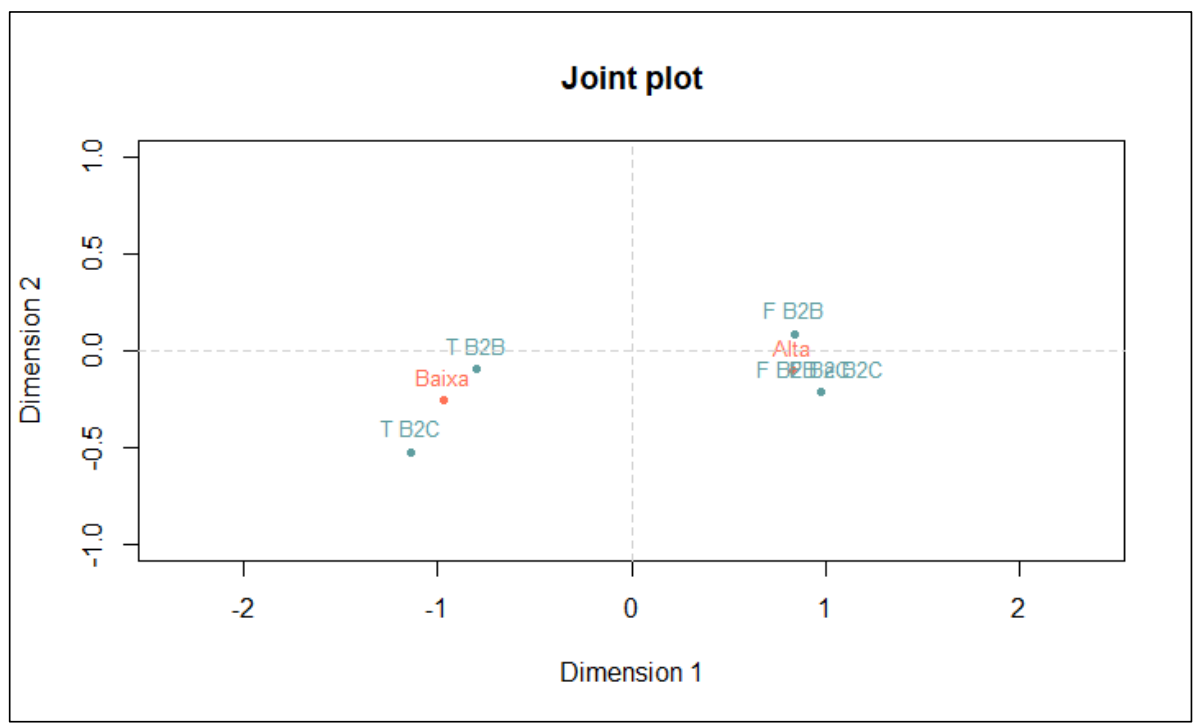

Fonte: produção do autor a partir do pacote ANACOR utilizado no programa $R$ Studio

Diversas fontes de informação podem ser utilizadas para obtenção dos preços dos concorrentes; entretanto, seu acesso nem sempre é fácil (Dutta et al., 2003; Garda, 1991; Roll, 2009). A fim de investigar a facilidade de acesso aos dados da concorrência, foi aplicada uma questão fechada à qual se atribuiu pontos de um a cinco. $\mathrm{O}$ total de pontos indica o nível de facilidade. As estatísticas descritivas da questão podem ser observadas na tabela a seguir.

Tabela 16 - Estatística descritiva para a assertiva 28

\begin{tabular}{|c|c|c|c|c|c|c|c|c|c|c|}
\hline \multirow[b]{3}{*}{ Assertiva } & \multirow[b]{3}{*}{$\#$} & \multicolumn{6}{|c|}{ 1-> Discordo totalmente } & \multicolumn{3}{|c|}{5 -> Concordo totalmente } \\
\hline & & \multicolumn{2}{|c|}{ Concordância } & \multicolumn{5}{|c|}{ Frequência Absoluta e (Relativa) das Respostas } & \multirow{2}{*}{ Mediana } & \multirow{2}{*}{ Moda } \\
\hline & & $\begin{array}{c}\text { Não } \\
\text { Concorda }\end{array}$ & Concorda & 1 & 2 & 3 & 4 & 5 & & \\
\hline $\begin{array}{l}\text { Temos facilidade em identificar os preços } \\
\text { cobrados pelos nossos concorrentes (é ampla a } \\
\text { divulgação prévia dos preços em catálogos por } \\
\text { exemplo). }\end{array}$ & 28 & $50 \%$ & $25 \%$ & $7(19,4 \%)$ & $11(30,6 \%)$ & $9(25,0 \%)$ & $6(16,7 \%)$ & $3(8,3 \%)$ & 3 & 2 \\
\hline
\end{tabular}

Fonte: produção do autor

Observa-se que $25 \%$ da amostra relata facilidade na obtenção dos dados de preço estabelecidos pela concorrência. A análise da tabela de contingência, que pode ser visualizada a seguir, evidencia a relação entre a facilidade de obtenção dos dados da concorrência com os 
formadores de preço B2B. Da mesma maneira que evidencia a relação entre tomadores de preço B2B com a menor facilidade de acesso aos dados da concorrência.

Tabela 17 - Tabela de contingência: comportamento de preço e facilidade de acesso a dados da concorrência

\begin{tabular}{|lrrrrrr|}
\cline { 2 - 7 } \multicolumn{1}{c|}{} & \multicolumn{6}{c|}{$\begin{array}{c}\text { Facilidade de acesso aos dados da } \\
\text { concorrência }\end{array}$} \\
\hline Comportamento & $\mathbf{1}$ & $\mathbf{2}$ & $\mathbf{3}$ & $\mathbf{4}$ & $\mathbf{5}$ & Total \\
\hline Tomador de Preço B2C & & & & 1 & 1 \\
Tomador de Preço B2B e B2C & & & 1 & & 1 \\
Tomador de Preço B2B & 5 & 10 & 1 & 1 & 17 \\
Formador de Preço B2C & 1 & & 1 & & & 2 \\
Formador de Preço B2B e B2C & 1 & & 1 & 3 & & 5 \\
Formador de Preço B2B & & 1 & 5 & 1 & 3 & 10 \\
\hline Total Geral & $\mathbf{7}$ & $\mathbf{1 1}$ & $\mathbf{9}$ & $\mathbf{6}$ & $\mathbf{3}$ & $\mathbf{3 6}$ \\
\hline
\end{tabular}

Foi realizado o teste Qui-Quadrado com a conclusão de que as variáveis são dependentes com p-valor igual a 0,0045 e valor 40,33. A partir da utilização do pacote "ANACOR" (Leeuw \& Mair, 2009) do programa $R$ Studio, foi gerado o mapa perceptual da relação entre comportamento de preço e a facilidade de acesso ao preço da concorrência. Mais uma vez, optou-se por avaliar separadamente os formadores e tomadores preço de acordo com o ambiente de atuação (B2B e B2C).

Gráfico 21 - Mapa perceptual: comportamento de preço e facilidade de acesso ao preço da concorrência

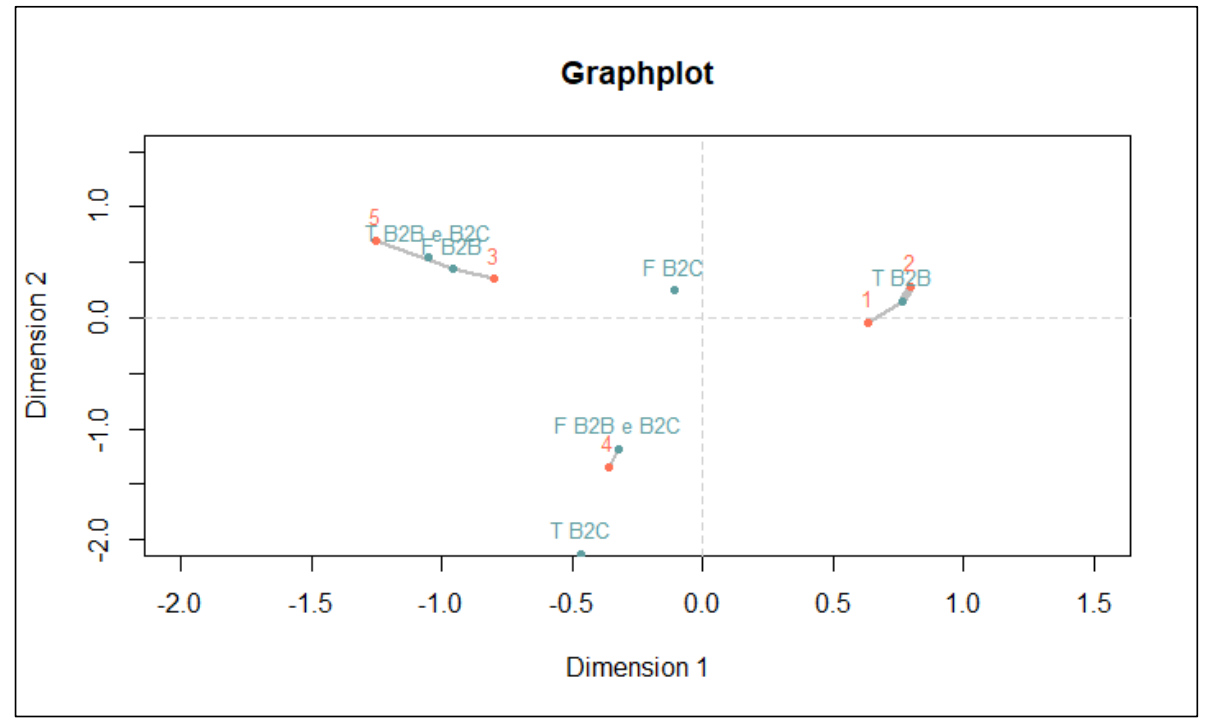

Fonte: produção do autor a partir do pacote ANACOR utilizado no programa R Studio 
Percebe-se que tomadores de preço B2B (T B2B em verde) apresentam associação com a menor facilidade de acesso ao preço da concorrência (pontos 1 e 2 em vermelho). A dificuldade da obtenção de correta informação do preço da concorrência em função da grande quantidade de itens vendáveis e da prática adotada pelo mercado de trabalhar com descontos e rebates sobre a lista de preços foi apontada em pesquisas anteriores (Dutta et al., 2003; Garda, 1991).

É possível observar a relação entre formadores de preço B2B e B2C (F B2B e B2C em verde) com a maior facilidade de acesso ao preço da concorrência (ponto 4 em vermelho); já que itens destinados ao mercado consumidor fatalmente apresentam os preços expostos.

Apesar da literatura ter se debruçado sobre o impacto da intensidade de competição na abordagem de preços, os resultados são conflitantes (Amaral, 2017), e a sua relação com a abordagem do valor ainda é escassa. Por essa razão, pesquisas empíricas que buscam entender a influência da intensidade de competição na determinação do preço de venda são necessárias (Amaral, 2017). As estatísticas descritivas das assertivas relacionadas aos indicadores estão disponíveis na tabela a seguir.

Tabela 18 - Estatística descritiva: intensidade de competição

\begin{tabular}{|l|c|c|c|c|c|c|c|r|r|r|}
\hline \multirow{2}{*}{ Assertiva } & \multirow{2}{*}{$\#$} & \multicolumn{2}{|c|}{ Concordância } & \multicolumn{3}{|c|}{ Frequência Absoluta e (Relativa) das Respostas } & \multirow{2}{*}{ Mediana } & Moda \\
\cline { 4 - 11 } & & $\begin{array}{c}\text { Não } \\
\text { Concorda }\end{array}$ & Concorda & 1 & 2 & 3 & 4 & 5 & 5 \\
\hline A concorrência na nossa indústria é intensa. & 22 & $14 \%$ & $81 \%$ & $1(2,8 \%)$ & $4(11,1 \%)$ & $2(5,6 \%)$ & $7(19,4 \%)$ & $22(61,1 \%)$ & 5 & 5 \\
\hline $\begin{array}{l}\text { Há muitas "guerras de promoção" em nossa } \\
\text { indústria. }\end{array}$ & 23 & $19 \%$ & $56 \%$ & $3(8,3 \%)$ & $4(11,1 \%)$ & $9(25,0 \%)$ & $8(22,2 \%)$ & $12(33,3 \%)$ & 4 & 5 \\
\hline $\begin{array}{l}\text { Qualquer diferencial que um competidor pode } \\
\text { oferecer, outros podem oferecer prontamente. }\end{array}$ & 25 & $44 \%$ & $25 \%$ & $7(19,4 \%)$ & $9(25,0 \%)$ & $11(30,6 \%)$ & $8(22,2 \%)$ & $1(2,8 \%)$ & 3 & 3 \\
\hline
\end{tabular}

Fonte: produção do autor

A análise das modas indica que a maior parte da amostra apresenta alto nível de competição; entretanto, os formadores de preço relatam haver mais guerras de promoção no ambiente em que atuam assim como maior percepção de intensidade de competição, conforme pode ser observado na tabela a seguir. 
Tabela 19 - Intensidade de competição

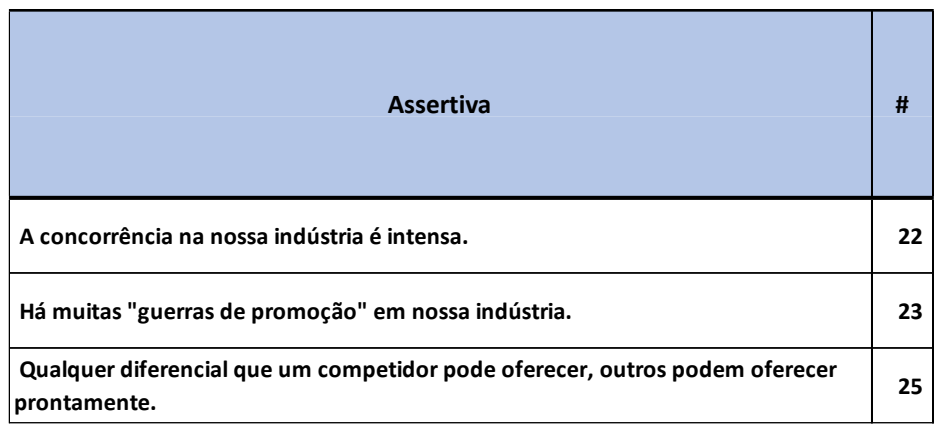

\begin{tabular}{|c|c|c|c|}
\hline \multicolumn{2}{|c|}{ Discordância (\%) } & \multicolumn{2}{c|}{ Concordância (\%) } \\
\hline \multicolumn{2}{|c|}{ Comportamento } & \multicolumn{2}{c|}{ Comportamento } \\
\hline Formador & Tomador & Formador & Tomador \\
\hline $11 \%$ & $17 \%$ & $78 \%$ & $67 \%$ \\
\hline $22 \%$ & $33 \%$ & $67 \%$ & $33 \%$ \\
\hline $33 \%$ & $67 \%$ & $22 \%$ & $17 \%$ \\
\hline
\end{tabular}

Fonte: produção do autor

Em resumo, evidenciou-se que os formadores de preço apresentam maior diferenciação em seus produtos ou serviços, enquanto os tomadores apresentam menor diferenciação. Em relação à facilidade de acesso à informação de preços da concorrência, é possível relacionar a maior facilidade em formadores de preço B2B e B2C e menor facilidade de acesso aos tomadores de preço B2B.

\subsection{ABORDAGEM DE PREÇOS}

A forma de estabelecimento de preços foi identificada nesta pesquisa pela resposta à assertiva 37: "Indique a principal forma de operacionalização do estabelecimento de preços". O resultado obtido foi consistente com pesquisas empíricas realizadas em diversos países ao indicar que a abordagem de custo constitui a forma mais utilizada pelas empresas.

Gráfico 22 - Forma de operacionalização do preço de venda

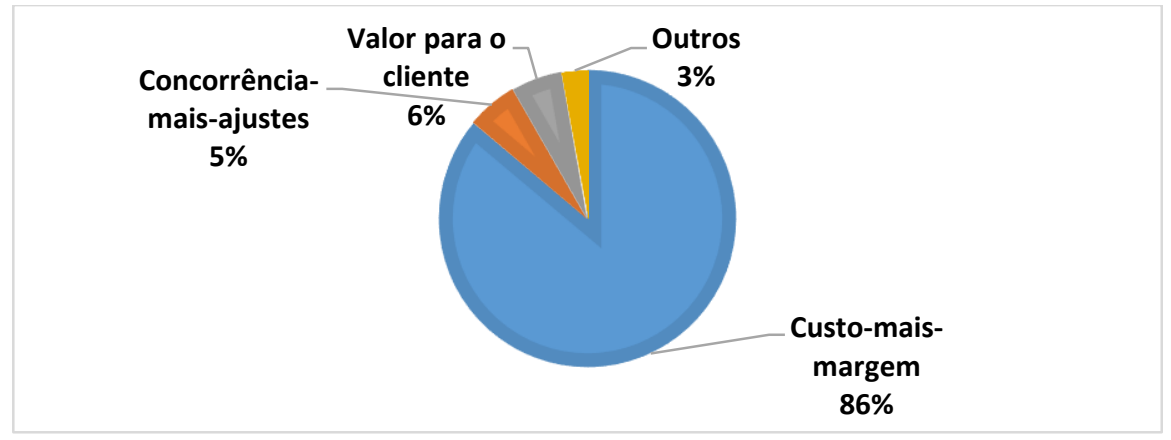

Fonte: produção do autor

Entretanto, este achado parece estar relacionado à questão do formato utilizado pelas empresas e não à abordagem que buscamos identificar: Amaral (2017) e Guerreiro e Amaral (2018) ressaltam que a fórmula matemática utilizada para o cálculo de preços usualmente 
considera informações de custo; entretanto, o uso desta fórmula não indica necessariamente a adoção da abordagem de custos.

Para averiguar este entendimento, é necessário analisar a concordância e discordância em relação a seis assertivas utilizadas na pesquisa e que estão relatadas na tabela a seguir.

Tabela 20 - Análise da forma de estabelecimento de preço de venda

\begin{tabular}{|c|c|c|c|}
\hline & & & \\
\hline & & Custo-ma & is-margem \\
\hline Assertiva & \# & Discordância & Concordância \\
\hline Nós determinamos o nosso preço de acordo com o preço dos concorrentes. & 29 & $55 \%$ & $23 \%$ \\
\hline Todos os nossos produtos têm margens parecidas & 32 & $74 \%$ & $19 \%$ \\
\hline Todos os nossos segmentos de clientes têm margens parecidas. & 33 & $71 \%$ & $23 \%$ \\
\hline $\begin{array}{l}\text { A definição da margem independe da consideração de características específicas dos } \\
\text { produtos (por exemplo, a margem de produtos simples é similar à margem de produtos } \\
\text { sofisticados) }\end{array}$ & 34 & $71 \%$ & $19 \%$ \\
\hline $\begin{array}{l}\text { A definição da margem independe da consideração de características específicas dos } \\
\text { clientes, como porte e localidade }\end{array}$ & 35 & $42 \%$ & $29 \%$ \\
\hline $\begin{array}{l}\text { A definição da margem independe da consideração da importância que os clientes vêem } \\
\text { nos produtos }\end{array}$ & 36 & $42 \%$ & $29 \%$ \\
\hline
\end{tabular}

Fonte: produção do autor

A assertiva 29 merece análise por indicar com clareza a utilização da abordagem da concorrência por aqueles que concordam com ela. Entretanto, observa-se que $23 \%$ das empresas que utilizam a forma de custo-mais-margem concordaram com a assertiva. Além disso, observase mais de $70 \%$ de discordância para as assertivas 32, 33 e 34 e mais de $40 \%$ de discordância para as assertivas 35 e 36 . A discordância a estas assertivas indica que estas empresas utilizam margens diferentes em função das características de seus produtos e de seus clientes. De acordo com a literatura da área, esta prática é relacionada à abordagem do valor.

Sendo assim, há indícios suficientes para afirmar que as manifestações realizadas à assertiva 37 se referem à forma do estabelecimento do preço de venda e não à abordagem ou ao método do estabelecimento do preço de venda.

Uma vez esclarecida esta questão, deve-se informar que foram escolhidos dois indicadores para classificar a abordagem de formação do preço de venda. O primeiro é obtido através da confirmação do uso da abordagem da concorrência (assertiva 29); o segundo se refere ao nível de concordância às assertivas $31,32,33,34,35$ e 36 . As estatísticas descritivas das assertivas relacionadas aos indicadores estão disponíveis na tabela a seguir. 
Tabela 21 - Estatística descritiva: Abordagem de preços

\begin{tabular}{|c|c|c|c|c|c|c|c|c|c|c|}
\hline \multirow[b]{3}{*}{ Assertiva } & \multirow[b]{3}{*}{$\#$} & \multicolumn{6}{|c|}{1 - > Discordo totalmente } & \multicolumn{3}{|c|}{5 -> Concordo totalmente } \\
\hline & & \multicolumn{2}{|c|}{ Concordância } & \multicolumn{5}{|c|}{ Frequência Absoluta e (Relativa) das Respostas } & \multirow{2}{*}{ Mediana } & \multirow{2}{*}{ Moda } \\
\hline & & $\begin{array}{c}\text { Não } \\
\text { Concorda }\end{array}$ & Concorda & 1 & 2 & 3 & 4 & 5 & & \\
\hline $\begin{array}{l}\text { Nós determinamos o nosso preço de acordo com o } \\
\text { preço dos concorrentes. }\end{array}$ & 29 & $53 \%$ & $25 \%$ & $6(16,7 \%)$ & $13(36,1 \%)$ & $8(22,2 \%)$ & $8(22,2 \%)$ & $1(2,8 \%)$ & 2 & 2 \\
\hline $\begin{array}{l}\text { A margem colocada sobre os custos é definida } \\
\text { isoladamente pelo departamento financeiro }\end{array}$ & 31 & $67 \%$ & $11 \%$ & $12(33,3 \%)$ & $12(33,3 \%)$ & $8(22,2 \%)$ & $4(11,1 \%)$ & $0(0,0 \%)$ & 2 & 1 \\
\hline Todos os nossos produtos têm margens parecidas & 32 & $78 \%$ & $17 \%$ & $15(41,7 \%)$ & $13(36,1 \%)$ & $2(5,6 \%)$ & $5(13,9 \%)$ & $1(2,8 \%)$ & 2 & 1 \\
\hline $\begin{array}{l}\text { Todos os nossos segmentos de clientes têm } \\
\text { margens parecidas. }\end{array}$ & 33 & $72 \%$ & $19 \%$ & $13(36,1 \%)$ & $13(36,1 \%)$ & $3(8,3 \%)$ & $6(16,7 \%)$ & $1(2,8 \%)$ & 2 & 1 \\
\hline $\begin{array}{l}\text { A definição da margem independe da } \\
\text { consideração de características específicas dos } \\
\text { produtos (por exemplo, a margem de produtos } \\
\text { simples é similar à margem de produtos } \\
\text { sofisticados) }\end{array}$ & 34 & $72 \%$ & $19 \%$ & $12(33,3 \%)$ & $14(38,9 \%)$ & $3(8,3 \%)$ & $4(11,1 \%)$ & $3(8,3 \%)$ & 2 & 2 \\
\hline $\begin{array}{l}\text { A definição da margem independe da } \\
\text { consideração de características específicas dos } \\
\text { clientes, como porte e localidade }\end{array}$ & 35 & $47 \%$ & $28 \%$ & $7(19,4 \%)$ & $10(27,8 \%)$ & $9(25,0 \%)$ & $5(13,9 \%)$ & $5(13,9 \%)$ & 3 & 2 \\
\hline $\begin{array}{l}\text { A definição da margem independe da } \\
\text { consideração da importância que os clientes vêem } \\
\text { nos produtos }\end{array}$ & 36 & $44 \%$ & $28 \%$ & $4(11,1 \%)$ & $12(33,3 \%)$ & $10(27,8 \%)$ & $5(13,9 \%)$ & $5(13,9 \%)$ & 3 & 2 \\
\hline
\end{tabular}

Fonte: produção do autor

Foram classificados como utilizadores da abordagem da concorrência aqueles que indicaram os pontos (scores) 4 e 5 da assertiva 29, equivalendo a $25 \%$ da amostra. As assertivas de números 31 a 36 tiveram seus pontos somados. Foram classificadas como utilizadores da abordagem do custo aqueles respondentes que assinalaram pontos iguais ou acima de 18 pontos, equivalendo a $17 \%$ da amostra. Aquelas empresas que assinalaram até 17 pontos foram classificadas como praticantes da abordagem do valor, correspondendo a $58 \%$ da amostra, conforme gráfico a seguir.

\section{Gráfico 23 - Abordagem de preços}

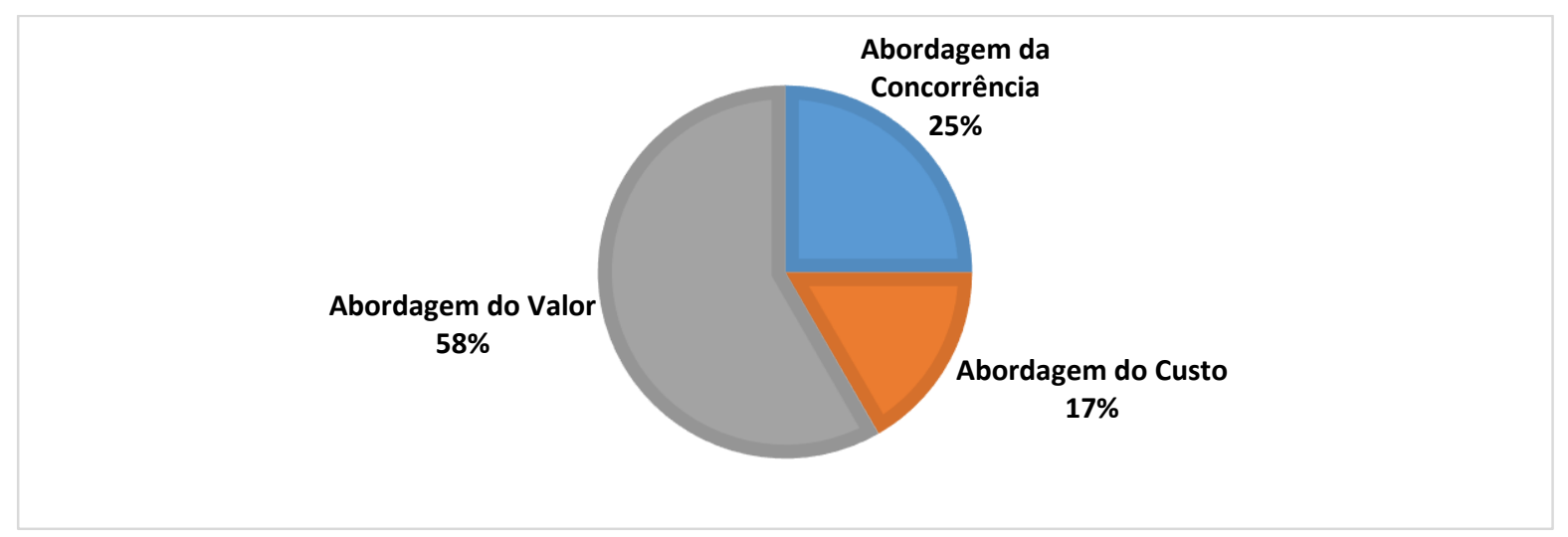


Com o objetivo de adicionar uma camada de validade e de confiabilidade desta classificação, optou-se por investigar a relação entre as abordagens de preço e o constructo “essência valor" (Amaral, 2017). Este foi formado pela soma dos pontos das assertivas de número 34, 35 e 26. As empresas com até 7 pontos foram classificadas como alta essência valor, as empresas com 8 a 10 pontos foram classificadas como média essência valor e finalmente, as empresas com 11 a 15 pontos foram classificadas como baixa essência valor. Inicialmente foi realizado o teste Qui-Quadrado para testar a hipótese nula de independência das variáveis, que foi rejeitada com p-valor 0,0141 e valor 12,4880 .

Uma vez confirmada a dependência das variáveis, passou-se para construção da tabela de contingência, que pode ser visualizada a seguir.

Tabela 22 - Tabelas de contingência: Abordagem de preço e essência valor

\begin{tabular}{lcccrr} 
& \multicolumn{5}{c}{ Essência valor } \\
\cline { 2 - 6 } Essência valor & Baixa & & Média & Alta & Total \\
\hline Abordagem do Custo & 4 & 1 & 1 & 6 \\
Abordagem da Concorrência & 3 & 1 & 5 & 9 \\
Abordagem do Valor & 1 & 2 & 18 & 21 \\
\hline Total & $\mathbf{8}$ & $\mathbf{4}$ & $\mathbf{2 4}$ & $\mathbf{3 6}$ \\
& Fonte: produção do autor
\end{tabular}

A partir da utilização do pacote “ANACOR” (Leeuw \& Mair, 2009) do programa $R$ Studio, foi gerado o mapa perceptual da relação entre as abordagens de preço e a essência valor. Percebe-se que a utilização da abordagem do valor está relacionada com essência valor alta, a abordagem da concorrência está relacionada com essência valor média e a abordagem dos custos está relacionada com essência valor baixa.

Gráfico 24 - Mapa perceptual: abordagem de preço e essência valor

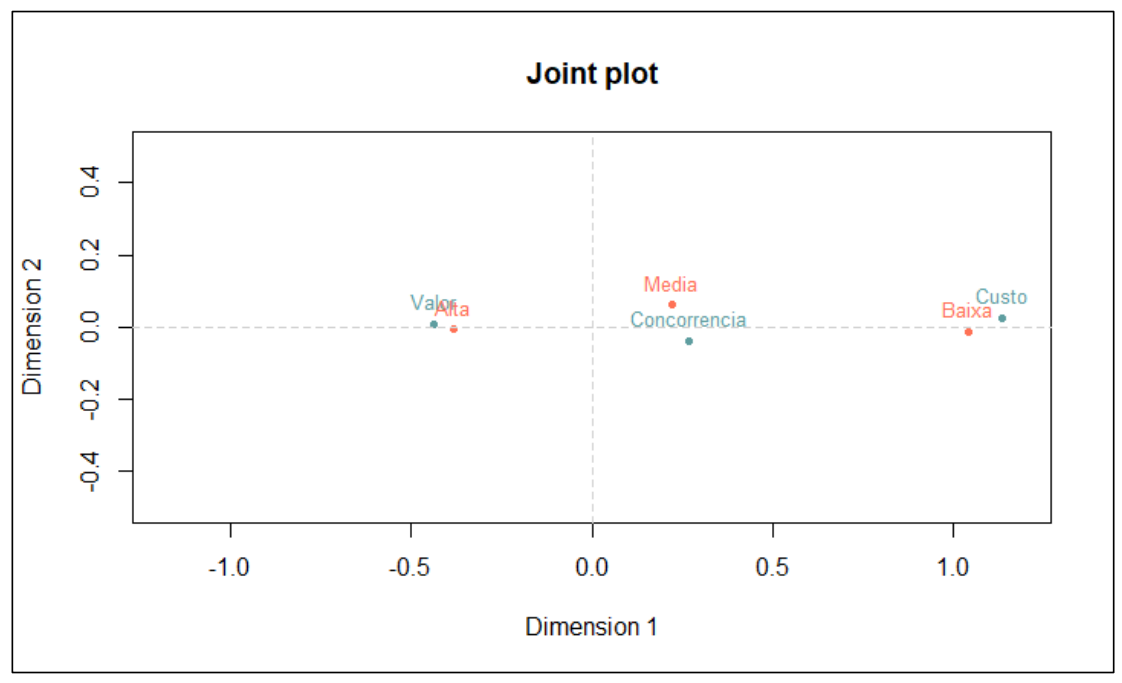

Fonte: produção do autor a partir do pacote ANACOR utilizado no programa R Studio 
Adicionalmente, foi investigada a relação entre as abordagens de preço e a essência custos. Primeiramente foi realizado o teste Qui-Quadrado para testar a hipótese nula de independência das variáveis, que foi rejeitada com p-valor de 0,0174 e valor 11,9930.

A partir da utilização do pacote "ANACOR" (Leeuw \& Mair, 2009) do programa $R$ Studio, foi gerado o mapa perceptual da relação entre as abordagens de preço e a essência custo. Percebe-se que a utilização da abordagem do valor está relacionada com essência custo baixa, assim como está relacionada com essência valor alta.

Gráfico 25 - Mapa perceptual: abordagem de preço e essência custo

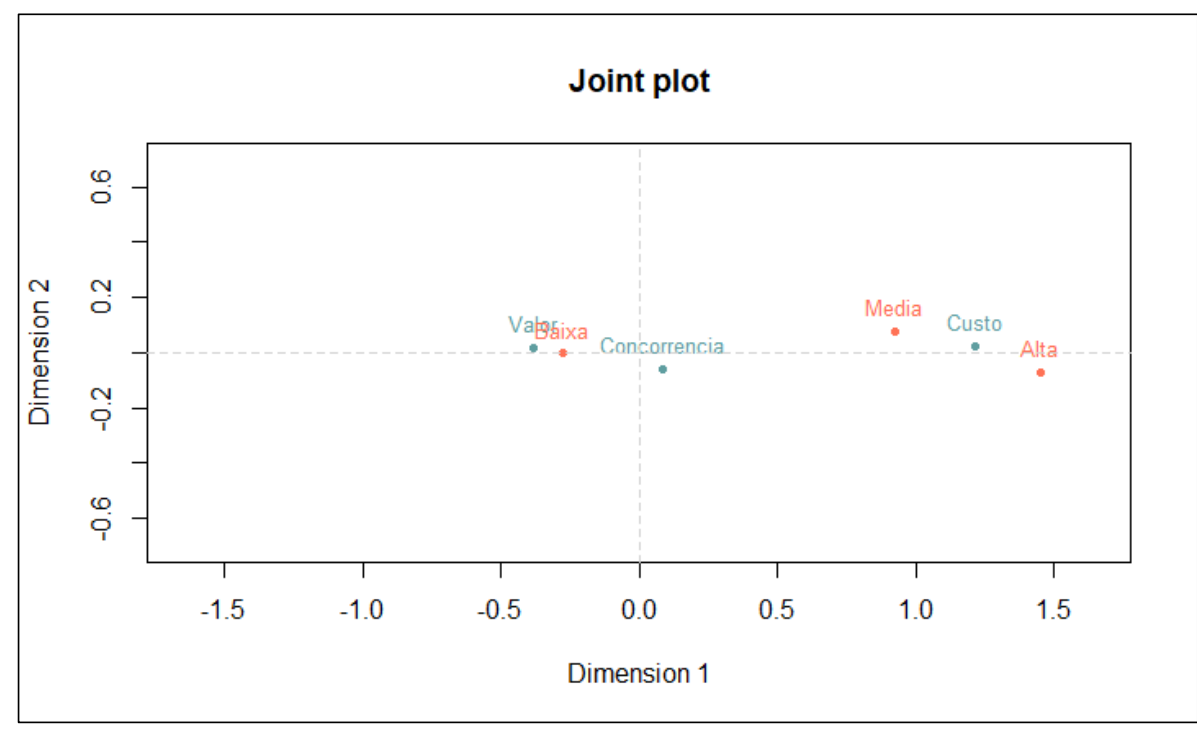

Fonte: produção do autor a partir do pacote ANACOR utilizado no programa R Studio

Em relação à facilidade de acesso aos preços dos concorrentes, pode-se observar na tabela a seguir que as empresas que adotam a abordagem do valor apresentam a menor facilidade dentre todas as abordagens.

Tabela 23 - Relação entre facilidade de acesso aos preços da concorrência e abordagens de formação do preço de venda

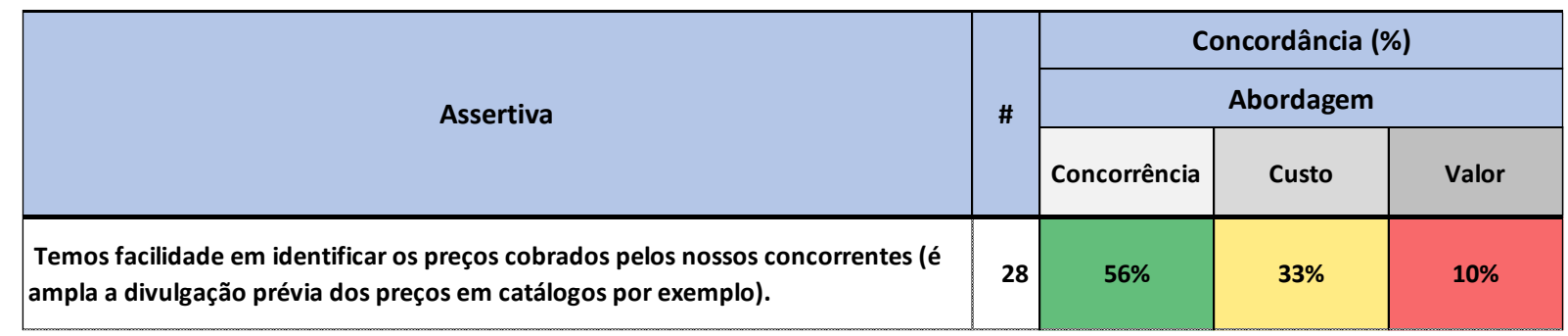

Fonte: produção do autor a partir do pacote ANACOR utilizado no programa R Studio 
Em resumo, observa-se que a abordagem do custo é a forma do estabelecimento do preço escolhida por $86 \%$ da amostra, resultado condizente com pesquisas empíricas anteriores. Entretanto, releva enfatizar que, apesar da fórmula matemática utilizar dados de custos para o cálculo de preços, o uso da fórmula não indica, necessariamente, a adoção da abordagem de custos para determinação do preço de venda. Uma análise mais rigorosa permite dizer que uma parte significativa das empresas que utilizam a forma baseada em custos utiliza margens diferentes em função das características de seus produtos e de seus clientes na determinação do preço de venda; prática condizente com a abordagem do valor. Dessa maneira, há indícios suficientes para afirmar que a forma custo-mais-margem não é necessariamente conflitante com a abordagem do valor.

Com o apoio dos constructos essência custos e essência valor, conclui-se que a abordagem do valor é utilizada por $58 \%$ da amostra. A análise de correspondência identificou a relação entre a abordagem do valor e a alta essência valor, assim como identificou a relação entre esta abordagem e a baixa essência custo. Além disso, a baixa facilidade de acessar dados de preço da concorrência também foi relacionada com a abordagem do valor.

Releva informar que a análise de correspondência entre a abordagem e o comportamento de preço não pode ser realizada em função do teste Qui-Quadrado não rejeitar a hipótese nula de independência das variáveis, com p-valor de 0,6464. Adicionalmente foi realizado o teste não paramétrico de Fisher com a mesma hipótese nula que resultou em um p-valor de 0,7019, também insuficiente para rejeitar a hipótese nula de independência das variáveis.

Em função das evidências apresentadas, não é possível aceitar a Hipótese 1 de que a escolha da abordagem do valor está associada ao comportamento de formadores de preço.

\subsection{ESTRUTURA ORGANIZACIONAL DE PREÇOS}

A estrutura organizacional de preços é analisada através de quatro indicadores, cujos resultados serão expostos a seguir. O primeiro indicador avaliado é o da formalização, que pode ser definido pela extensão pela qual regras formais e procedimentos padrões permeiam o processo de determinação do preço de venda (Burkert et al., 2017). As estatísticas descritivas relacionadas a este indicador estão demonstradas na tabela a seguir. 
Tabela 24 - Estatística descritiva: Formalização

\begin{tabular}{|c|c|c|c|c|c|c|c|c|c|c|}
\hline \multirow{2}{*}{ Assertiva } & \multirow{2}{*}{$\#$} & \multicolumn{2}{|c|}{ Concordância } & \multicolumn{5}{|c|}{ Frequência Absoluta e (Relativa) das Respostas } & \multirow{2}{*}{ Mediana } & \multirow{2}{*}{ Moda } \\
\hline & & $\begin{array}{c}\text { Não } \\
\text { Concorda }\end{array}$ & Concorda & 1 & 2 & 3 & 4 & 5 & & \\
\hline $\begin{array}{l}\text { A responsabilidade pelas decisões de preços foi } \\
\text { claramente atribuída aos indivíduos } \\
\text { organizacionais em nossa empresa. }\end{array}$ & 1 & $3 \%$ & $92 \%$ & $0(0,0 \%)$ & $1(2,8 \%)$ & $2(5,6 \%)$ & $13(36,1 \%)$ & $20(55,6 \%)$ & 5 & 5 \\
\hline $\begin{array}{l}\text { Dentro da nossa organização, os canais formais de } \\
\text { comunicação interna são seguidos quando se } \\
\text { trabalha em preços. }\end{array}$ & 2 & $0 \%$ & $78 \%$ & $0(0,0 \%)$ & $0(0,0 \%)$ & $8(22,2 \%)$ & $10(27,8 \%)$ & $18(50,0 \%)$ & 5 & 5 \\
\hline $\begin{array}{l}\text { Em nossa empresa, o raciocínio para as decisões } \\
\text { de preços está bem documentado e arquivado } \\
\text { para referência futura }\end{array}$ & 3 & $17 \%$ & $64 \%$ & $2(5,6 \%)$ & $4(11,1 \%)$ & $7(19,4 \%)$ & $9(25,0 \%)$ & $14(38,9 \%)$ & 4 & 5 \\
\hline $\begin{array}{l}\text { Para coordenar as partes de nossa organização } \\
\text { que trabalham em preços, procedimentos } \\
\text { operacionais padrão foram estabelecidos. }\end{array}$ & 4 & $11 \%$ & $67 \%$ & $2(5,6 \%)$ & $2(5,6 \%)$ & $8(22,2 \%)$ & $11(30,6 \%)$ & $13(36,1 \%)$ & 4 & 5 \\
\hline
\end{tabular}

Fonte: produção do autor

A amostra possuiu elevado grau de formalização, com modas iguais a 5 pontos e medianas variando entre 4 e 5 pontos nas assertivas deste constructo. Entretanto, verifica-se que a frequência de respostas positivas entre as empresas que utilizam a abordagem do valor é significativamente maior em relação às demais.

Tabela 25 - Relação entre formalização e abordagens de formação do preço de venda

\begin{tabular}{|c|c|c|c|c|}
\hline \multirow{3}{*}{ Assertiva } & \multirow{3}{*}{$\#$} & \multicolumn{3}{|c|}{ Concordância (\%) } \\
\hline & & \multicolumn{3}{|c|}{ Abordagem } \\
\hline & & Concorrência & Custo & Valor \\
\hline $\begin{array}{l}\text { A responsabilidade pelas decisões de preços foi claramente atribuída aos } \\
\text { indivíduos organizacionais em nossa empresa. }\end{array}$ & 1 & $89 \%$ & $83 \%$ & $95 \%$ \\
\hline $\begin{array}{l}\text { Dentro da nossa organização, os canais formais de comunicação interna são } \\
\text { seguidos quando se trabalha em preços. }\end{array}$ & 2 & $67 \%$ & $83 \%$ & $81 \%$ \\
\hline $\begin{array}{l}\text { Em nossa empresa, o raciocínio para as decisões de preços está bem } \\
\text { documentado e arquivado para referência futura }\end{array}$ & 3 & $44 \%$ & $50 \%$ & $76 \%$ \\
\hline $\begin{array}{l}\text { Para coordenar as partes de nossa organização que trabalham em preços, } \\
\text { procedimentos operacionais padrão foram estabelecidos. }\end{array}$ & 4 & $56 \%$ & $67 \%$ & $71 \%$ \\
\hline
\end{tabular}

Fonte: produção do autor

Quando se compara a formalização entre tomadores e formadores de preços, observa-se que estes apresentam maior grau de formalização em relação aqueles em quase todas as assertivas, conforme pode ser conferido na tabela a seguir. 
Tabela 26 - Relação entre formalização e comportamento de preços

\begin{tabular}{|l|r|}
\hline \multicolumn{1}{|c|}{ Assertiva } & $\#$ \\
\hline $\begin{array}{l}\text { A responsabilidade pelas decisões de preços foi claramente atribuída aos } \\
\text { indivíduos organizacionais em nossa empresa. }\end{array}$ & 1 \\
\hline $\begin{array}{l}\text { Dentro da nossa organização, os canais formais de comunicação interna são } \\
\text { seguidos quando se trabalha em preços. }\end{array}$ & $\mathbf{2}$ \\
\hline $\begin{array}{l}\text { Em nossa empresa, o raciocínio para as decisões de preços está bem } \\
\text { documentado e arquivado para referência futura }\end{array}$ & $\mathbf{3}$ \\
\hline $\begin{array}{l}\text { Para coordenar as partes de nossa organização que trabalham em preços, } \\
\text { procedimentos operacionais padrão foram estabelecidos. }\end{array}$ & $\mathbf{4}$ \\
\hline
\end{tabular}

\begin{tabular}{|c|c|c|c|}
\hline \multicolumn{2}{|c|}{ Discordância (\%) } & \multicolumn{2}{c|}{ Concordância (\%) } \\
\hline \multicolumn{2}{|c|}{ Comportamento } & \multicolumn{2}{c|}{ Comportamento } \\
\hline Formador & Tomador & Formador & Tomador \\
\hline $11 \%$ & $0 \%$ & $89 \%$ & $100 \%$ \\
\hline $0 \%$ & $0 \%$ & $89 \%$ & $50 \%$ \\
\hline $11 \%$ & $17 \%$ & $67 \%$ & $50 \%$ \\
\hline $11 \%$ & $17 \%$ & $67 \%$ & $33 \%$ \\
\hline
\end{tabular}

Fonte: produção do autor

O indicador cooperação procura identificar em que medida os atores envolvidos no processo de precificação colaboram mutuamente a fim de atingir o objetivo de preço (Burkert et al., 2017). As estatísticas descritivas relacionadas a este indicador estão demonstradas na tabela a seguir.

Tabela 27 - Estatística descritiva: Cooperação

\begin{tabular}{|c|c|c|c|c|c|c|c|c|c|c|}
\hline \multirow{3}{*}{ Assertiva } & \multirow{3}{*}{$\#$} & \multicolumn{5}{|c|}{1 - > Discordo totalmente } & \multicolumn{4}{|c|}{5 -> Concordo totalmente } \\
\hline & & \multicolumn{2}{|c|}{ Concordância } & \multicolumn{5}{|c|}{ Frequência Absoluta e (Relativa) das Respostas } & \multirow{2}{*}{ Mediana } & \multirow{2}{*}{ Moda } \\
\hline & & $\begin{array}{c}\text { Não } \\
\text { Concorda }\end{array}$ & Concorda & 1 & 2 & 3 & 4 & 5 & & \\
\hline $\begin{array}{l}\text { Na gestão de preços, os departamentos } \\
\text { envolvidos colaboram sem atrito. }\end{array}$ & 6 & $8 \%$ & $67 \%$ & $0(0,0 \%)$ & $3(8,3 \%)$ & $9(25,0 \%)$ & $15(41,7 \%)$ & $9(25,0 \%)$ & 4 & 4 \\
\hline $\begin{array}{l}\text { Na gestão de preços, os departamentos agem em } \\
\text { conjunto. }\end{array}$ & 7 & $3 \%$ & $78 \%$ & $0(0,0 \%)$ & $1(2,8 \%)$ & $7(19,4 \%)$ & $13(36,1 \%)$ & $15(41,7 \%)$ & 4 & 5 \\
\hline $\begin{array}{l}\text { Na gestão de preços, os departamentos têm } \\
\text { poucos problemas na sua cooperação. }\end{array}$ & 8 & $3 \%$ & $67 \%$ & $1(2,8 \%)$ & $0(0,0 \%)$ & $11(30,6 \%)$ & $15(41,7 \%)$ & $9(25,0 \%)$ & 4 & 4 \\
\hline $\begin{array}{l}\text { Na gestão de preços, os departamentos } \\
\text { envolvidos atingem os seus objetivos comuns. }\end{array}$ & 9 & $3 \%$ & $75 \%$ & $0(0,0 \%)$ & $1(2,8 \%)$ & $8(22,2 \%)$ & $16(44,4 \%)$ & $11(30,6 \%)$ & 4 & 4 \\
\hline $\begin{array}{l}\text { Na gestão de preços, os departamentos } \\
\text { envolvidos confiam um no outro. }\end{array}$ & 10 & $3 \%$ & $86 \%$ & $1(2,8 \%)$ & $0(0,0 \%)$ & $4(11,1 \%)$ & $14(38,9 \%)$ & $17(47,2 \%)$ & 4 & 5 \\
\hline
\end{tabular}

Fonte: produção do autor

A amostra possuiu alto grau de cooperação, com modas e medianas variando entre 4 e 5 pontos na escala Likert. Entretanto, verifica-se que a frequência de respostas positivas entre as empresas que utilizam a abordagem do custo é significativamente maior em relação às demais. 
Tabela 28 - Relação entre cooperação e abordagens de formação do preço de venda

\begin{tabular}{|c|c|c|c|c|}
\hline \multirow{3}{*}{ Assertiva } & \multirow{3}{*}{ \# } & \multicolumn{3}{|c|}{ Concordância (\%) } \\
\hline & & \multicolumn{3}{|c|}{ Abordagem } \\
\hline & & Concorrência & Custo & Valor \\
\hline Na gestão de preços, os departamentos envolvidos colaboram sem atrito. & 6 & $67 \%$ & $83 \%$ & $62 \%$ \\
\hline Na gestão de preços, os departamentos agem em conjunto. & 7 & $78 \%$ & $83 \%$ & $76 \%$ \\
\hline $\begin{array}{l}\text { Na gestão de preços, os departamentos têm poucos problemas na sua } \\
\text { cooperação. }\end{array}$ & 8 & $56 \%$ & $83 \%$ & $67 \%$ \\
\hline $\begin{array}{l}\text { Na gestão de preços, os departamentos envolvidos atingem os seus objetivos } \\
\text { comuns. }\end{array}$ & 9 & $78 \%$ & $100 \%$ & $67 \%$ \\
\hline Na gestão de preços, os departamentos envolvidos confiam um no outro. & 10 & $78 \%$ & $83 \%$ & $90 \%$ \\
\hline
\end{tabular}

Fonte: produção do autor

Quando se compara a cooperação entre tomadores e formadores de preços, observa-se que estes apresentam significativamente maior cooperação em relação àqueles em todas as assertivas, conforme pode ser conferido na tabela a seguir.

Tabela 29 - Relação entre cooperação e comportamento de preços

\begin{tabular}{|l|c|}
\hline \multicolumn{1}{|c|}{ Assertiva } & $\#$ \\
\hline Na gestão de preços, os departamentos envolvidos colaboram sem atrito. & 6 \\
\hline Na gestão de preços, os departamentos agem em conjunto. & 7 \\
\hline $\begin{array}{l}\text { Na gestão de preços, os departamentos têm poucos problemas na sua } \\
\text { cooperação. }\end{array}$ & 8 \\
\hline $\begin{array}{l}\text { Na gestão de preços, os departamentos envolvidos atingem os seus objetivos } \\
\text { comuns. }\end{array}$ & 9 \\
\hline Na gestão de preços, os departamentos envolvidos confiam um no outro. & 10 \\
\hline
\end{tabular}

\begin{tabular}{|c|c|c|c|}
\hline \multicolumn{2}{|c|}{ Discordância (\%) } & \multicolumn{2}{c|}{ Concordância (\%) } \\
\hline \multicolumn{2}{|c|}{ Comportamento } & \multicolumn{2}{c|}{ Comportamento } \\
\hline Formador & Tomador & Formador & Tomador \\
\hline $0 \%$ & $0 \%$ & $78 \%$ & $33 \%$ \\
\hline $11 \%$ & $0 \%$ & $89 \%$ & $50 \%$ \\
\hline $0 \%$ & $17 \%$ & $78 \%$ & $33 \%$ \\
\hline $11 \%$ & $0 \%$ & $78 \%$ & $17 \%$ \\
\hline $0 \%$ & $17 \%$ & $100 \%$ & $67 \%$ \\
\hline
\end{tabular}

Fonte: produção do autor

O indicador especialização procura identificar em que medida há profissionais dedicados exclusivamente à precificação (Burkert et al., 2017). As estatísticas descritivas relacionadas a este indicador estão demonstradas na tabela a seguir. 
Tabela 30 - Estatística descritiva: Especialização

\begin{tabular}{|c|c|c|c|c|c|c|c|c|c|c|}
\hline \multirow{3}{*}{ Assertiva } & \multirow{3}{*}{$\#$} & \multicolumn{5}{|c|}{ 1-> Discordo totalmente } & \multicolumn{4}{|c|}{5 -> Concordo totalmente } \\
\hline & & \multicolumn{2}{|c|}{ Concordância } & \multicolumn{5}{|c|}{ Frequência Absoluta e (Relativa) das Respostas } & \multirow{2}{*}{ Mediana } & \multirow{2}{*}{ Moda } \\
\hline & & $\begin{array}{c}\text { Não } \\
\text { Concorda }\end{array}$ & Concorda & 1 & 2 & 3 & 4 & 5 & & \\
\hline $\begin{array}{l}\text { Na nossa organização há "especialistas em preços" } \\
\text { que direcionam seus esforços para a gestão de } \\
\text { preços. }\end{array}$ & 11 & $22 \%$ & $50 \%$ & $4(11,1 \%)$ & $4(11,1 \%)$ & $10(27,8 \%)$ & $6(16,7 \%)$ & $12(33,3 \%)$ & 4 & 5 \\
\hline $\begin{array}{l}\text { Há treinamentos padronizados para cargos que } \\
\text { envolvem atividades de preços. }\end{array}$ & 12 & $56 \%$ & $25 \%$ & $7(19,4 \%)$ & $13(36,1 \%)$ & $7(19,4 \%)$ & $4(11,1 \%)$ & $5(13,9 \%)$ & 2 & 2 \\
\hline $\begin{array}{l}\text { Há descrição escrita das atividades, funções e } \\
\text { objetivos esperados dos especialistas de preços. }\end{array}$ & 13 & $47 \%$ & $31 \%$ & $8(22,2 \%)$ & $9(25,0 \%)$ & $8(22,2 \%)$ & $6(16,7 \%)$ & $5(13,9 \%)$ & 3 & 2 \\
\hline
\end{tabular}

Fonte: produção do autor

Cerca de 50\% das empresas possuem especialistas em preços; entretanto, observa-se que $25 \%$ oferecem treinamentos padronizados e $31 \%$ mantêm descrição formal das atividades, funções e objetivos esperados dos especialistas de preço. Observa-se que as empresas que adotam a abordagem da concorrência apresentam a menor existência de treinamentos padronizados.

Tabela 31 - Relação entre especialização e abordagens de formação do preço de venda

\begin{tabular}{|c|c|c|c|c|}
\hline \multirow{3}{*}{ Assertiva } & \multirow{3}{*}{ \# } & \multicolumn{3}{|c|}{ Concordância (\%) } \\
\hline & & \multicolumn{3}{|c|}{ Abordagem } \\
\hline & & Concorrência & Custo & Valor \\
\hline $\begin{array}{l}\text { Na nossa organização há "especialistas em preços" que direcionam seus esforços } \\
\text { para a gestão de preços. }\end{array}$ & 11 & $56 \%$ & $50 \%$ & $48 \%$ \\
\hline Há treinamentos padronizados para cargos que envolvem atividades de preços. & 12 & $11 \%$ & $33 \%$ & $29 \%$ \\
\hline $\begin{array}{l}\text { Há descrição escrita das atividades, funções e objetivos esperados dos } \\
\text { especialistas de preços. }\end{array}$ & 13 & $33 \%$ & $33 \%$ & $29 \%$ \\
\hline
\end{tabular}

Fonte: produção do autor

Quando se analisa a relação de especialização com faturamento, observa-se que há maior frequência de concordância entre as empresas com faturamento acima de R \$ 500 milhões. A mesma análise feita pelo porte, indica haver maior especialização entre as empresas com mais de 500 funcionários. 
Tabela 32 - Relação entre especialização e faturamento

\begin{tabular}{|c|c|c|c|c|c|}
\hline Faturamento & $\#$ & $\begin{array}{l}\text { Menos de } \mathbf{R} \$ \\
250 \text { milhões }\end{array}$ & $\begin{array}{c}\text { Entre R\$ } 250 \text { e } \\
\text { R\$ } 499 \\
\text { milhões }\end{array}$ & $\begin{array}{c}\text { Entre R\$ } 500 \text { e } \\
\text { R\$ } 999 \\
\text { milhões }\end{array}$ & $\begin{array}{l}\text { Mais de R\$ } 1 \\
\text { bilhão }\end{array}$ \\
\hline $\begin{array}{l}\text { Na nossa organização há "especialistas em preços" que } \\
\text { direcionam seus esforços para a gestão de preços. }\end{array}$ & 11 & $42 \%$ & $50 \%$ & $100 \%$ & $75 \%$ \\
\hline $\begin{array}{l}\text { Há treinamentos padronizados para cargos que envolvem } \\
\text { atividades de preços. }\end{array}$ & 12 & $15 \%$ & $25 \%$ & $100 \%$ & $50 \%$ \\
\hline $\begin{array}{l}\text { Há descrição escrita das atividades, funções e objetivos } \\
\text { esperados dos especialistas de preços. }\end{array}$ & 13 & $23 \%$ & $25 \%$ & $100 \%$ & $50 \%$ \\
\hline
\end{tabular}

Fonte: produção do autor

Tabela 33 - Relação entre especialização e quantidade de funcionários

\begin{tabular}{|c|c|c|c|c|c|}
\hline Quantidade de Funcionários & $\#$ & Menos de 20 & Entre 20 e 99 & $\begin{array}{c}\text { Entre } 100 \text { e } \\
499\end{array}$ & Mais de 500 \\
\hline $\begin{array}{l}\text { Na nossa organização há "especialistas em preços" que } \\
\text { direcionam seus esforços para a gestão de preços. }\end{array}$ & 11 & $33 \%$ & $40 \%$ & $50 \%$ & $67 \%$ \\
\hline $\begin{array}{l}\text { Há treinamentos padronizados para cargos que envolvem } \\
\text { atividades de preços. }\end{array}$ & 12 & $33 \%$ & $20 \%$ & $14 \%$ & $44 \%$ \\
\hline $\begin{array}{l}\text { Há descrição escrita das atividades, funções e objetivos } \\
\text { esperados dos especialistas de preços. }\end{array}$ & 13 & $33 \%$ & $20 \%$ & $29 \%$ & $44 \%$ \\
\hline
\end{tabular}

Fonte: produção do autor

Quando se compara a cooperação entre tomadores e formadores de preços, observa-se que estes apresentam significativamente maior cooperação em relação àqueles em todas as assertivas, conforme pode ser conferido na tabela a seguir.

Tabela 34 - Relação entre especialização e comportamento de preços

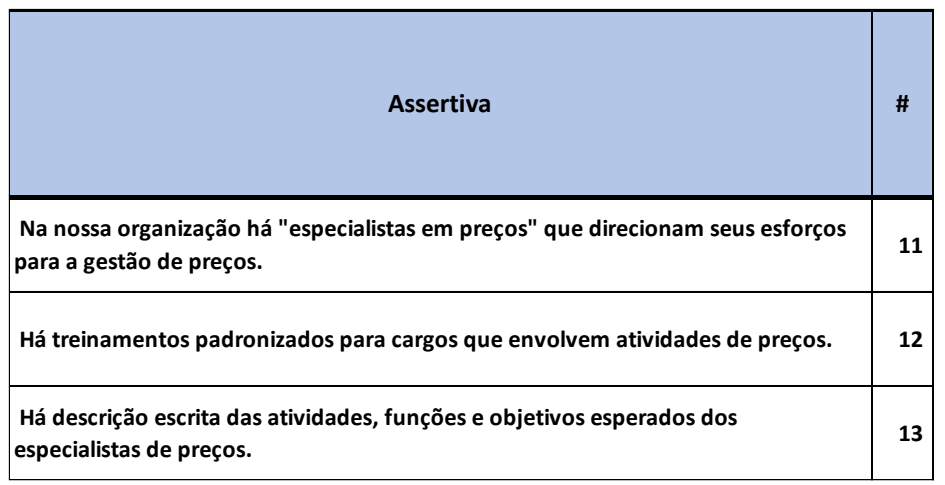

\begin{tabular}{|c|c|c|c|}
\hline \multicolumn{2}{|c|}{ Discordância (\%) } & \multicolumn{2}{c|}{ Concordância (\%) } \\
\hline \multicolumn{2}{|c|}{ Comportamento } & \multicolumn{2}{c|}{ Comportamento } \\
\hline Formador & Tomador & Formador & Tomador \\
\hline $22 \%$ & $17 \%$ & $44 \%$ & $17 \%$ \\
\hline $56 \%$ & $50 \%$ & $33 \%$ & $17 \%$ \\
\hline $44 \%$ & $50 \%$ & $22 \%$ & $17 \%$ \\
\hline
\end{tabular}

Fonte: produção do autor

O indicador "envolvimento da alta gerência" procura identificar o desenvolvimento da cultura de preços na organização em razão do envolvimento da alta gerência. É apontado como um direcionador importante para a geração de valor (Burkert et al., 2017; Liozu et al., 2012). As estatísticas descritivas relacionadas a este constructo estão demonstradas na tabela a seguir. 
Tabela 35 - Estatística descritiva: Envolvimento da alta gerência

\begin{tabular}{|c|c|c|c|c|c|c|c|c|c|c|}
\hline \multirow{3}{*}{ Assertiva } & \multirow{3}{*}{$\#$} & \multicolumn{5}{|c|}{ 1-> Discordo totalmente } & \multicolumn{4}{|c|}{5 -> Concordo totalmente } \\
\hline & & \multicolumn{2}{|c|}{ Concordância } & \multicolumn{5}{|c|}{ Frequência Absoluta e (Relativa) das Respostas } & \multirow{2}{*}{ Mediana } & \multirow{2}{*}{ Moda } \\
\hline & & $\begin{array}{c}\text { Não } \\
\text { Concorda }\end{array}$ & Concorda & 1 & 2 & 3 & 4 & 5 & & \\
\hline $\begin{array}{l}\text { Nossa alta gerência considera os esforços para } \\
\text { melhorar a gestão de preços como um valioso } \\
\text { investimento de recursos. }\end{array}$ & 18 & $8 \%$ & $72 \%$ & $3(8,3 \%)$ & $0(0,0 \%)$ & $7(19,4 \%)$ & $11(30,6 \%)$ & $15(41,7 \%)$ & 4 & 5 \\
\hline $\begin{array}{l}\text { Nossa alta gerência considera nossas atividades de } \\
\text { preços como um fator crítico de sucesso. }\end{array}$ & 19 & $8 \%$ & $81 \%$ & $2(5,6 \%)$ & $1(2,8 \%)$ & $4(11,1 \%)$ & $7(19,4 \%)$ & $22(61,1 \%)$ & 5 & 5 \\
\hline $\begin{array}{l}\text { Nossa alta administração pretende aumentar a } \\
\text { conscientização de preços da empresa. }\end{array}$ & 20 & $14 \%$ & $72 \%$ & $2(5,6 \%)$ & $3(8,3 \%)$ & $5(13,9 \%)$ & $8(22,2 \%)$ & $18(50,0 \%)$ & 5 & 5 \\
\hline
\end{tabular}

Fonte: produção do autor

A amostra possuiu alto grau de envolvimento da alta gerência, com medianas variando entre 4 e 5 pontos e modas de 5 pontos na escala Likert. Entretanto, nota-se que os índices referentes à abordagem do valor são significativamente menores do que os demais.

Tabela 36 - Relação entre envolvimento da alta gerência e abordagens de formação do preço de venda

\begin{tabular}{|c|c|c|c|c|}
\hline \multirow{3}{*}{ Assertiva } & \multirow{3}{*}{$\#$} & \multicolumn{3}{|c|}{ Concordância (\%) } \\
\hline & & \multicolumn{3}{|c|}{ Abordagem } \\
\hline & & Concorrência & Custo & Valor \\
\hline $\begin{array}{l}\text { Nossa alta gerência considera os esforços para melhorar a gestão de preços como } \\
\text { um valioso investimento de recursos. }\end{array}$ & 18 & $89 \%$ & $83 \%$ & $62 \%$ \\
\hline $\begin{array}{l}\text { Nossa alta gerência considera nossas atividades de preços como um fator crítico } \\
\text { de sucesso. }\end{array}$ & 19 & $78 \%$ & $100 \%$ & $76 \%$ \\
\hline $\begin{array}{l}\text { Nossa alta administração pretende aumentar a conscientização de preços da } \\
\text { empresa. }\end{array}$ & 20 & $78 \%$ & $83 \%$ & $67 \%$ \\
\hline
\end{tabular}

Fonte: produção do autor

Quando se compara a cooperação entre tomadores e formadores de preços, observa-se que estes apresentam significativamente maior envolvimento da alta gerência em relação àqueles em todas as assertivas, conforme pode ser conferido na tabela a seguir. 
Tabela 37 - Relação entre envolvimento da alta gerência e comportamento de preços

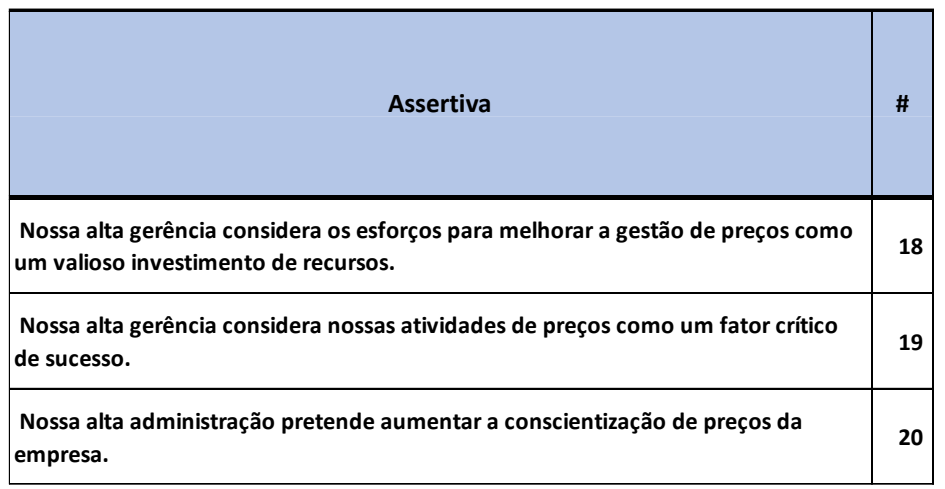

\begin{tabular}{|c|c|c|c|}
\hline \multicolumn{2}{|c|}{ Discordância (\%) } & \multicolumn{2}{c|}{ Concordância (\%) } \\
\hline \multicolumn{2}{|c|}{ Comportamento } & \multicolumn{2}{c|}{ Comportamento } \\
\hline Formador & Tomador & Formador & Tomador \\
\hline $11 \%$ & $17 \%$ & $67 \%$ & $33 \%$ \\
\hline $11 \%$ & $17 \%$ & $78 \%$ & $33 \%$ \\
\hline $22 \%$ & $33 \%$ & $67 \%$ & $33 \%$ \\
\hline
\end{tabular}

Fonte: produção do autor

Apesar da literatura ter se debruçado sobre as vantagens e desvantagens da chamada delegação vertical da autoridade de preço, os resultados são esparsos e conflitantes (Homburg et al., 2012), e sua relação com a abordagem do valor ainda é escassa. Por essa razão, pesquisas empíricas que buscam entender os fatores favoráveis a maior ou menor delegação da autoridade de preços são necessárias (Frenzen et al., 2010). As estatísticas descritivas relacionadas a este constructo estão demonstradas na tabela a seguir.

Tabela 38 - Estatística descritiva: Delegação vertical da autoridade de preços

\begin{tabular}{|c|c|c|c|c|c|c|c|c|c|c|}
\hline \multirow{2}{*}{ Assertiva } & \multirow{2}{*}{ \# } & \multicolumn{2}{|c|}{ Concordância } & \multicolumn{5}{|c|}{ Frequência Absoluta e (Relativa) das Respostas } & \multirow{2}{*}{ Mediana } & \multirow{2}{*}{ Moda } \\
\hline & & $\begin{array}{c}\text { Não } \\
\text { Concorda }\end{array}$ & Concorda & 1 & 2 & 3 & 4 & 5 & & \\
\hline $\begin{array}{l}\text { As decisões importantes de preços devem ser } \\
\text { submetidas a nível hierárquico acima para a } \\
\text { resposta final. }\end{array}$ & 14 & $3 \%$ & $94 \%$ & $0(0,0 \%)$ & $1(2,8 \%)$ & $1(2,8 \%)$ & $8(22,2 \%)$ & $26(72,2 \%)$ & 5 & 5 \\
\hline $\begin{array}{l}\text { Pessoas envolvidas em importantes decisões de } \\
\text { preços têm de perguntar ao seu superior antes de } \\
\text { fazerem quase tudo. }\end{array}$ & 15 & $17 \%$ & $64 \%$ & $2(5,6 \%)$ & $4(11,1 \%)$ & $7(19,4 \%)$ & $13(36,1 \%)$ & $10(27,8 \%)$ & 4 & 4 \\
\hline $\begin{array}{l}\text { Os funcionários que tomam decisões importantes } \\
\text { de preços precisam ter a aprovação do chefe em } \\
\text { primeiro lugar. }\end{array}$ & 16 & $6 \%$ & $67 \%$ & $1(2,8 \%)$ & $1(2,8 \%)$ & $10(27,8 \%)$ & $10(27,8 \%)$ & $14(38,9 \%)$ & 4 & 5 \\
\hline $\begin{array}{l}\text { Os gerentes geralmente tomam decisões } \\
\text { importantes de preços apenas depois de verificá- } \\
\text { los com alguém da equipe de gerencial. }\end{array}$ & 17 & $14 \%$ & $69 \%$ & $2(5,6 \%)$ & $3(8,3 \%)$ & $6(16,7 \%)$ & $16(44,4 \%)$ & $9(25,0 \%)$ & 4 & 4 \\
\hline
\end{tabular}

Fonte: produção do autor

A avaliação das medianas indica que a maior parte da amostra apresenta baixos níveis de delegação das decisões de preço para as camadas hierárquicas mais baixas. Entretanto, notase que as empresas que adotam a abordagem do valor praticam maior nível de delegação do que as empresas que adotam a abordagem da concorrência. 
Tabela 39 - Relação entre delegação vertical da autoridade de preços e abordagens de formação do preço de venda

\begin{tabular}{|c|c|c|c|c|}
\hline \multirow{3}{*}{ Assertiva } & \multirow{3}{*}{$\#$} & \multicolumn{3}{|c|}{ Concordância (\%) } \\
\hline & & \multicolumn{3}{|c|}{ Abordagem } \\
\hline & & Concorrência & Custo & Valor \\
\hline $\begin{array}{l}\text { As decisões importantes de preços devem ser submetidas a nível hierárquico } \\
\text { acima para a resposta final. }\end{array}$ & 14 & $100 \%$ & $100 \%$ & $90 \%$ \\
\hline $\begin{array}{l}\text { Pessoas envolvidas em importantes decisões de preços têm de perguntar ao seu } \\
\text { superior antes de fazerem quase tudo. }\end{array}$ & 15 & $100 \%$ & $67 \%$ & $48 \%$ \\
\hline $\begin{array}{l}\text { Os funcionários que tomam decisões importantes de preços precisam ter a } \\
\text { aprovação do chefe em primeiro lugar. }\end{array}$ & 16 & $100 \%$ & $33 \%$ & $62 \%$ \\
\hline $\begin{array}{l}\text { Os gerentes geralmente tomam decisões importantes de preços apenas depois de } \\
\text { verificá-los com alguém da equipe de gerencial. }\end{array}$ & 17 & $100 \%$ & $33 \%$ & $67 \%$ \\
\hline
\end{tabular}

Fonte: produção do autor

Quando se compara a delegação das decisões de preço entre formadores e tomadores, observa-se que estes não sinalização nenhuma discordância nas assertivas, embora apresentem níveis de concordância semelhantes aos formadores de preço.

Tabela 40 - Relação entre delegação vertical e comportamento de preços

\begin{tabular}{|l|l|}
\hline \multicolumn{1}{|c|}{ Assertiva } & $\#$ \\
\hline $\begin{array}{l}\text { As decisões importantes de preços devem ser submetidas a nível hierárquico } \\
\text { acima para a resposta final. }\end{array}$ & 14 \\
\hline $\begin{array}{l}\text { Pessoas envolvidas em importantes decisões de preços têm de perguntar ao seu } \\
\text { superior antes de fazerem quase tudo. }\end{array}$ & 15 \\
\hline $\begin{array}{l}\text { Os funcionários que tomam decisões importantes de preços precisam ter a } \\
\text { aprovação do chefe em primeiro lugar. }\end{array}$ & 16 \\
\hline $\begin{array}{l}\text { Os gerentes geralmente tomam decisões importantes de preços apenas depois de } \\
\text { verificá-los com alguém da equipe de gerencial. }\end{array}$ & 17 \\
\hline
\end{tabular}

\begin{tabular}{|c|c|c|c|}
\hline \multicolumn{2}{|c|}{ Discordância (\%) } & \multicolumn{2}{c|}{ Concordância (\%) } \\
\hline \multicolumn{2}{|c|}{ Comportamento } & \multicolumn{2}{c|}{ Comportamento } \\
\hline Formador & Tomador & Formador & Tomador \\
\hline $11 \%$ & $0 \%$ & $89 \%$ & $83 \%$ \\
\hline $33 \%$ & $0 \%$ & $44 \%$ & $50 \%$ \\
\hline $11 \%$ & $0 \%$ & $67 \%$ & $33 \%$ \\
\hline $44 \%$ & $0 \%$ & $44 \%$ & $67 \%$ \\
\hline
\end{tabular}

Fonte: produção do autor

Em resumo, há maior formalização entre as empresas que adotam a abordagem do valor, embora haja menor cooperação em comparação com as que adotam a abordagem de custo. Uma possível explicação a ser investigada em pesquisas futuras pode estar na possibilidade de que as empresas que adotam a abordagem de valor tenham conflitos com a equipe de vendas e a equipe de produto, em função dos diferentes níveis de margens entre clientes e entre linhas de 
produto. Fato que não ocorreria entre as empresas que adotam a abordagem de custo, já que as margens por cliente e por produto seriam semelhantes.

Em relação à especialização, há indícios de que as maiores empresas, com faturamento acima de R 500 milhões ou com mais de 500 funcionários, apresentam maiores níveis de especialização, independentemente da abordagem de determinação de preço de venda praticada.

Em relação ao envolvimento da alta gerência, os maiores índices de concordância estão presentes nas empresas que adotam a abordagem do custo. Uma possível explicação a ser investigada em pesquisas futuras pode estar na possibilidade de que as empresas que adotam a abordagem do custo tenham o sentimento de que há maior necessidade de desenvolvimento em relação ao estado atual de maturidade da organização de preços. Ao contrário, as empresas que adotam a abordagem do valor, teriam o sentimento de que há menor necessidade de desenvolvimento por considerarem sua organização de preço suficientemente desenvolvida.

Além disso, nota-se que as empresas que adotam a abordagem do valor praticam maior nível de delegação das decisões de preço para as camadas hierárquicas mais baixas do que as que adotam a abordagem da concorrência.

Face ao exposto, não há evidências suficientes para rejeitar a hipótese 2 deste estudo: As características da organização de preços das empresas que adotam a abordagem do valor são distintas das empresas que adotam as demais abordagens.

Por fim, destaca-se que, nos aspectos organizacionais, os formadores de preço apresentam maior grau de formalização, cooperação, especialização e envolvimento da alta gerência em relação aos tomadores de preço, confirmando assim a hipótese 3 deste estudo. 


\section{CONSIDERAÇÕES FINAIS}

A fim de avaliar como se dá formação do preço de venda com base no valor em empresas formadoras e tomadoras de preço no ambiente B2B brasileiro, esta pesquisa realizou um estudo em determinantes de preço internos e externos de empresas da indústria eletroeletrônica associadas à ABINEE. Entre os determinantes internos, avaliou-se as características das margens utilizadas assim como as características da estrutura organizacional de preços. Entre os externos, avaliou-se as características de empresas formadoras e tomadoras de preço, a intensidade de diferenciação e de competição no mercado.

A coleta de dados foi realizada através de questionário aplicado aos gestores responsáveis pela determinação do preço de venda. Em função da sensibilidade do tema, a taxa de resposta de 13,6\% é considerada adequada, além de ser compatível com estudos anteriores. $\mathrm{O}$ instrumento da pesquisa foi submetido a um pré-teste de validade, além de basear-se no arcabouço teórico pertinente ao tema, partindo de constructos, indicadores e variáveis assemelhadas a outras utilizadas em estudos anteriores. O teste de confiabilidade resultou em um Alpha de Cronbach de 0,86. Análises de correspondências e estatísticas descritivas foram utilizadas como técnicas de análise dos dados.

Em relação ao comportamento de preços, a análise de correspondência evidenciou a maior diferenciação dos produtos e dos serviços oferecidos pelas empresas que se comportam como formadoras de preço, e ao contrário, evidenciou a relação entre a menor diferenciação e o comportamento de tomadores de preço. Já no que se refere à intensidade de competição, os formadores de preço relatam haver mais guerras de promoção no ambiente em que atuam, assim como maior percepção de intensidade de competição. Nos aspectos organizacionais, os formadores de preço apresentam maior grau de formalização, cooperação, especialização, envolvimento da alta gerência em relação aos tomadores de preço, confirmando assim a hipótese 3 deste estudo.

Em relação à facilidade de acesso à informação de preços da concorrência, a análise de correspondência indicou a maior facilidade de acesso em formadores de preço que atuam concomitante nos ambientes B2B e B2C e menor facilidade de acesso em tomadores de preço que atuam exclusivamente no ambiente B2B. A maior facilidade de acesso aos preços das empresas que atuam tanto no ambiente B2B quanto no B2C está condizente com o previsto na literatura, já que bens destinados ao mercado consumidor fatalmente possuem os preços expostos. Já a dificuldade de obtenção da correta informação do preço da concorrência no 
ambiente B2B foi apontada em pesquisas anteriores. A grande quantidade de itens vendáveis e a prática adotada pelo mercado de trabalhar com descontos e rebates sobre a lista de preços, são exemplos das dificuldades encontradas nestas pesquisas.

Em relação à abordagem de determinação do preço de venda, identificou-se que a abordagem do custo é a forma do estabelecimento do preço escolhida por $86 \%$ da amostra, resultado condizente com pesquisas empíricas anteriores. Entretanto, releva enfatizar que apesar da fórmula matemática utilizar dados de custo para o cálculo de preços, o uso da fórmula não indica necessariamente a adoção da abordagem de custos para a determinação do preço de venda. Uma análise mais rigorosa permite dizer que uma parte significativa das empresas que utilizam a forma baseada em custos, utiliza margens diferentes em função das características de seus produtos e de seus clientes na determinação do preço de venda, prática condizentes com a abordagem do valor. Dessa maneira, há indícios suficientes para ratificar que a forma customais-margem não é conflitante com a abordagem do valor.

Com o apoio dos constructos essência custos e essência valor, chega-se ao resultado de que a abordagem do valor é utilizada por $58 \%$ da amostra. A análise de correspondência identificou a relação entre a abordagem do valor e a alta essência valor, assim como identificou a relação entre esta abordagem e a baixa essência custo. A menor facilidade de acessar dados de preço da concorrência foi relacionada com a abordagem do valor.

No aspecto organizacional, percebe-se a existência de maior grau de formalização entre as empresas que adotam a abordagem do valor, embora haja menor cooperação em comparação com as empresas que adotam a abordagem de custo. Uma possível explicação a ser investigada em pesquisas futuras pode estar na possibilidade de que as empresas que adotam a abordagem de valor tenham conflitos com a equipe de vendas e a equipe de produto, em função dos diferentes níveis de margens entre clientes e entre linhas de produto. Fato que não ocorreria entre as empresas que adotam a abordagem de custo, já que as margens por cliente e por produto seriam semelhantes.

Em relação à especialização, há indícios de que as maiores empresas, com faturamento acima de $\mathrm{R} \$ 500$ milhões ou com mais de 500 funcionários, apresentam maiores níveis de especialização, independentemente da abordagem de determinação de preço de venda praticada.

Em relação ao envolvimento da alta gerência, curiosamente os maiores índices de concordância estão presentes nas empresas que adotam a abordagem do custo. Uma possível explicação a ser investigada em pesquisas futuras pode estar na possibilidade de que as empresas que adotam a abordagem do custo tenham o sentimento de que há maior necessidade 
de desenvolvimento em relação ao estado atual de maturidade da organização de preços. Ao contrário, as empresas que adotam a abordagem do valor, teriam o sentimento de que há menor necessidade de desenvolvimento por considerarem sua organização de preço suficientemente desenvolvida.

Além disso, nota-se que as empresas que adotam a abordagem do valor praticam maior nível de delegação das decisões de preço para as camadas hierárquicas significativamente mais baixas do que as empresas que adotam a abordagem da concorrência.

Face ao exposto, não há evidências suficientes para rejeitar a hipótese 2 deste estudo: As características da organização de preços das empresas que adotam a abordagem do valor são distintas das empresas que adotam as demais abordagens.

Releva informar que a análise de correspondência entre a abordagem e o comportamento de preço não pode ser realiza em função do teste Qui-Quadrado não rejeitar a hipótese nula de independência das variáveis, com p-valor de 0,6464. Adicionalmente foi realizado o teste não paramétrico de Fisher com a mesma hipótese nula que resultou em um p-valor de 0,7019, também insuficiente para rejeitar a hipótese nula de independência das variáveis. Em função das evidências apresentadas, não é possível aceitar a Hipótese 1 de que a escolha da abordagem do valor está associada ao comportamento de formadores de preço. 


\section{REFERÊNCIAS BIBLIOGRÁFICAS}

Abratt, R., \& Pitt, L. F. (1985). Pricing practices in two industries. Industrial Marketing Management, 14(4), 301-306. http://doi.org/10.1016/0019-8501(85)90023-9

Albadvi, A., \& Hosseini, M. (2011). Mapping B2B value exchange in marketing relationships: a systematic approach. Journal of Business \& Industrial Marketing, 26(7), 503-513. http://doi.org/10.1108/08858621111162307

Aloini, D., Dulmin, R., \& Mininno, V. (2012). E-reverse auction design: critical variables in a B2B context. Business Process Management Journal, 18(2), 219-249. http://doi.org/10.1108/14637151211225180

Amaral, J. V. (2017). Custos mais margem: A forma ou a essência do estabelecimento dos preços? Universidade de São Paulo. Retrieved from http://www.teses.usp.br/teses/disponiveis/12/12136/tde-14062017-

114043/publico/CorrigidaJuliana.pdf

Anderson, J. C., Jain, D. C., \& Chintagunta, P. K. (1993). Customer Value Assessment in Business Markets: A State-of-Practice Study. Journal of Business-to-Business Marketing, 1(1), 3-29. http://doi.org/10.1300/J033v01n01

Anderson, J. C., \& Wynstra, F. (2010). Purchasing higher-value, higher-price offerings in business markets. Journal of Business-to-Business Marketing, 17(1), 29-61. http://doi.org/10.1080/10517120903000363

Anderson, J., \& Narus, J. (1998). No Business Marketing: Understand What Customers Value Title. Harvard Business Review, 76(6), 53-61. Retrieved from https://hbr.org/1998/11/business-marketing-understand-what-customers-value

Argouslidis, P. C., \& Indounas, K. (2010). Exploring the role of relationship pricing in industrial export settings: Empirical evidence from the UK. Industrial Marketing Management, 39(3), 460-472. http://doi.org/10.1016/j.indmarman.2009.09.001

Armstrong, J. S., \& Overton, T. S. (1977). Estimating Nonresponse Bias in Mail Surveys. Journal of Marketing Research, 14(3), 396. http://doi.org/10.2307/3150783

Arslanagic-Kalajdzic, M., \& Zabkar, V. (2015). The external effect of marketing accountability in business relationships: Exploring the role of customer perceived value. Industrial Marketing Management, 46, 83-97. http://doi.org/10.1016/j.indmarman.2015.03.002

Avlonitis, G. J., \& Indounas, K. (2004). The impact of market structure on pricing objectives of service firms. Journal of Product \& Brand Management, 13(5), 343-358. http://doi.org/10.1108/10610420410554421

Avlonitis, G. J., \& Indounas, K. (2005). Pricing objectives and pricing methods in the services sector. Journal of Services Marketing, 19(1), 47-57. http://doi.org/10.1108/08876040510579398

Avlonitis, G. J., \& Indounas, K. (2006a). How are prices set? An exploratory investigation in the Greek services sector. Journal of Product \& Brand Management, 15(3), 203-213. http://doi.org/10.1108/10610420610668649

Avlonitis, G. J., \& Indounas, K. (2006b). Pricing practices of service organizations. Journal of Services Marketing, 20(5), 346-356. http://doi.org/10.1108/08876040610679954

Avlonitis, G. J., \& Indounas, K. (2007a). An empirical examination of the pricing policies and their antecedents in the services sector. European Journal of Marketing, 41(7/8), 740-764. 
http://doi.org/10.1108/03090560710752384

Avlonitis, G. J., \& Indounas, K. (2007b). Service pricing: An empirical investigation. Journal of Retailing and Consumer Services, 14(1), 83-94. http://doi.org/10.1016/j.jretconser.2006.04.003

Bhardwaj, P. (2001). Delegating Pricing Decisions. Marketing Science, 20(2), 143-169. http://doi.org/10.1287/mksc.1060.0254

Bonoma, T. V. (2006). Major sales: who really does the buying? Harvard Business Review, 84(7-8), 172-181.

Borg, S. W., \& Freytag, P. V. (2012). Helicopter view: an interpersonal relationship sales process framework. Journal of Business \& Industrial Marketing, 27(7), 564-571. http://doi.org/10.1108/08858621211257338

Borg, S. W., \& Young, L. (2014). Continuing the evolution of the selling process: A multi-level perspective. Industrial Marketing Management, 43(4), 543-552. http://doi.org/10.1016/j.indmarman.2014.02.013

Brooksbank, R. (1995). Selling and Sales Management in Action: The New Model of Personal Selling: Micromarketing. Journal of Personal Selling \& Sales Management, 15(2), 61-66.

Burkert, M., Ivens, B. S., Henneberg, S., \& Schradi, P. (2016). Organizing for value appropriation: Configurations and performance outcomes of price management. Industrial Marketing Management. http://doi.org/10.1016/j.indmarman.2016.06.007

Burkert, M., Ivens, B. S., Henneberg, S., \& Schradi, P. (2017). Organizing for value appropriation: Configurations and performance outcomes of price management. Industrial Marketing Management, 61, 194-209. http://doi.org/10.1016/j.indmarman.2016.06.007

Cadogan, J. W., Sundqvist, S., Salminen, R. T., \& Puumalainen, K. (2005). Export marketing, interfunctional interactions, and performance consequences. Journal of the Academy of Marketing Science, 33(4), 520-535. http://doi.org/10.1177/0092070305276148

Calabrese, A., \& De Francesco, F. (2014). A pricing approach for service companies: service blueprint as a tool of demand-based pricing. Business Process Management Journal, 20(6), 906-921. http://doi.org/10.1108/BPMJ-07-2013-0087

Campomar, M. B. (2012). Economias de escala e de escopo na fixação de preços em marketing: estudo de caso no setor bancário. Universidade de São Paulo. Retrieved from www.teses.usp.br/teses/disponiveis/12/12139/tde.../MarceloBarbieriCampomarVC.pdf

Campomar, M. B. (2017). Decisões sobre preço em marketing considerando a influência de impostos: um estudo internacional comparando o Brasil e a Itália. Universidade de São Paulo. Retrieved from www.teses.usp.br/teses/disponiveis/12/12139/tde27112017.../CorrigidoMarcelo.pdf

Carricano, M., Trinquecoste, J.-F., \& Mondejar, J.-A. (2010). The rise of the pricing function: origins and perspectives. Journal of Product \& Brand Management, 19, 468-476. http://doi.org/10.1108/10610421011086883

Collins, M., \& Parsa, H. G. (2006). Pricing strategies to maximize revenues in the lodging industry. International Journal of Hospitality Management, 25(1), 91-107. http://doi.org/10.1016/j.ijhm.2004.12.009

Cooper, D. J., \& Morgan, W. (2008). Case study research in accounting. Accounting Horizons, 22(2), 159-178. http://doi.org/10.2308/acch.2008.22.2.159

Decormier, R. A., \& Jobber, D. (1993). The counselor selling method concepts and constructs. 
Journal of Personal Selling and Sales Management, 13(4), 39-59. http://doi.org/10.1080/08853134.1993.10753966

Diamantopoulos, A., \& Mathews, B. P. (1994). The Specification of Pricing Objectives: Empirical Evidence from an Oligopoly Firm. Managerial \& Decision Economics, 15(1), 73-85. http://doi.org/10.1002/mde.4090150109

Dutta, S., Zbaracki, M. J., \& Bergen, M. (2003). Pricing process as a capability: A resourcebased perspective. Strategic Management Journal, 24(7), 615-630. http://doi.org/10.1002/smj.323

Eggert, A., \& Ulaga, W. (2002). Customer perceived value: a substitute for satisfaction in business markets? Journal of Business \& Industrial Marketing, 17(2/3), 107-118. http://doi.org/10.1108/08858620210419754

Fabiani, S., Druant, M., Hernando, I., Kwapil, C., Landau, B., Loupias, C., ... Stokman, A. C. J. (2005). The Pricing Behaviour of Firms in The Euro Area New Survey Evidence. Ecb, October(535), 49. Retrieved from http://www.ecb.int/pub/pdf/scpwps/ecbwp535.pdf

FIESP. (2017). Panorama da indústria de transformação brasileira. São Paulo. Retrieved from http://az545403.vo.msecnd.net/uploads/2017/11/panorama-da-industria_15a-edicao.pdf

Flint, D. J., \& Woodruff, R. B. (2001). The Initiators of Changes in Customers' Desired Value: Results from a Theory Building Study. Industrial Marketing Management, 30(4), 321337. http://doi.org/10.1016/S0019-8501(99)00117-0

Forbis, J. L., \& Mehta, N. T. (1981). Value-based strategies for industrial products. Business Horizons, 24(3), 32-42. http://doi.org/10.1016/0007-6813(81)90125-7

Forman, H., \& Hunt, J. M. (2005). Managing the influence of internal and external determinants on international industrial pricing strategies. Industrial Marketing Management, 34(2 SPEC. ISS.), 133-146. http://doi.org/10.1016/j.indmarman.2004.07.011

Forman, H., \& Lancioni, R. (2002). The Determinants of Pricing Strategies for Industrial Products in International Markets. Journal of Business-to-Business Marketing, 9(2), 2964. http://doi.org/10.1300/J033v09n02

Fornell, C., Johnson, M. D., Anderson, E. W., \& Bryant, B. E. (1996). The American Customer Satisfaction Index : Nature, Purpose, and Findings The American Customer Satisfaction Index: Nature, Purpose, and. Journal of Marketing, 60(4), 7-18. http://doi.org/10.2307/1251898

Frenzen, H., Hansen, A.-K., Krafft, M., Mantrala, M. K., \& Schmidt, S. (2010). Delegation of pricing authority to the sales force: An agency-theoretic perspective of its determinants and impact on performance. International Journal of Research in Marketing, 27(1), 5868. http://doi.org/10.1016/j.ijresmar.2009.09.006

Garda, R. A. (1991). Use Tactical Pricing to Uncover Hidden Profits. Journal of Business Strategy, 12(5), 17-23. http://doi.org/10.1108/eb039438

Gil, A. C. (2002). Como elaborar projetos de pesquisa (4th ed.). São Paulo: Atlas.

Grewal, D., Monroe, K. B., \& Krishnan, R. (1998). The Effects of Price-Comparison Advertising on Buyers' Perceptions of Acquisition Value, Transaction Value, and Behavioral Intentions. Journal of Marketing, 62(2), 46. http://doi.org/10.2307/1252160

Grönroos, C. (2008). Service logic revisited: who creates value? And who co-creates? European Business Review, 20(4), 298-314. http://doi.org/10.1108/09555340810886585

Guerreiro, R., \& Amaral, J. V. (2018). Cost-based price and value-based price: Are they 
conflicting approaches? Journal of Business \& Industrial Marketing, 30(1), 00-00. http://doi.org/10.1108/JBIM-04-2016-0085

Guilding, C., Drury, C., \& Tayles, M. (2005). An empirical investigation of the importance of cost-plus pricing. Managerial Auditing Journal, 20(2), 125-137. http://doi.org/10.1108/02686900510574548

Gummesson, E. (2004). Return on relationships (ROR): the value of relationship marketing and CRM in business-to-business contexts. Journal of Business \& Industrial Marketing, 19(2), 136-148. http://doi.org/10.1108/08858620410524016

Haas, A., Snehota, I., \& Corsaro, D. (2012). Creating value in business relationships: The role of sales. Industrial Marketing Management, 41(1), 94-105. http://doi.org/10.1016/j.indmarman.2011.11.004

Hair, Jr., J. F., Anderson, R. E., Tathan, R. L., \& Black, W. C. (2005). Análise Multivariada de Dados. Bookman (5th ed.). Porto Alegre: Bookman.

Hallberg, N. L. (2017). The micro-foundations of pricing strategy in industrial markets: A case study in the European packaging industry. Journal of Business Research, 76, 179-188. http://doi.org/10.1016/j.jbusres.2017.01.001

Hansen, A.-K., Joseph, K., \& Krafft, M. (2008). Price Delegation in Sales Organizations: An Empirical Investigation. Business Research, 1(1), 94-104. http://doi.org/10.1007/BF03342704

Hinterhuber, A. (2008a). Customer value-based pricing strategies: why companies resist. Journal of Business Strategy, 29(4), 41-50. http://doi.org/10.1108/02756660810887079

Hinterhuber, A. (2008b). Value delivery and value-based pricing in industrial markets. In Advances in Business Marketing and Purchasing (Vol. 14, pp. 381-448). http://doi.org/10.1016/S1069-0964(08)14011-X

Hinterhuber, A., \& Liozu, S. (2012). Is it time to rethink your pricing strategy? MIT Sloan Management Review, 53(4), 69-77. Retrieved from https://ezproxy.library.bi.no/login?url=http://search.proquest.com/docview/1023762001? accountid=142923\%5Cnhttp://95.172.89.218/bi?url_ver=Z39.88-

2004\&rft_val_fmt=info:ofi/fmt:kev:mtx:journal\&genre=article\&sid=ProQ:ProQ:abiglob al\&atitle=Is+It+Time+to+Rethi

Holbrook, M. B. (Columbia U. (1996). Special Session Summary Customer Value: a Framework For Analysis and Research. Advances in Consumer Research, 23(1), 138-142. Retrieved from http://acrwebsite.org/volumes/7929/volumes/v23/NA-23

Homburg, C., Droll, M., \& Totzek, D. (2008). Customer Prioritization: Does It Pay Off, and How Should It Be Implemented? Journal of Marketing, 72(5), 110-130. http://doi.org/10.1509/jmkg.72.5.110

Homburg, C., \& Jensen, O. (2007). The Thought Worlds of Marketing and Sales: Which Differences Make a Difference? Journal of Marketing, 71(3), 124-142. http://doi.org/10.1509/jmkg.71.3.124

Homburg, C., Jensen, O., \& Hahn, A. (2012). How to Organize Pricing? Vertical Delegation and Horizontal Dispersion of Pricing Authority. Journal of Marketing, 76(5), 49-69. http://doi.org/10.1509/jm.11.0251

Homburg, C., Workman Jr., J. P., \& Jensen, O. (2000). Fundamental Changes in Marketing Organization: The Movement toward a Customer-Focused Organizational Structure. Journal of the Academy of Marketing Science, 28(4), 459-478. 
http://doi.org/10.1177/0092070300284001

Homburg, C., Workman Jr., J. P., \& Krohmer, H. (1999). Marketing's Influence within the Firm. Journal of Marketing, 63(2), 1. http://doi.org/10.2307/1251942

Hornby, W. B., \& Macleod, M. (1996). Pricing behaviour in the Scottish computer industry. Management Decision, 34(6), 31-42. http://doi.org/10.1108/00251749610121461

Howe, W. S. (1978). Industrial Economics. London: Macmillan Education UK. http://doi.org/10.1007/978-1-349-86141-5

Indounas, K. (2008). The relationship between pricing and ethics in two industrial service industries. Journal of Business \& Industrial Marketing, 23(3), 161-169. http://doi.org/10.1108/08858620810858427

Indounas, K. (2009). Successful industrial service pricing. Journal of Business \& Industrial Marketing, 24, 86-97. http://doi.org/10.1108/08858620910931703

Indounas, K., \& Avlonitis, G. J. (2009). Pricing objectives and their antecedents in the services sector. Journal of Service Management, 20(3), 342-374. http://doi.org/http://dx.doi.org/10.1108/09564230910964426

Indounas, K., \& Avlonitis, G. J. (2011). New industrial service pricing strategies and their antecedents: empirical evidence from two industrial sectors. Journal of Business \& Industrial Marketing, 26(1), 26-33. http://doi.org/10.1108/08858621111097184

Indounas, K., \& Roth, S. (2012). Antecedents and consequences of strategic price management: An analysis in the New Zealand industrial service context. Australasian Marketing Journal, 20(2), 113-121. http://doi.org/10.1016/j.ausmj.2011.10.006

Ingenbleek, P. (2007). Value-informed Pricing in Its Organizational Context: Literature Review, Conceptual Framework, and Directions for Future Research. Journal of Product \& Brand Management, 16(7), 441-458. http://doi.org/10.1108/10610420710834904

Ingenbleek, P. T. M. (2007). Value-informed Pricing in Its Organizational Context: Literature Review, Conceptual Framework, and Directions for Future Research. Journal of Product \& Brand Management, 16(7), 441-458. http://doi.org/10.1108/10610420710834904

Ingenbleek, P. T. M., Debruyne, M., Frambach, R. T., \& Verhallen, T. M. M. (2003). Successful new product pricing practices: A contingency approach. Marketing Letters, 14(4), 289305. http://doi.org/10.1023/B:MARK.0000012473.92160.3d

Ingenbleek, P. T. M., \& van der Lans, I. A. (2013). Relating price strategies and price-setting practices. European Journal of Marketing, 47(1/2), 27-48. http://doi.org/10.1108/03090561311285448

Jaworski, B. J., \& Kohli, A. K. (1993). Market Orientation: Antecedents and Consequences. Journal of Marketing. Retrieved from https://bear.warrington.ufl.edu/weitz/mar7786/articles/jaworski and kohli.pdf

Johansson, M., Keränen, J., Hinterhuber, A., Liozu, S., \& Andersson, L. (2015). Value assessment and pricing capabilities--how to profit from value. Journal of Revenue and Pricing Management, 14(3), 178-197. http://doi.org/http://dx.doi.org/10.1057/rpm.2015.8

Keränen, J., \& Jalkala, A. (2014). Three strategies for customer value assessment in business markets. Management Decision, 52(1), 79-100. http://doi.org/10.1108/MD-04-2013-0230

Lakatos, E. M., \& Marconi, M. de A. (1992). Metodologia do trabalho científico: procedimentos básicos, pesquisa bibliográfica, projeto e relatório, publicações e 
trabalhos científicos (4th ed.). São Paulo: Atlas.

Lancioni, R., Schaur, H. J., \& Smith, M. F. (2005). Intraorganizational influences on businessto-business pricing strategies: A political economy perspective. Industrial Marketing Management, $34(2 \quad$ SPEC. $\quad$ ISS.), 123-131. http://doi.org/10.1016/j.indmarman.2004.07.010

Leeuw, J. De, \& Mair, P. (2009). Simple and Canonical Correspondence Analysis Using the R Package anacor. Journal of Statistical Software, 31(5), 1-18.

Levin, I. P., \& Johnson, R. D. (1984). Estimating Using Price-Quality Tradeoffs Using Comparative Judgments. Journal of Consumer Research, 11(1), 593-600. Retrieved from http://www.jstor.org/stable/2489146

Liinamaa, J., Viljanen, M., Hurmerinta, A., Ivanova-Gongne, M., Luotola, H., \& Gustafsson, M. (2016). Performance-based and functional contracting in value-based solution selling. $\begin{array}{llll}\text { Industrial Marketing } \quad \text { Management, } & \text { 37-49, }\end{array}$ http://doi.org/10.1016/j.indmarman.2016.05.032

Liozu, S. M. (2017). Value-based pricing special issue: Editorial. Journal of Revenue and Pricing Management, 16(1), 1-3. http://doi.org/10.1057/s41272-016-0058-9

Liozu, S. M., \& Hinterhuber, A. (2013). Pricing orientation, pricing capabilities, and firm performance. Management Decision, 51(3), 594-614. http://doi.org/10.1108/00251741311309670

Liozu, S. M., Hinterhuber, A., Boland, R., \& Perelli, S. (2012). The conceptualization of valuebased pricing in industrial firms. Journal of Revenue and Pricing Management, 11(1), 1234. http://doi.org/10.1057/rpm.2011.34

Liu, A., Leach, M., \& Chugh, R. (2015). A sales process framework to regain B2B customers. Journal of Business \& Industrial Marketing, 30(8), 906-914. http://doi.org/10.1108/JBIM-02-2014-0026

Lucas, M. . (2003). Pricing decisions and the neoclassical theory of the firm. Management Accounting Research, 14(3), 201-217. http://doi.org/10.1016/S1044-5005(03)00044-1

Marn, M. V, \& Rosiello, R. L. (1992). Managing Price, Gaining Profit. Harvard Business Review, 70(5), 84-93.

Martins, G. de A., \& Theóphilo, C. R. (2009). Metodologia da Investigação Científica para Ciências Sociais Aplicadas (2. ed.). São Paulo: Atlas.

Megliorini, E. (2003). Análise Critica dos Conceitos de Mensuração Utilizados por Empresas Brasileiras Produtoras de Bens de Capital sob Encomenda.

Menon, A., Jaworski, B. J., \& Kohli, A. K. (1997). Product Quality: Impact of Interdepartmental Interactions. Journal of the Academy of Marketing Science, 25(3), 187200. http://doi.org/10.1177/0092070397253001

Moncrief, W. C., \& Marshall, G. W. (2005). The evolution of the seven steps of selling. Industrial Marketing Management, 34(1), 13-22. http://doi.org/10.1016/j.indmarman.2004.06.001

Monroe, K. B. (2003). Pricing: Making Profitable Decisions. New York: McGraw-Hill.

Munnukka, J., \& Järvi, P. (2012). The price-category effect and the formation of customer value of high-tech products. Journal of Consumer Marketing, 29(4), 293-301. http://doi.org/10.1108/07363761211237362

Nagle, T. T., \& Holden, R. K. (2003). Estratégias e táticas de preços: um guia para decisões 
lucrativas. São Paulo: Prentice Hall.

Noble, P. Mi. P. T. and M. P., \& Gruca, T. S. (1999). Industrial Pricing: Theory and Managerial Practice. Marketing Science, 18(3), 435-454. http://doi.org/10.1287/mksc.18.3.435

Olson, E. M., Slater, S. F., \& Hult, G. T. M. (2005). The Performance Implications of Fit Among Business Strategy, Marketing Organization Structure, and Strategic Behavior. Journal of Marketing, 69(3), 49-65. http://doi.org/10.1509/jmkg.69.3.49.66362

Özer, Ö., \& Phillips, R. (2012a). Current Challenges and Future Prospects for Pricing Management. In Ö. Özer \& R. Phillips (Eds.), The Oxford Handbook of Pricing Management (pp. 1-9). Oxford University Press. http://doi.org/10.1093/oxfordhb/9780199543175.013.0035

Özer, Ö., \& Phillips, R. (2012b). Introduction. In R. Ozer, Ozalp; Phillips (Ed.), The Oxford Handbook of Pricing Management (pp. 1-10). Oxford University Press. http://doi.org/DOI: 10.1093/oxfordhb/9780199543175.013.0001

Parasuraman, A. (1997). Reflections on Gaining Competitive Advantage Through Customer Value. Journal of the Academy of Marketing Scienceemy of. http://doi.org/10.1007/BF02894351

Pestana, M. C., Dziabas, M. C. C., Garcia, E. M., Santos, M. F. dos, Nascimento, M. M., \& Cardoso, S. C. (2016). Diretrizes para apresentação de dissertações e teses da USP: parte II (APA). (V. M. B. de O. Funaro, Ed.). Universidade de São Paulo. Sistema Integrado de Bibliotecas. http://doi.org/10.11606/9788573140576

Phillips, R. (2012). Customized Pricing. The Oxford Handbook of Pricing Management. http://doi.org/10.1093/oxfordhb/9780199543175.013.0021

Piercy, N. (2014). Export Strategy: Markets and Competition (RLE Marketing). Routledge. http://doi.org/10.4324/9781315764344

Plank, R. E., \& Dempsey, W. A. (1980). A framework for personal selling to organizations. Industrial Marketing Management, 9(2), 143-149. http://doi.org/10.1016/00198501(80)90021-8

Provines, C. D. (2017). Value-based pricing meets twenty-first century procurement. Journal of Revenue and Pricing Management, 16(1), 4-17. http://doi.org/10.1057/s41272-0170080-6

Rajala, R., Töytäri, P., \& Hervonen, T. (2015). Assessing Customer-Perceived Value in Industrial Service Systems. Service Science, 7(3), 210-226. http://doi.org/10.1287/serv.2015.0108

Ravald, A., \& Grönroos, C. (1996). The value concept and relationship marketing. European Journal of Marketing, 30(2), 19-30. http://doi.org/10.1108/03090569610106626

Roll, O. (2009). Pricing trends from a management perspective. Journal of Revenue and Pricing Management, 8(4), 396-398. http://doi.org/10.1057/rpm.2009.22

Secomandi, N., \& Johnson, J. D. (2007). Operations management and business pricing. Retrieved from http://repository.cmu.edu/tepper/438/\%5Cnpapers3://publication/uuid/E2AF46B24CCC-4FAF-B4A5-3BE0E81BE913

Sharma, A., \& Iyer, G. R. (2011). Are pricing policies an impediment to the success of customer solutions? Industrial Marketing Management, 40(5), 723-729. http://doi.org/10.1016/j.indmarman.2011.06.002 
Shipley, D., \& Jobber, D. (2001). Integrative Pricing via the Pricing Wheel. Industrial Marketing Management, 30(3), 301-314. http://doi.org/10.1016/S0019-8501(99)00098-X

Sizer, J. (1966). The Accountant's contribution to the pricing decision. Journal of Management Studies, 3(2), 131-149.

Skinner, R. C. (1970). The Determination of Selling Prices. He Journal of Industrial Economics, 18(3), 201-217. Retrieved from http://www.jstor.org/stable/2097610

Smith, A. (1776). An Inquiry into the Nature and Causes of the Wealth of Nations (Facsimile). University Of Chicago Press.

Smith, M. (2015). Research Methods in Accounting (3rd ed.). London: SAGE.

Stephenson, P. R., Cron, W. L., \& Frazier, G. L. (1979). Delegating Pricing Authority to the Sales Force: The Effects on Sales and Profit Performance. Journal of Marketing, 43(2), 21. http://doi.org/10.2307/1250738

Storbacka, K., Ryals, L., Davies, I. A., \& Nenonen, S. (2009). The changing role of sales: viewing sales as a strategic, cross-functional process. European Journal of Marketing, 43(7/8), 890-906. http://doi.org/10.1108/03090560910961443

Teetor, P. (2011). R Cookbook: Proven Recipes for Data Analysis, Statistics, and Graphics. O'Reilly Media.

Tellis, G. J., \& Gaeth, G. J. (1990). Best Value, Price-Seeking, and Price Aversion: The Impact of Information and Learning on Consumer Choices. Journal of Marketing, 54(2), 34. http://doi.org/10.2307/1251868

Töytäri, P., Alejandro, T. B., Parvinen, P., Ollila, I., \& Rosendahl, N. (2011). Bridging the theory to application gap in value-based selling. The Journal of Business \& Industrial Marketing, 26(7), 493-502. http://doi.org/http://dx.doi.org/10.1108/08858621111162299

Töytäri, P., Keränen, J., \& Rajala, R. to implementing value-based pricing in industrial markets: A. micro-foundations perspective. (2017). Barriers to implementing value-based pricing in industrial markets: A micro-foundations perspective. Journal of Business Research, 76, 237-246. http://doi.org/http://dx.doi.org/10.1016/j.jbusres.2016.04.183

Töytäri, P., \& Rajala, R. (2015). Value-based selling: An organizational capability perspective. Industrial Marketing Management, 45(1), 101-112. http://doi.org/10.1016/j.indmarman.2015.02.009

Töytäri, P., Rajala, R., \& Alejandro, T. B. (2015). Organizational and institutional barriers to value-based pricing in industrial relationships. Industrial Marketing Management, 47, 5364. http://doi.org/10.1016/j.indmarman.2015.02.005

Ulaga, W., \& Eggert, A. (2005). Relationship Value in Business Markets: The Construct and Its Dimensions. Journal of Business-to-Business Marketing, 12(1), 73-99. http://doi.org/10.1300/J033v12n01_04

Vargo, S. L., \& Lusch, R. F. (2004). Evolving to a New Dominant Logic for Marketing. Journal of Marketing, 68(1), 1-17. http://doi.org/10.1509/jmkg.68.1.1.24036

Varian, H. R. (2012). Microeconomia: uma abordagem moderna (8a ed.). Rio de Janeiro: Campus.

Verhoef, P. C., \& Leeflang, P. S. . (2009). Understanding the Marketing Department's Influence Within the Firm. Journal of Marketing, 73(2), 14-37. http://doi.org/10.1509/jmkg.73.2.14

Vlaar, P. W. L., Van Den Bosch, F. A. J., \& Volberda, H. W. (2006). Coping with problems of understanding in interorganizational relationships: Using formalization as a means to 
make sense. Organization Studies, 27(11), 1617-1638. http://doi.org/10.1177/0170840606068338

Vorhies, D. W., \& Morgan, N. A. (2003). A Configuration Theory Assessment of Marketing Organization Fit with Business Strategy and Its Relationship with Marketing Performance. Journal of Marketing, 67(1), 100-115. http://doi.org/10.1509/jmkg.67.1.100.18588

Weber, T. A. (2012). Price Theory in Economics. In R. Ozer, Ozalp; Phillips (Ed.), The Oxford Handbook of Pricing Management. Oxford University Press. http://doi.org/10.1093/oxfordhb/9780199543175.013.0017

Woodruff, R. B. (1997). Customer Value: The Next Source for Competitive Advantage. Journal of the Academy of Marketing Science, 25(2), 129-153.

Workman, J. P., Homburg, C., \& Jensen, O. (2003). Intraorganizational determinants of key account management effectiveness. Journal of the Academy of Marketing Science, 31(1), 3-21. http://doi.org/10.1177/0092070302238599

Zeithaml, V. A. (1988). Consumer Perceptions of Price, Quality, and Value: A Means-End Model and Synthesis of Evidence. Journal of Marketing, 52(3), 2-22. Retrieved from http://www.jstor.org/stable/1251446 


\section{APÊNCIDE A - E-MAIL CONVITE}

\section{Caro profissional,}

Sua empresa foi selecionada por nossa equipe para participar de um estudo sobre práticas de formação de preços. O estudo está sendo desenvolvido na Faculdade de Economia, Administração e Contabilidade da Universidade de São Paulo (FEA-USP) e leva apenas alguns minutos.

Se o(a) senhor(a) não está envolvido(a) na determinação dos preços, peço a gentileza de encaminhar este e-mail ao profissional da sua empresa que é o principal responsável pelo estabelecimento dos preços.

Ao aceitar participar deste estudo, além de contribuir com a Faculdade de Economia, Administração e Contabilidade da Universidade de São Paulo, você receberá, ao final do projeto, um relatório individualizado dos resultados da pesquisa, assim como uma revisão da literatura de precificação.

Todas as informações fornecidas pelo profissional serão estritamente confidenciais e serão tratadas com a ética e com o rigor dos métodos científicos. É importante seja honesto e sincero ao responder o questionário. Em caso de dúvida ou sugestão entre em contato conosco.

Para participar, basta responder ao questionário em Word anexo a este e-mail para alyson.aires@usp.br, ou se preferir, acesse a versão eletrônica disponível no Google Forms em https://goo.gl/forms/C6B29fpNuJVxNk813.

Contamos com sua participação e antecipadamente agradecemos a colaboração.

Cordialmente,

Prof. Dr. Reinaldo Guerreiro

reiguerr@usp.br

Professor da FEA/USP
Alyson Aires de Souza

alyson.aires@usp.br

Pesquisador da FEA-USP 


\section{APÊNDICE B - QUESTIONÁRIO DA PESQUISA (MODELO WORD)}

\section{Questionário de Pesquisa}

Instruções

- As questões a seguir aplicam-se ao estabelecimento de preços dos produtos do principal seguimento da sua empresa, ou seja, daquele segmento que tem a maior expressividade nos seus negócios.

- As respostas devem espelhar a situação predominante em sua empresa, ou seja, a situação que ocorre com maior frequência.

- Indique com um " $\mathrm{x}$ " nos quadrados correspondes, sendo 1 = Discordo totalmente e $5=$ Concordo totalmente.

\begin{tabular}{|c|c|c|c|c|c|c|}
\hline no & Questões & 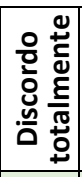 & & & & 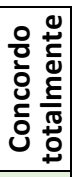 \\
\hline & & 1 & 2 & 3 & 4 & 5 \\
\hline 1 & $\begin{array}{l}\text { A responsabilidade pelas decisões de preços foi claramente } \\
\text { atribuída aos indivíduos organizacionais em nossa empresa. }\end{array}$ & & & & & \\
\hline 2 & $\begin{array}{l}\text { Dentro da nossa organização, os canais formais de comunicação } \\
\text { interna são seguidos quando se trabalha em preços. }\end{array}$ & & & & & \\
\hline 3 & $\begin{array}{l}\text { Em nossa empresa, o raciocínio para as decisões de preços está } \\
\text { bem documentado e arquivado para referência futura }\end{array}$ & & & & & \\
\hline 4 & $\begin{array}{l}\text { Para coordenar as partes de nossa organização que trabalham } \\
\text { em preços, procedimentos operacionais padrão foram } \\
\text { estabelecidos. }\end{array}$ & & & & & \\
\hline & Na gestão de preços, os departamentos envolvidos ... & & & & & \\
\hline 6 & ... colaboram sem atrito. & & & & & \\
\hline 7 & ... agem em conjunto. & & & & & \\
\hline 8 & ... têm poucos problemas na sua cooperação. & & & & & \\
\hline 9 & ... atingem os seus objetivos comuns. & & & & & \\
\hline 10 & ... confiam um no outro. & & & & & \\
\hline 11 & $\begin{array}{l}\text { Na nossa organização há "especialistas em preços" que } \\
\text { direcionam seus esforços para a gestão de preços. }\end{array}$ & & & & & \\
\hline 12 & $\begin{array}{l}\text { Há treinamentos padronizados para cargos que envolvem } \\
\text { atividades de preços. }\end{array}$ & & & & & \\
\hline 13 & $\begin{array}{l}\text { Há descrição das atividades, funções e objetivos esperados dos } \\
\text { especialistas de preço. }\end{array}$ & & & & & \\
\hline 14 & $\begin{array}{l}\text { As decisões importantes de preços devem ser submetidas a } \\
\text { nível hierárquico acima para a resposta final. }\end{array}$ & & & & & \\
\hline 15 & $\begin{array}{l}\text { Pessoas envolvidas em importantes decisões de preços têm de } \\
\text { perguntar ao seu superior antes de fazerem quase tudo. }\end{array}$ & & & & & \\
\hline 16 & $\begin{array}{l}\text { Os funcionários que tomam decisões importantes de preços } \\
\text { precisam ter a aprovação do chefe em primeiro lugar. }\end{array}$ & & & & & \\
\hline 17 & $\begin{array}{l}\text { Os gerentes geralmente tomam decisões importantes de preços } \\
\text { apenas depois de verificá-los com alguém da equipe gerencial. }\end{array}$ & & & & & \\
\hline 18 & $\begin{array}{l}\text { Nossa alta gerência considera os esforços para melhorar a } \\
\text { gestão de preços como um valioso investimento de recursos. }\end{array}$ & & & & & \\
\hline 19 & $\begin{array}{l}\text { Nossa alta gerência considera nossas atividades de preços como } \\
\text { um fator crítico de sucesso. }\end{array}$ & & & & & \\
\hline 20 & $\begin{array}{l}\text { Nossa alta administração pretende aumentar a conscientização } \\
\text { de preços da empresa. }\end{array}$ & & & & & \\
\hline 22 & A concorrência na nossa indústria é intensa. & & & & & \\
\hline 23 & Há muitas "guerras de promoção" em nossa indústria. & & & & & \\
\hline
\end{tabular}

Continua na próxima página... 
Os atributos e funcionalidades dos nossos produtos são

24 diferentes dos atributos e funcionalidades dos produtos dos nossos concorrentes.

25 Qualquer diferencial que um competidor pode oferecer, outros podem oferecer prontamente.

cos produtos são diferentes dos produtos oferecidos pelos nossos concorrentes. Como nossos produtos são diferenciados, não precisamos colocar preços exatamente iguais aos preços dos nossos concorrentes.

Temos facilidade em identificar os preços cobrados pelos nossos

28 concorrentes (é ampla a divulgação prévia dos preços em catálogos por exemplo).

29 concorrentes.

30 No nosso mercado, não é possível estabelecer o preço acima dos praticados pela concorrência.

31 A margem colocada sobre os custos é definida isoladamente pelo departamento financeiro.

32 Todos os nossos produtos têm margens parecidas.

33 Todos os nossos segmentos de clientes têm margens parecidas. A definição da margem independe da consideração de

$34 \begin{aligned} & \text { características específicas dos produtos (por exemplo, } \\ & \text { de produtos simples é similar à margem de produtos }\end{aligned}$ sofisticados)

35 A definição da margem independe da consideração de características específicas dos clientes, como porte e localidade

36 A definição da margem independe da consideração da

36 importância que os clientes veem nos produtos

37 - Indique com um " $x$ " a principal forma de operacionalização do estabelecimento de preços:

$\downarrow \quad$ O preço é estabelecido...

... a partir dos custos mais margem (margem de contribuição ou do lucro).

... a partir dos preços dos concorrentes (+/-) ajustes.

... com base no valor oferecido ao cliente.

... a partir de tentativa e erro.

... de outra forma (não descrita anteriormente).

Digite seu nome (opcional)

38 Indique o e-mail para recebimento do resultado da pesquisa:

daiane.silva@viqua.com.br

Continua na próxima página... 


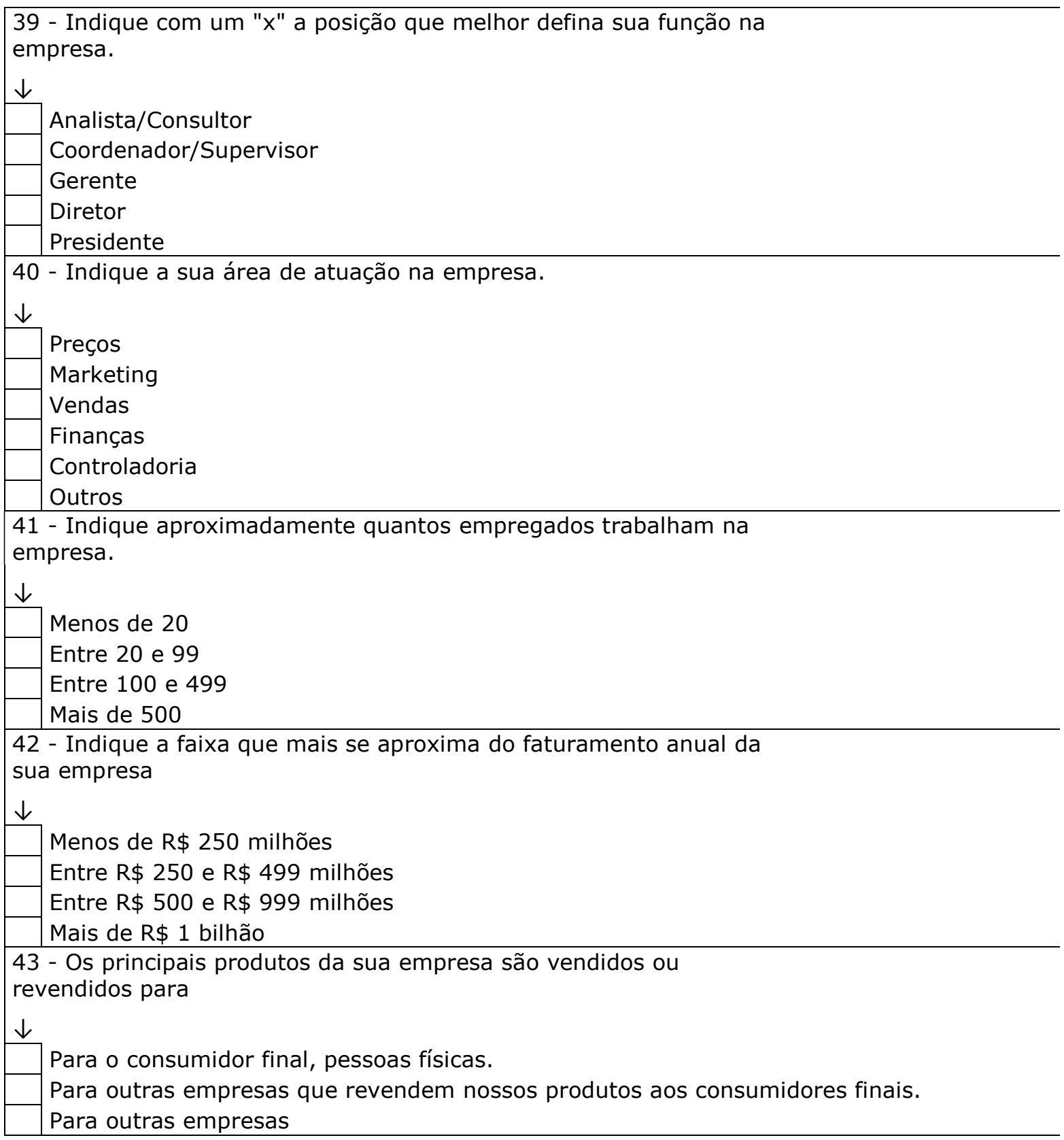

Fim.

Contamos com sua participação e antecipadamente agradecemos a colaboração.

Cordialmente,

Prof Dr. Reinaldo Guerreiro

reiguerr@usp.br

Professor da FEA/USP
Alyson Aires de Souza

alyson.aires@usp.br

Pesquisador da FEA-USP 


\section{APÊNCIDE C - E-MAIL DE AGRADECIMENTO}

Prezado (a)

Obrigado por participar do estudo sobre práticas de formação de preços da Faculdade de Economia, Administração e Contabilidade da Universidade de São Paulo (FEA-USP).

Assim que a coleta e a análise dos dados forem concluídas, encaminharemos um relatório individualizado com a comparação entre as suas respostas e as respostas dominantes na amostra.

Cordialmente,

Prof. Dr. Reinaldo Guerreiro

reiguerr@usp.br

Professor da FEA/USP
Alyson Aires de Souza

alyson.aires@usp.br

Pesquisador da FEA-USP 


\section{APÊNCIDE D - E-MAIL DE ENVIO DO RELATÓRIO INDIVIDUALIZADO}

FEAUSP

\section{Prezado (a)}

Obrigado por participar do estudo sobre práticas de formação de preços da Faculdade de Economia, Administração e Contabilidade da Universidade de São Paulo (FEA-USP).

Como retribuição à sua participação nesta pesquisa, tenho o prazer de encaminhar o relatório individualizado com os resultados desta pesquisa. Nele é possível comparar a sua resposta com a média resultante das respostas das empresas do segmento.

Em caso de qualquer dúvida, não hesite em nos contatar.

Cordialmente,

Prof. Dr. Reinaldo Guerreiro

reiguerr@usp.br

Professor da FEA/USP
Alyson Aires de Souza

alyson.aires@usp.br

Pesquisador da FEA-USP 


\section{APÊNCIDE E - MODELO DO RELATÓRIO INDIVIDUALIZADO}

Resultado Geral por Pergunta

Código da Empresa:

1 - > Discordo totalment

5 -> Concordo totalmente

\begin{tabular}{|c|c|c|c|c|c|c|c|c|c|c|}
\hline \\
\hline Pergunta & Sua resposta & $\begin{array}{l}\text { Respostas } \\
\text { mais } \\
\text { frequentes } \\
\text { da amostra }\end{array}$ & $\begin{array}{l}\text { Não } \\
\text { Concorda }\end{array}$ & Concorda & 1 & 2 & 3 & 4 & 5 & Gráfico \\
\hline $\begin{array}{l}\text { A responsabilidade pelas decisões de preços foi } \\
\text { claramente atribuída aos indivíduos organizacionais em } \\
\text { nossa empresa. }\end{array}$ & 5 & 5 & $7 \%$ & $87 \%$ & $0 \%$ & $7 \%$ & $7 \%$ & $33 \%$ & $53 \%$ & \\
\hline $\begin{array}{l}\text { Dentro da nossa organização, os canais formais de } \\
\text { comunicação interna são seguidos quando se trabalha } \\
\text { em preços. }\end{array}$ & 5 & 5 & $0 \%$ & $67 \%$ & $0 \%$ & $0 \%$ & $33 \%$ & $20 \%$ & $47 \%$ & \\
\hline $\begin{array}{l}\text { Em nossa empresa, o raciocínio para as decisões de } \\
\text { preços está bem documentado e arquivado para } \\
\text { referência futura }\end{array}$ & 1 & 4 & $33 \%$ & $47 \%$ & $7 \%$ & $27 \%$ & $20 \%$ & $27 \%$ & $20 \%$ & \\
\hline $\begin{array}{l}\text { Para coordenar as partes de nossa organização que } \\
\text { trabalham em preços, procedimentos operacionais } \\
\text { padrão foram estabelecidos. }\end{array}$ & 1 & 5 & $20 \%$ & $60 \%$ & $7 \%$ & $13 \%$ & $20 \%$ & $27 \%$ & $33 \%$ & \\
\hline $\begin{array}{l}\text { Em nossa empresa, antes de submeter cotações de } \\
\text { preços, mantemos registros detalhados das políticas e } \\
\text { métodos usados para definir os preços em um } \\
\text { formulário padrão (documento) relativo à decisão de } \\
\text { preço. }\end{array}$ & 1 & 5 & $13 \%$ & $67 \%$ & $7 \%$ & $7 \%$ & $20 \%$ & $27 \%$ & $40 \%$ & \\
\hline $\begin{array}{l}\text { Na gestão de preços, os departamentos envolvidos } \\
\text { colaboram sem atrito. }\end{array}$ & 4 & 4 & $7 \%$ & $53 \%$ & $0 \%$ & $7 \%$ & $40 \%$ & $47 \%$ & $7 \%$ & \\
\hline $\begin{array}{l}\text { Na gestão de preços, os departamentos agem em } \\
\text { conjunto. }\end{array}$ & 4 & 4 & $7 \%$ & $67 \%$ & $0 \%$ & $7 \%$ & $27 \%$ & $40 \%$ & $27 \%$ & \\
\hline $\begin{array}{l}\text { Na gestão de preços, os departamentos têm poucos } \\
\text { problemas na sua cooperação. }\end{array}$ & 4 & 4 & $7 \%$ & $60 \%$ & $7 \%$ & $0 \%$ & $33 \%$ & $53 \%$ & $7 \%$ & \\
\hline $\begin{array}{l}\text { Na gestão de preços, os departamentos envolvidos } \\
\text { atingem os seus objetivos comuns. }\end{array}$ & 5 & 4 & $7 \%$ & $60 \%$ & $0 \%$ & $7 \%$ & $33 \%$ & $40 \%$ & $20 \%$ & \\
\hline $\begin{array}{l}\text { Na gestão de preços, os departamentos envolvidos } \\
\text { confiam um no outro. }\end{array}$ & 5 & 5 & $7 \%$ & $73 \%$ & $7 \%$ & $0 \%$ & $20 \%$ & $33 \%$ & $40 \%$ & \\
\hline
\end{tabular}


1 - > Discordo totalmente

5 -> Concordo totalmente

\begin{tabular}{|c|r|r|}
\hline Pergunta & Sua resposta & $\begin{array}{c}\text { Respostas } \\
\text { mais } \\
\text { frequentes } \\
\text { da amostra }\end{array}$ \\
\hline Na nossa organização há "especialistas em preços" que & & \\
\hline
\end{tabular}

direcionam seus esforços para a gestão de preços.

Há treinamentos padronizados para cargos que

envolvem atividades de preços.

Há descrição escrita das atividades, funções e objetivos
esperados dos especialistas de preços.

As decisões importantes de preços devem ser

submetidas a nível hierárquico acima para a resposta

final.

\begin{tabular}{|l|}
\hline \\
\hline $\begin{array}{l}\text { Pessoas envolvidas em importantes decisões de preços } \\
\text { têm de perguntar ao seu superior antes de fazerem }\end{array}$ \\
\hline
\end{tabular}

quase tudo. Os funcionários que tomam decisões importantes de
preços precisam ter a aprovação do chefe em primeiro

lugar.

Os gerentes geralmente tomam decisões importantes

Os gerentes geralmente tomam decisões importantes
de preços apenas depois de verificá-los com alguém da equipe de gerencial.

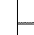

Nossa alta gerência considera os esforços para melhorar a gestão de preços como um valioso investimento de recursos.

\begin{tabular}{l} 
Nossa ata gerencia considera nossas ativides de \\
\hline
\end{tabular}

Nossa alta gerência considera nossas atividades de preços como um fator crítico de sucesso.

\section{更}

Nossa alta administração pretende aumentar a

conscientização de preços da empresa.

Nossa administração promove formalmente e incentiva

os funcionários a lidar com questões de preços.

A concorrência na nossa indústria é intensa.

\begin{tabular}{|l|r|r|}
\hline A concorrência na nossa indústria é intensa. & 5 & 5 \\
\hline Há muitas "guerras de promoção" em nossa indústria. & 5 & 5 \\
\hline
\end{tabular}
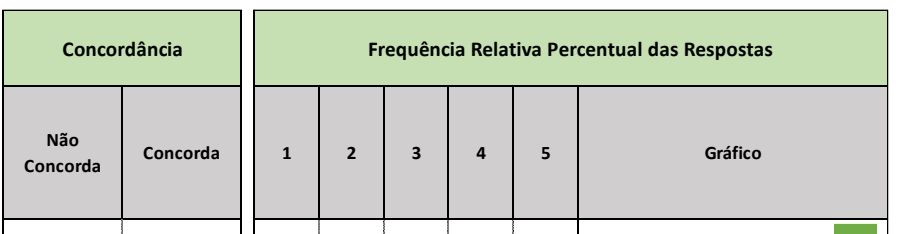

$47 \%$

\begin{tabular}{|l|l|l|l|l|}
$20 \%$ & $7 \%$ & $27 \%$ & $13 \%$ & $33 \%$ \\
\hline
\end{tabular}

\begin{tabular}{|l|l|l|l|l|l|l}
\hline & & & & & & \\
\hline $33 \%$ & $33 \%$ & $13 \%$ & $7 \%$ & $13 \%$ & \\
\hline
\end{tabular}

$27 \%$

\begin{tabular}{|l|l|l|l|l|}
\hline $40 \%$ & $20 \%$ & $13 \%$ & $13 \%$ & $13 \%$ \\
\hline
\end{tabular}

$100 \%$

\begin{tabular}{|l|l|l|l|l}
\hline $0 \%$ & $0 \%$ & $0 \%$ & $33 \%$ & $67 \%$ \\
\hline
\end{tabular}

$67 \%$

\begin{tabular}{|l|l|l|l|l|l|l|}
$7 \%$ & $0 \%$ & $27 \%$ & $27 \%$ & $40 \%$ & \\
\hline $7 \%$ & $0 \%$ & $27 \%$ & $33 \%$ & $33 \%$ & \\
\hline
\end{tabular}

\begin{tabular}{|l|l|l|l|l|}
\hline $7 \%$ & $7 \%$ & $13 \%$ & $47 \%$ & $27 \%$ \\
\hline
\end{tabular}

$67 \%$

\begin{tabular}{|l|l|l|l|l|}
$13 \%$ & $0 \%$ & $20 \%$ & $13 \%$ & $53 \%$ \\
\hline
\end{tabular}

5

(78

$73 \%$

\begin{tabular}{|l|l|l|l|l}
\hline $7 \%$ & $0 \%$ & $20 \%$ & $20 \%$ & $53 \%$ \\
\hline
\end{tabular}

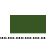

\begin{tabular}{|l|l|l|l|l|}
\hline $7 \%$ & $7 \%$ & $13 \%$ & $13 \%$ & $60 \%$ \\
\hline
\end{tabular}

$\square$

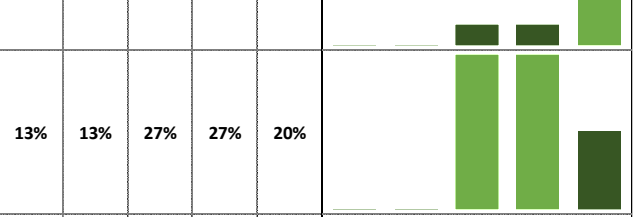

\begin{tabular}{|l|l|l|l|l|}
\hline $0 \%$ & $7 \%$ & $0 \%$ & $20 \%$ & $73 \%$ \\
\hline
\end{tabular}

\begin{tabular}{|l|l|l|l|} 
& & & \\
& & & \\
\end{tabular}

\begin{tabular}{|l|l|l|l|l|}
\hline $7 \%$ & $7 \%$ & $27 \%$ & $20 \%$ & $40 \%$ \\
\hline
\end{tabular} 
1 - > Discordo totalmente

5 -> Concordo totalmente

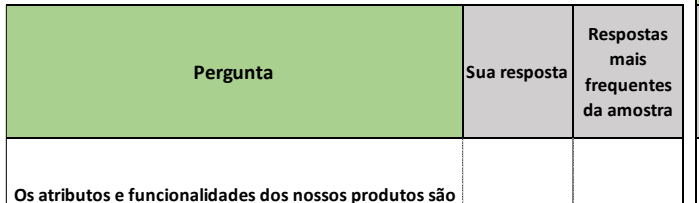

Os atributos e funcionalidades dos nossos produtos são diferentes dos atributos $\mathrm{e}$ funcionalidades dos produtos dos nossos concorrentes.$$
\text { . }
$$

Qualquer diferencial que um competidor pode oferecer, outros podem oferecer prontamente.

\begin{tabular}{|l|}
\hline oferecer, outros podem oferecer prontamente. \\
\hline $\begin{array}{l}\text { Os clientes consideram que nossos produtos são } \\
\text { diferentes dos produtos oferecidos pelos nossos } \\
\text { concorrentes. }\end{array}$ \\
\hline $\begin{array}{l}\text { Como nossos produtos são diferenciados, não } \\
\text { precisamos colocar preços exatamente iguais aos preços } \\
\text { dos nossos concorrentes. }\end{array}$ \\
\hline
\end{tabular}

dos nossos concorrentes.

Temos facilidade em identificar os preços cobrados pelos nossos concorrentes (é escassa a divulgação prévia dos preços em catálogos por exemplo).

$$
\text { . }
$$

Nós determinamos o nosso preço de acordo com o preço dos concorrentes.

\begin{tabular}{|l|}
\hline \\
\hline $\begin{array}{l}\text { No nosso mercado, não é possível estabelecer o preço } \\
\text { acima dos praticados pela concorrência. }\end{array}$
\end{tabular}

acima dos praticados pela concorrência.

A margem colocada sobre os custos é definida isoladamente pelo departamento financeiro$$
\begin{array}{|l|}
\hline \text { Todos os nossos produtos têm margens parecidas } \\
\hline \begin{array}{l}
\text { Todos os nossos segmentos de clientes têm margens } \\
\text { parecidas. }
\end{array} \\
\hline \begin{array}{l}
\text { A definição da margem independe da consideração de } \\
\text { características específicas dos produtos (por exemplo, a } \\
\text { margem de produtos simples é similar à margem de } \\
\text { produtos sofisticas) }
\end{array} \\
\hline
\end{array}
$$

\begin{tabular}{|l|r|r|}
\hline $\begin{array}{l}\text { A definição da margem independe da consideração de } \\
\text { características específicas dos clientes, como porte e } \\
\text { localidade }\end{array}$ & 1 & 1 \\
\hline $\begin{array}{l}\text { A definição da margem independe da consideração da } \\
\text { importância que os clientes vêem nos produtos }\end{array}$ & 1 & 3 \\
\hline
\end{tabular}

\begin{tabular}{|c|c|c|c|c|c|c|c|}
\hline \multicolumn{2}{|c|}{ Concordância } & \multicolumn{6}{|c|}{ Frequência Relativa Percentual das Respostas } \\
\hline $\begin{array}{l}\text { Não } \\
\text { Concorda }\end{array}$ & Concorda & 1 & 2 & 3 & 4 & 5 & Gráfico \\
\hline $20 \%$ & $47 \%$ & $13 \%$ & $7 \%$ & $33 \%$ & $47 \%$ & $0 \%$ & \\
\hline $47 \%$ & $20 \%$ & $20 \%$ & $27 \%$ & $33 \%$ & $13 \%$ & $7 \%$ & \\
\hline $20 \%$ & $60 \%$ & $7 \%$ & $13 \%$ & $20 \%$ & $47 \%$ & $13 \%$ & \\
\hline $47 \%$ & $27 \%$ & $20 \%$ & $27 \%$ & $27 \%$ & $27 \%$ & $0 \%$ & \\
\hline $40 \%$ & $33 \%$ & $27 \%$ & $13 \%$ & $27 \%$ & $20 \%$ & $13 \%$ & \\
\hline $27 \%$ & $40 \%$ & $0 \%$ & $27 \%$ & $33 \%$ & $33 \%$ & $7 \%$ & \\
\hline $20 \%$ & $40 \%$ & $0 \%$ & $20 \%$ & $40 \%$ & $13 \%$ & $27 \%$ & \\
\hline $67 \%$ & $7 \%$ & $33 \%$ & $33 \%$ & $27 \%$ & $7 \%$ & $0 \%$ & \\
\hline $73 \%$ & $20 \%$ & $47 \%$ & $27 \%$ & $7 \%$ & $13 \%$ & $7 \%$ & \\
\hline $60 \%$ & $27 \%$ & $27 \%$ & $33 \%$ & $13 \%$ & $20 \%$ & $7 \%$ & \\
\hline $60 \%$ & $20 \%$ & $33 \%$ & $27 \%$ & $20 \%$ & $7 \%$ & $13 \%$ & \\
\hline $33 \%$ & $40 \%$ & $7 \%$ & $27 \%$ & $27 \%$ & $20 \%$ & $20 \%$ & \\
\hline $60 \%$ & $20 \%$ & $13 \%$ & $47 \%$ & $20 \%$ & $13 \%$ & $7 \%$ & \\
\hline
\end{tabular}




\begin{tabular}{|l|c|c|}
\hline Principal forma do estabelecimento de preços & Sua resposta & $\begin{array}{c}\text { Distribuição } \\
\text { das } \\
\text { respostas da } \\
\text { amostra }\end{array}$ \\
\hline $\begin{array}{l}\text { O preço é estabelecido a partir dos custos mais margem } \\
\text { (margem de contribuição, do lucro bruto ou de lucro } \\
\text { liquido) }\end{array}$ & $x$ & $80,0 \%$ \\
\hline $\begin{array}{l}\text { O preço é estabelecido a partir dos preços dos } \\
\text { concorrentes (+/-) ajustes }\end{array}$ & $6,7 \%$ \\
\hline $\begin{array}{l}\text { O preço é estabelecido com base no valor oferecido ao } \\
\text { cliente }\end{array}$ & $6,7 \%$ \\
\hline $\begin{array}{l}\text { O preço é estabelecido de outra forma (não descrita } \\
\text { anteriormente) }\end{array}$ & & $6,7 \%$ \\
\hline
\end{tabular}

| 